\title{
The Future of the Sciences and Humanities
}

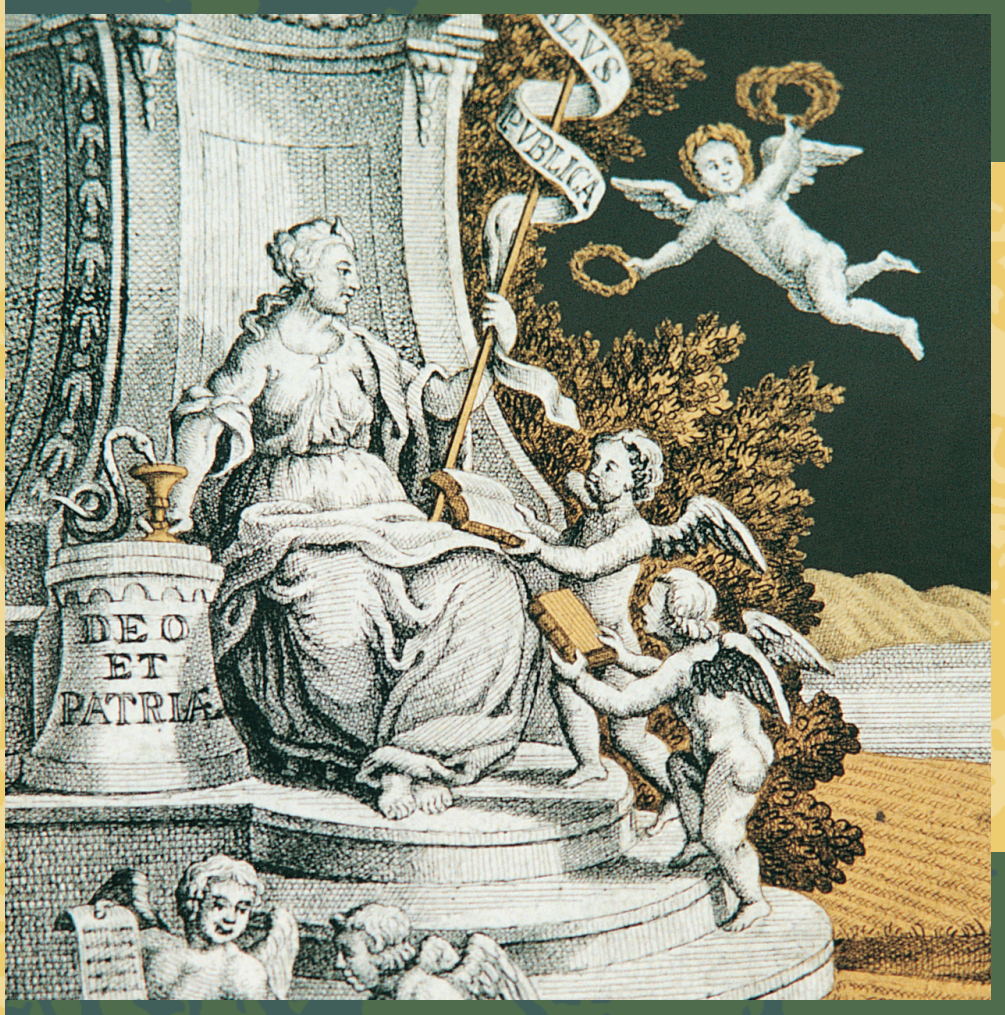

Peter Tindemans Alexander Verrijn-Stuart and Rob Visser (eds.)

Four Analytical Essays and a Critical Debate on the Future of Scholastic Endeavour 
The Future of the Sciences and Humanities 



\section{The Future of the Sciences and Humanities}

Four analytical essays and a critical debate on the future of scholastic endeavour

Contributions by

James McAllister, Johan van Benthem, Arie Rip, Herman Philipse

and

Diedel Kornet, Keith Devlin, Aant Elzinga, Paul Schnabel

Edited by

Peter Tindemans, Alexander Verrijn-Stuart and Rob Visser

A publication of the Amsterdam University Press on behalf of the Hollandsche Maatschappij der Wetenschappen ('Holland Society of Arts and Sciences')

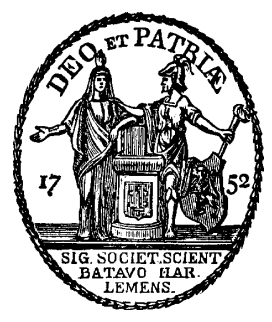

Amsterdam University Press 
ILLUSTRATION FRONT COVER

J. Zeuner (sa.)

After an engraving by J.C. Philips (frontispiece of the first Proceedings of the Holland Society, I754)

Reverse glass painting, detail, $30 \times 40 \mathrm{~cm}$

Collection of the Holland Society of Arts and Sciences

ILLUSTRATION BACK COVER

J.G. Holtzhey

Medal of honour of the Holland Society (1752)

Silver gilt, $54.6 \mathrm{~cm}$

One of the actual medals awarded to the winners of the Prize Competition of the Holland Society of Arts and Sciences (2002)

Cover design: Crasborn Grafisch Ontwerpers bno, Valkenburg a/d Geul Lay-out: BEELDVORM, Pijnacker

ISBN 905356 67I 6

NUGI 6II/6I5

(C) Amsterdam University Press, Amsterdam, 2002

All rights reserved. Without limiting the rights under copyright reserved above, no part of this book may be reproduced, stored in or introduced into a retrieval system, or transmitted, in any form or by any means (electronic, mechanical, photocopying, recording or otherwise) without the written permission of both the copyright owner and the author of the book. 


\section{Preface}

Ghosts of Plato and Aristotle, of Descartes, Newton, Kant and Wittgenstein speak to us, benevolent and admonishing. About natural sciences, liberal arts, the humanities and philosophy. Reminding us of our cultural heritage and social history. So what of the future?

The sciences and humanities evolve in two different and not always easily reconcilable ways: by specialisation and broadening of their scopes. Those dedicated to specialisation often accuse the 'broadeners' of fundamental shallowness. However, in many instances, innovation results from unusual combinations of views and techniques originating in widely different domains. The essential breakthrough usually consists in the recognition and solution of some ('deep') integration problem. From time to time, a new area emerges and takes on a life of its own, as a truly independent discipline.

In the $2 \mathrm{I}^{\text {st }}$ century, both approaches will continue to be productive. Unfortunately, 'broadening' research may be hampered by 'traditional' views and too rigid a set-up of research regimes. Among other things, one may rightly question the customary distinction: humanities, natural sciences, social sciences (sometimes referred to as the alpha, beta and gamma disciplines). Such strictly compartmentalized nomenclature will always lead to confusion in cases of more detailed interdisciplinary research. Irrespective of the names associated with emerging disciplines, the organizational links with established institutions may well have to differ radically from current arrangements.

New departures require new views. That applies to research approaches in general and to governmental and institutional policies in particular. All need open dialogues and critical self-assessment. In this connection, the way we talk about arts and sciences has become of increasing importance.

The four essays in this book present a variety of illuminating and refreshing points of view on the problems in question. Many angles were 
further developed in the Sciences and Arts Debate held by the Hollandsche Maatschappij der Wetenschappen ("Holland Society of Arts and Sciences") on $\mathrm{I}^{\text {th }}$ February 2002, triggered by the presentations of the authors and the reviews by the invited discussants. The editors of this volume discuss the conclusions (and highlights) in the first chapter and add a summary in an epilogue. While not overly important as such, one must admit that the traditional "Arts and Sciences" in the Society's name and in the title of the symposium may have constituted an appropriate label for $18^{\text {th }}$ century practices, but today are more properly covered by "Sciences and Humanities"!

The inspiring help of the members of the Steering Committee and the external reviewer, Professor Theo Kuipers, is gratefully acknowledged. 


\section{Table of contents}

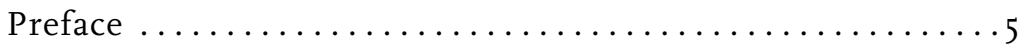

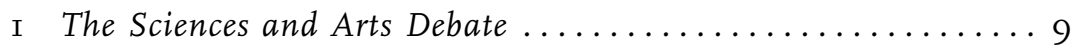

A review and some conclusions

Dr Peter A.J. Tindemans, Prof. Alexander A. Verrijn-

Stuart and Prof. Rob P.W. Visser

2 Historical and Structural Approaches in the Natural and Human Sciences .................................. I9

Dr James W. McAllister

(Leiden University, Faculty of Philosophy)

Discussion: The Role of Laws and Contingency in History ....55 Prof. Diedel J. Kornet

(Leiden University, Faculty of Mathematics \& Natural Sciences)

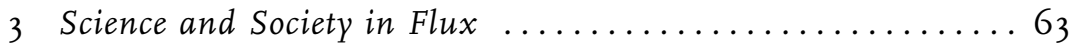
Prof. Johan F.A.K. van Benthem

(University of Amsterdam, Institute for Logic, Language and Computation, Faculty of Sciences, Mathematics and Computer Science)

Discussion: Does A New Kind of Science Require a New Kind of Scholar or a New Kind of University? .............. 9I Prof. Keith J. Devilin

(Center for the Study of Language and Information, Stanford University) 
4 Science for the $21^{\text {st }}$ Century ........................... 99

Prof. Arie Rip

(University Twente)

Discussion: Redrawing Disciplinar Boundaries - but to What Degree? ............................... I49

Prof. Aant Elzinga

(Göteborg University, Dept of History of Ideas and Theory of Science, and Collegium Helveticum, ETH Zürich)

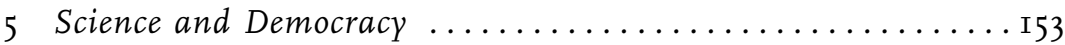

Prof. Herman Philipse

(Leiden University, Faculty of Philosophy)

Discussion: Science and Democracy: a Difficult Relationship 22I Prof. Paul Schnabel

(Utrecht University and Social \& Cultural Planning Bureau)

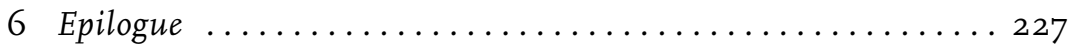

A Characterization and Four Theses (THE EDITORS)

Concluding Remarks (Dr Alexander H.G. Rinnooy Kan)

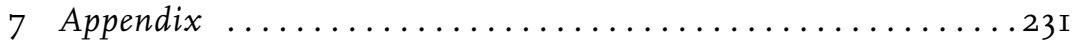

a The Holland Society of Arts and Sciences

$b$ The Prize Competition

$c$ The Contributors 


\title{
I The Sciences and Arts Debate
}

\author{
A review and some conclusions
}

Dr Peter A.J. Tindemans, Prof. Alexander A. Verrijn-Stuart ANd Prof. Rob P.W. Visser

The I999 Prize Competition of the Holland Society ${ }^{\mathrm{I}}$ challenged participants to express innovative views of the Sciences and Arts. Formally, they were asked to provide a meta-description such that newly emerging disciplines might be accommodated without the rigid categorization imposed by traditional nomenclature schemes. This overall objective was paraphrased as "indicating which elements might be helpful or, by contrast, obstructive in guiding scholarly endeavour in the 21st century", possibly including " $a$ reasoned rejection of the classical distinction sciences/humanities and other restrictive classifications, replacing these by a more effective taxonomy". Simply put, how can we talk about esoteric or unexpected developments in constructive ways? How may scholars, administrators and politicians really understand each other when entering largely unknown domains?

A well-known example of the nomenclature dilemma is the borderline between physics and chemistry. Where do we position fundamental research on chemical compounds? Are 'quantum chemical' studies physics (because of their quantum mechanical formalisms), chemistry (because one investigates chemical structures) or even applied mathematics (when the study essentially depends on the ability to compute results mathematically)? Fortunately, the physicist active in this area will be able to publish results in a journal on 'chemical physics', whereas the chemist will refer to the subject as 'physical chemistry'. Yet, in an era when all research is to be justified financially, a chemistry department may - and often does - object to new proposals if they cannot be classified strictly as 'chemistry', thus stifling innovation from within.

More problematic are the options for naming various applications of 'computing' (or 'computation', using these terms in the general sense of structuring abstractions such that they are capable of manipulation by 
computing machinery). Should research into ways of documenting art historical subjects such that subject-characteristic searches may be performed be called 'art-historical informatics' or 'computational art history'? Is it a special branch of 'artificial intelligence' or of 'information science'? Does it belong to the 'humanities', or is it a form of 'software engineering' normally positioned in the 'sciences'?

The last example illustrates two further problems associated with one's natural desire for clear subdivisions. The first is the traditional grouping of 'arts' versus 'sciences', where the 'arts' may be understood as certain branches of learning serving as intellectual instruments for more advanced studies (usually but not necessarily linked to human behaviour, cultural artifacts, or societies) and the 'sciences' imply elements of empirical acquisition of generalizable knowledge and, therefore, usually are given the epithet 'natural'2. In other words, the governing dichotomy is that of intellectual skills as opposed to practical experimentation and observation. Although mathematics typically represents intellectual structuring, it is traditionally grouped with the sciences, even if given a special place. The over-simplified arts-sciences antithesis may facilitate classification (if something is not in one class, then it is in the other) but does not do justice to the variety of facets that jointly make up the character of some discipline.

A second, seemingly trivial, problem is associated with the names we attach to various areas. When it is a noun from which an adjective may be derived (chemistry - chemical) one may easily distinguish main and subsidiary areas (physical chemistry is a specialization of chemistry, chemical physics one of physics). On the other hand, the domain of 'information' which is complex anyway - causes no end of difficulty and confusion. The French 'informatique' and German 'Informatik' have been translated by the (contrived) English term 'informatics'3. In none of these languages does a suitable adjective exist. Thus, we may speak of 'linguistic informatics', 'legal informatics', 'medical informatics' and so on, but we cannot express the fact that the emphasis is mostly on the area denoted by the adjective, whereas it should have been the opposite. The denotation 'informational' is just not on, though one begins to spot it here and there especially in referring to a new phase in human societies. Compounding this situation is the historical claim to the terminology 'Information Sciences' as a modern extension or even full alternative of 'Library Science'. On the 
other hand, 'computational' does work, even if it conjures up visions of machinery and mostly fits natural science subjects. It is a pity that the association with the essential characteristic 'information' cannot be expressed where it would be more appropriate.

These observations illustrate some evident problems of classification and terminology. It would be rather farfetched to conclude that there might well be areas that cannot be opened up because we have no proper words for them ${ }^{4}$. Anyway, mutual acceptance is a key element in the communication between scholars - for dissemination and assessment of their studies. It is also indispensable in the wider interaction between scientists and society - for instance, to be recognised and funded. We must be able to speak clearly about the sciences and arts. It is worthwhile investigating the essence of understanding them.

The Prize Competition asked for a high-level analysis of the area, in particular for an identification of features helpful or obstructive to innovation, among them the role of various interest groups with their professed and hidden agendas. The most direct question to be asked is "What is science about?", along with very general questions, such as "How do the sciences and arts relate to society?" How do we talk about the area, how should we subdivide it - if at all? What are the repercussions for academic and research management, for governments? These questions are all part of the overall problem.

The winning essayists have come up with an interesting range of issues and problem aspects. Their views are often personal but always well argued. The comments of the invited discussants intriguingly supplement this variety.

It should be understood that throughout this introductory chapter, 'science' refers to the natural sciences, social sciences and humanities alike, unless it is clearly stated that a more restricted use is intended.

The authors of the essays approached the question posed to them in different ways and focused on various dimensions of science and the scientific enterprise. Yet their answers make it clear that all these dimensions are linked by necessity and point to $2 \mathrm{I}^{\text {st }}$ century science being different indeed from what we have been used to. 
Rip shows convincingly that what we call science or scientific activities are never free from historical contingencies. He puts perhaps less emphasis on a cognitive approach to what science is and will look like in the coming decades than the others do. Nevertheless, it emerged clearly from the discussion following his introduction that also for him subjecting oneself to wide and 'non-inner circle' criticism - which implies that one adopts rational principles - is crucial for claims of truth or validity. This was indeed more or less taken for granted by van Benthem and Philipse, who prove themselves to be traditional rationalists in a sense, yet point out that the claims to validity and truth are not straightforward and rather linked to the organisation of the production of knowledge. Philipse's resort to A.D. de Groot's 'Forum' is reflected in van Benthem's emphasis that in an emerging area, such as information-and-cognition, 'knowledge producers' of very different backgrounds and traditions, some of which are not even bound to the traditional academic realm, all have to find and stake out new claims for valid knowledge. McAllister does not use the sociological categories and analyses of Rip but distinguishes two separate approaches to science, one seeking laws and structural regularities, the other focusing on historical events and contingencies. As van Benthem did for the case of information and cognition, he stakes out a wide claim: whereas the first approach has traditionally been identified with the natural sciences, and the other with the social sciences and humanities, in the future, every field of science will only advance by a combination of the two. The distinction between different domains could then be based purely on their object of inquiry. This kind of categorization, of course, is pragmatic and anyway much more fluid than the rigid dichotomy of 'nature' versus 'culture and society'. It may, indeed, be too pragmatic a view, as Kornet and Elzinga pointed out. The various objects of science and knowledge are 'cognitively distinct'. That is to say, they have characteristics (for instance, different levels of organisational complexity) that make them amenable in different degrees to the two research approaches. Or, as Elzinga put it: you cannot ignore the way nature is organised.

Now what, in a nutshell, are the specific answers given by the various authors to the question posed? In general, they touch upon three different levels. One is about the cognitive structure of science, including its subdi- 
vision in disciplines (or 'branches' as the Encyclopaedia Britannica proposes, referring to the underlying unity of science). A second one concentrates on the tools, the methods, the approaches to study the problems to arrive at relevant, valid, or true statements. The third addresses the institutional forms in the broadest sense - not just the organisations, but also quality control mechanisms, the reward and degree conferral systems, financial support schemes, for instance - that form the riverbed for the flow of science. Of course, the levels are interrelated, but a large part of the variety of the answers given derives from the different weights accorded to them.

McAllister essentially leaves open the demarcation between individual disciplines, or at a more aggregate level the natural sciences, the social sciences and the humanities, and concentrates on the tools. He did not say but might have said, as Rip did for the natural sciences, that the age of disciplines is over. The future of every bit of science depends on the ability to use all instruments from the toolbox, whether they have their origin in and were even largely identified with the natural sciences on the one hand and the social sciences and the humanities on the other. That such a strong claim is not shared by everybody has already been mentioned when reference was made to the comments by Kornet and Elzinga. Kornet accepts McAllister's general tenets but points out that his overall framework is insufficiently detailed. The extent to which 'laws' may be formulated, that is, the 'structural' element is introduced, will vary widely between, say, physics, biology and the human sciences. Modern multidisciplinary studies will benefit from McAllister's integration of approaches, but one must always be wary of oversimplification.

Rip in a sense makes a similar point but restricts himself to the natural sciences. His overall argument is that science, as an organised way of knowledge production, is not impervious to the way societies organise (i.e. institutionalise) their productive and other activities in general. The model of science - including part of its mechanisms to establish robustness which many scientists, but people outside science as well, have come to adopt as the one and only representation of science is a particular, 'pathdependent' result of the way the scientific enterprise evolved in the Western world. The particular sequence of specific knowledge production modes that characterised this Western model, from traditional knowledge 
to 'natural history'-type of knowledge to 'lab' knowledge, is now seen to have led to a situation that is no longer adequate to the ways and the intensity with which knowledge has pervaded almost all walks of life. "Complex reality strikes back at the laboratory," to paraphrase Rip. His answer then is a call for heterogeneity. One should not try to replace 'Mode I' by 'Mode 2' (the well-known opposition introduced by Gibbons, Nowotny et al.5) but use them both whenever appropriate. Provided adequate mechanisms are found to test robustness - criticism must be a general characteristic of all of these - one should also use the traditional, the 'natural history' and 'lab' approaches to knowledge production in combination. The resemblance of the genome project to the 'natural history' approach is a striking example in this context. Elzinga found himself in agreement on these observations but suggested a refinement in using the names 'craft', 'taxonomy' and 'profession' for these three stages, adding the 'systemic' stage to describe the eclectic, heterogeneous approach that now seems the way forward.

Philipse equally is not bothered very much with the internal demarcations in the scientific enterprise, nor for that matter with the tools it uses, but concentrates on the cognitive structure and body that science is. Are there arguments in the nature of how additions to this body of knowledge occur that prevent it from growing indefinitely, or at least at the same pace as in the past? In looking at science in the $2 \mathrm{I}^{\text {st }}$ century, he puts forward the equivalent of the 'limits to growth' debate of the I970s, when the focus was on the finite world and its finite resources. The growth of science cannot go on like this; there are diminishing returns as the economists would say. Therefore, he stakes out for science a 'steady state' era, as Ziman and others have called $\mathrm{it}^{6}$, using science policy arguments rather than the growth of our cognitive output. That does not lead him to a pessimistic view on the importance of science. Indeed, looking at the way science will impact the $2 \mathrm{I}^{\text {st }}$ century society, he claims that science is the underpinning of two great endeavours of societies, the creation of wealth and the functioning of our democracies: if only governments, industry, and the ordinary citizen would do what they have to do. A late echo indeed of Spinoza's elegiac complaint to be found on the Spinozahouse in Rijnsburg: "Als alle mensen waren goed en wijs; en deden daarbij wel; de aarde was een paradijs; nu is zij meest een hel".7 Schnabel feels that Philipse's argument holds better for the natural sciences than for the humanities and even the 
social sciences. He also points out that an organizational change is manifesting itself, in that professional education and scientific endeavour are moving apart. Thus, each will call on national resources, but the one in a national context (understandably debatable) and the other in an international context (not easily open to rationality).

Van Benthem winds up his argument with a plea similar to that of Philipse: profound as the changes are that he sees and prophesizes for science, its underlying Enlightenment ideals may have lost their appeal but not their value. Being the only one to tackle the issue of the demarcation of disciplines or areas head on, he uses the concreteness of his example - the information and cognition sciences - to propose and indeed forecast fundamental changes at all of the three levels mentioned before. The scientific effort itself at the cognitive level (which should not lead here to a regressio ad infinitum) will change so as to embrace the natural sciences, humanities and social sciences. As with all profound paradigm shifts, these should be accompanied by a new terminology. The tools of the trade are not widely discussed by van Benthem, but it seems evident that the same amalgam or eclectic combination advocated by Rip and McAllister would have to be adopted. On the organisational level, van Benthem, strongly supported by Devlin, sees a need for innovative organizational forms as well as financial schemes to overcome the fragmentation that stands in the way of further scientific and societal progress. The boundaries of academia no longer matter strongly; the role scientists were used to playing as the dominant class in the empire of knowledge will undergo deep transformations.

The ensuing 'Sciences and Arts Debate' was a lively affair. As one might expect, it answered few questions. Many must remain open. The following are some of the views that were generally accepted.

- Disciplines will remain with us, but no longer as the primary basis for research arrangements.

- Naming domains of heterogeneous scholastic enterprise may present creative challenges, but reference to the constituents and the specific tools will help explain what such innovations are about.

- Successful new departures - often embedded in and triggered by primarily 'engineering' type organizations - will require the support of 
more than one sector of society. There should not just be an industrial background or, conversely, exclusive government funding.

- Openness is what is most needed. Tribal behaviour, a characteristic of many existing research establishments, is to be avoided.

- Funding should be given wisely. As one discussant said, "what research needs is not just a budget, not just a focus, but both simultaneously".

- It is also obvious that science - in the wider sense of including studies in the humanities and social sciences - must be truly embedded in society.

These views are characteristic of the emerging trends. They are emphasized in various degrees in the next four chapters. Each contains an essay by a Prize Competition laureate followed by the written comments of the discussant invited to review it. The chapter sequence is the same as in the Debate. The final Epilogue sums it all up.

\section{Notes}

I See Appendix (b).

2 By extension, there exist methodologically related fields, such as 'life sciences', 'social sciences', etc. The term 'science', of course, is also used in the general sense of 'body of facts or truths gained by systematic study', as derived from the Latin scientia $=$ knowledge. Traditionally, arithmetic and geometry together with music and astronomy constituted the medieval Quadrivium (or artes liberales); consequently, the proper translation of 'mathematics' is ars mathematica.

3 The French and German terms are generally understood as equating to 'computer science', whereas the English term 'informatics' is generally accepted as also covering 'management science', 'business computing', 'artificial intelligence', 'knowledge management' and a number of specializations, such as 'medical informatics'.

4 Yet, this appears to be implied by the last line of Wittgenstein's Tractatus LogicoPhilosophicus "Wovon man nicht sprechen kann, darüber muss man schweigen" (Whereof one cannot speak, thereof one must be silent - tr. C.K. Ogden)

5 See Rip's essay in Chapter 4. 
6 See Rip's essay in Chapter 4.

7 "If people all were good and wise / And always acted well, The earth would be a paradise / But, now, is mostly hell". 



\section{Historical and Structural Approaches in the Natural and Human Sciences}

James W. McAllister

Aвstract. In developing their models of the world, the sciences have traditionally drawn on two general approaches. One regards the world as the result of historical events and contingencies, whereas the other portrays it as the consequence of systematic constraints and regularities. The comparative merits of these approaches have been the subject of a long debate in intellectual history. This debate has been conducted in different contexts and terms, however, so its unity has hitherto not been appreciated. The debate was pursued in one form in the nineteenth-century German discussion of the methods of the human sciences; in another form, it has been pursued in recent controversies about the role of natural laws and historical contingency in the life sciences. The aim of this essay is to demonstrate the continuity of the debate between the two approaches over the past 150 years, to study its evolution, and to draw lessons from it for new resolutions of the outstanding issues. 
How does the world come to have the structure that it has? Answering this question is traditionally regarded as a central aim of the sciences. To tackle it, the sciences have developed two fundamental and general approaches which suggest the form that the answer should take. In one approach, the structure of the world is a result of contingent historical events and processes. In the other approach, it is a consequence of constraints and regularities that are general and necessary. I shall call these the historical and the structural approach, respectively.

Each of these approaches has impressive achievements to its credit. Each appears natural and compelling in certain domains of inquiry. Our view of art, for example, is based largely on the premise that artworks spring from unpredictable human creativity, and that they can be fully understood only by retracing the contingent evolution of the artist and of society. Our modern understanding of the cosmos, by contrast, rests largely on the assumption that laws of nature provide an invariant framework within which the universe unfolds.

The two approaches have a long history. They can be discerned in the philosophies of Plato and Aristotle. They are even more clearly visible in the two world views that have most shaped modern Western culture: the Enlightenment notion of a rationally ordered world and the Romantic ideal of the Promethean self-development of the individual.

The two approaches have various conceptual elements. Let us focus on four: their metaphysical, epistemological, axiological, and methodological elements. To begin with, the two approaches offer alternative metaphysical accounts of the world: in the historical approach, the world is a historical entity consisting primarily of occurrences, whereas the structural approach views the world primarily as a timeless system of rules or laws. These metaphysical accounts have epistemological implications. To understand the world in the historical approach requires us to retrace historical events backward in time to ascertain how the world acquired the structure that it now exhibits. To understand the world in the structural approach, by contrast, involves grasping how the structure of the world is determined by universal constraints. The axiological element pertains to the intellectual aims and values that govern each approach: whereas the 
historical approach values complexity and particularity, the structural approach attributes higher worth to simplicity and generality. Lastly, the two approaches have differing methodological implications. The historical approach calls for differentiation, concern for particulars, and historical sensitivity, whereas the structural approach fosters holism, reductionism, mathematization, abstraction, idealization, logicism, and a systematic style of theorizing.

Critics may object that these two approaches are the endpoints of a range of attitudes towards the world, and that any real scientific research can and should draw on both. Whereas such a response sounds superficially plausible, it is a little too glib - at least at this point in our inquiry. The strategy of combining the two approaches has proved, in intellectual history, both less popular and more difficult to implement than one might expect. Most thinkers who have addressed the topic have adopted a clearcut position in favour of one approach, excluding any reliance on the other. Research programmes in which the two approaches are truly integrated have rarely been formulated, as we shall see. As a result, most scientific disciplines for most of their history have been dominated by one approach, while the other approach has been restricted to an auxiliary or supplementary role at best. Before we can advocate combining the two approaches in future scientific research, we must be certain that we have understood why this strategy has had so little success in the past.

The tension between the historical and structural approaches has manifested itself in a debate between their advocates that has endured throughout intellectual history. This debate has aimed at resolving several questions: What is the nature of the difference between the two approaches? Does one approach have a stronger claim to scientific status than the other? Are the classes of phenomena that can be understood by each approach mutually exclusive, or do researchers in every field have a choice between the approaches? What are the implications of the existence of two such different approaches for the thesis of the ontological and methodological unity of science? Do the two approaches lend themselves to integration and, if so, how? Does any further approach exist on an equally fundamental level? The debate on these questions has been conducted in contexts so varied that its underlying unity and continuity are masked. In the human sciences in the nineteenth century, for example, the debate focused 
on the tension between explanatory and interpretative perspectives. In the present-day natural sciences, the debate addresses the relation between law-based and evolutionary research programmes.

In this essay, we revisit some episodes of the debate over the past I5O years. The aims of this essay are to demonstrate the unity that underlies the different manifestations of the debate; to explore some of its enduring themes, which transcend domains of inquiry; to study the evolution of the terms of the debate; and to suggest elements of a new resolution of it.

We begin in section 2 by reviewing the debate between interpretative and explanatory perspectives in the human sciences in nineteenth-century German culture. In section 3, we look at the continuation of that debate in different terms among twentieth-century Anglo-American theorists of science. Our attention then turns from theory to practice. In section 4 , we examine the interplay of the historical and structural approaches in historiography and anthropology. In section 5, we investigate the debate between law-based and evolutionary research programmes in present-day life science. In the final section, we draw some conclusions for the future development of science.

\section{Explanation and Interpretation in the Human Sciences}

The first episode of the debate between the historical and the structural approaches on which we focus unfolded in nineteenth-century Germany. It pertained to the aims and methods of the human sciences and the difference between these disciplines and the natural sciences. ${ }^{\mathrm{I}}$

The debate arose largely as a reaction to a perceived threat to the intellectual legitimacy and specificity of the human sciences posed by Kantianism and positivism. Immanuel Kant, at the close of the eighteenth century, attributed a subsidiary place to the human sciences in his system. Kant prescribed that, in order to count as a science, knowledge should satisfy the requirements of necessity and generality. The paradigmatic science in Kant's eyes was Newtonian mechanics. Kant regarded historical knowledge, by contrast, as contingent and arbitrary. Historical knowledge therefore does not constitute a science in Kant's view: historical disciplines are relatively inconsequential. 
The threat was intensified by positivism. Auguste Comte suggested in the I83os that every scientific discipline begins by collecting facts and progresses to formulating natural laws. On the strength of this account, Comte proposed a hierarchy of the sciences in which he located, in descending order, astronomy, physics, chemistry, physiology, and "social physics", or sociology. This hierarchy has three dimensions. To begin with, it contains a historical claim. Comte believed that the hierarchy reflected the times of origin and stages of development of the scientific disciplines. Astronomy has been practised the longest and has thus reached the greatest degree of maturity; social science is in its infancy. Second, the hierarchy is logical. The sciences that arose first are devoted to the simplest and thus to the most general and abstract phenomena. Later sciences study phenomena that are increasingly complex, specialised, and concrete. Each science is founded on the knowledge of the preceding one and forms the foundation of the succeeding one. Third, the hierarchy reflects the "relative perfection" of the sciences. Comte defined perfection in terms of unity, abstraction, simplicity, universality, precision, and coordination of facts. He declared that, whereas astronomy is precise and tightly organized, the sciences of organic phenomena - especially social physics could never be very exact or systematic. The perfection of a science was closely connected to its use of natural laws: Comte considered that Newton's law of gravitation had brought astronomy to the "highest philosophical perfection" that any science could hope to achieve. ${ }^{2}$

The human sciences in the mid-nineteenth century thus found themselves in a largely hostile intellectual climate. Kant - whose work enjoyed enormous prestige, especially in Germany - had consigned the human sciences to a secondary place on the epistemological scene. While promoting the concept of a science of society, Comte had put forward a view of the human sciences that was even more disparaging than that of Kant, although philosophically less sophisticated and less influential. The message for the practitioners of the human sciences was stark: whereas they were probably barred from attaining full scientific status, any progress towards that end would be achieved only by conforming as fully as possible to the model of the natural sciences.

These limitations and prescriptions seemed incompatible with the practice and richness of the human sciences in the mid-nineteenth centu- 
ry. The human sciences at that time were characterized largely by forms of historicism, a doctrine that holds that historical epochs are radically distinct from one another and that historical phenomena must be studied and evaluated in their own terms. Historicism contrasts with the assumption which prevailed in the eighteenth century that human nature and social institutions are relatively unchanging. A form of historicism was also entrenched in nineteenth-century German educational theory, which conceived of education not as the enhancement of a universal capacity for rationality but as the development of an incomparable individual personality or Bildung. 3 The influence of historicism rendered the human sciences unamenable to the approach typical of the natural sciences admired by Kant and Comte.

History and economics provide good examples. One of the leading figures of the mid-nineteenth-century German school of history was Leopold von Ranke, whose work focussed mainly on the diplomatic and military relations between the great powers in the modern period. Ranke's view of history emphasized the individuality of statesmen and thinkers and the uniqueness of their ideas and acts, to the neglect of the collectivity. His historiographic approach involved subjecting documents of state and other primary sources to the interpretative and critical methods developed by philologists. He argued that in order to develop an understanding of history, one had to cultivate empathy with historical characters, putting oneself in their mind and environment. He opposed the positivist view that history must simply discover laws resembling those in the natural sciences. 4 Ranke came to be regarded as the founder of the science of history and of objective historiography, but clearly these were a form of science and of objectivity unlike those recognized by Kantianism and positivism.

Economics is an even more revealing case. Classical and neoclassical economists had used an abstract axiomatic-deductive approach modelled on the natural sciences. The historical school of economists in nineteenthcentury Germany rejected this. Gustav Schmoller, a leading exponent of this school, emphasized the historical and changing nature of economic and social phenomena against simplified and mechanistic views of the laws of rational behaviour. Schmoller intended to free political economy from false abstractions and to place it on a solid empirical foundation, 
based on detailed historical research. A contemporary of his, Carl Menger, reasserted the necessity of applying the exact methods of the natural sciences and abstract logical reasoning to political economy. This difference of opinion led to the Methodenstreit, a dispute among German-speaking economists that centred largely on the comparative merits of inductive and deductive approaches. 5

Scholars who valued and identified with the approaches typified by Ranke and Schmoller were naturally reluctant to accept the view of the human sciences put forward by Kant and Comte. They believed that the human sciences constituted legitimate scientific disciplines with methods that differed from those of the natural sciences. Theoreticians of the human sciences therefore worked to create a philosophical space for their disciplines.

An early attempt to address these issues was made by Wilhelm Dilthey in the I880s. Dilthey believed that the solution was to be found in a strict separation of the human sciences (or Geisteswissenschaften) from the natural sciences. Dilthey argued that the natural sciences are concerned with explaining (erklären) natural events in terms of regularities, but that the human sciences have an essentially different subject matter and content. In his view, the human sciences are chiefly concerned with the study of the human spirit or Geist and its acts. These acts are unique and freely chosen: they can be understood only in terms of beliefs and intentions, and only from the inside. He contrasted the freedom of the human spirit with the lawfulness of nature. The practitioner of the human sciences is thus interested not in regularities, but in individualities, including individual historical protagonists, distinctive cultures, and historical epochs.

The human sciences therefore cannot conform to the aim of the natural sciences of seeking regularities and laws. Instead, they aim at the empathetic reproduction and interpretative understanding of immediate, lived experience. Our lived experience (Erleben or Erlebnis), Dilthey argued, is an initially unanalyzed complex of sensations, memories, intentions, evaluations, and the like. This lived experience is the ultimate subject matter of the human sciences. It is captured first in empathetic reproduction or Nacherleben, and in a fuller form in imaginative interpretative understanding or Verstehen.

Expressed in such subjectivist, idealist and anti-naturalist terms, this 
sounds like a difficult task. It is rendered slightly easier by the fact that Dilthey regards texts, artefacts, and institutions as objectified traces of the human spirit. The life of the spirit can be reconstructed, in his opinion, by interpreting these traces. ${ }^{6}$

Working along lines similar to Dilthey, Georg Simmel distinguished the disciplines concerned with concrete reality (or Wirklichkeitswissenschaften) from the nomological sciences (or Gesetzeswissenschaften). The former achieve understanding of past human behaviour and beliefs by means of Verstehen, which Simmel interpreted chiefly as the historian's ability to identify with past actors. Simmel excluded that there could be invariant laws in history. Simmel's viewpoint was sophisticated in several respects, however: he recognized that universal laws of nature represented an ideal that the nomological sciences did not always attain, and that the historian could legitimately make recourse to statistical regularities.7

Dilthey's and Simmel's strategy for opening a philosophical space for the human sciences hinged on a demarcation of domains: they held that the natural and human sciences differed primarily in subject matter. Wilhelm Windelband found a distinction on such grounds unsystematic. He criticized the conventional partition of the empirical disciplines into Naturwissenschaften and Geisteswissenschaften. He cited psychology as an example of a discipline that cannot be classified unambiguously as either a natural or a human science: experimental psychology forms part of the natural sciences, but Dilthey's Geisteswissenschaften are also grounded on a psychological science of a sort.

In the place of a distinction based on subject matter, Windelband proposed one based on axiological and methodological criteria. In his view, the empirical sciences are divided into two groups: the Gesetzeswissenschaften and the Ereigniswissenschaften. The former pursue nomothetic knowledge of the general in the form of Gesetze or invariant laws. The natural sciences belong to this group because they mostly have nomothetic aims; but so too do economics and sociology. The Ereigniswissenschaften, by contrast, strive for idiographic knowledge of singular events or patterns. The human sciences, Windelband argued, seek exhaustively to describe a single event at a particular place and time. The historical disciplines usually strive for the identification of Gestalten, representations of unique configurations of particular events, conditions, or developments. The cognitive 
purpose of these disciplines is to reproduce and understand a form of human life in its unique actuality.

Windelband formulated his distinction between the natural and the human sciences as follows:

The principle of classification is the formal property of the theoretical or cognitive objectives of the science in question. One kind of science is an inquiry into general laws. The other kind of science is an inquiry into specific historical facts. In the language of formal logic, the objective of the first kind of science is the general, apodictic judgment; the objective of the other kind of science is the singular, assertoric proposition. Thus this distinction connects with the most important and crucial relationship in the human understanding [ . . ] : the relationship of the general to the particular. $^{8}$

While acknowledging that both the nomothetic and the idiographic approaches have strengths and weaknesses, Windelband was particularly emphatic about the shortcomings of the nomothetic approach for understanding individual events in their full complexity. The natural sciences deal in abstractions: they give us a world devoid of all sensuous qualities. Empirical particulars are of interest not only to the extent that they can be subsumed under general laws, but also if they form significant components of a vital totality (Gesamtanschauung). Applying the nomothetic approach to human affairs yields no more than trivial generalities. In practice, historians rely mainly upon their informal insight and intuition into human nature. Above all, as Windelband insisted, nomothetic knowledge can never really account for the distinctive patterns of real events. For Windelband, the historically and individually given always contains an ineffable and undefinable component, which resists analysis into general categories. We experience this component as causelessness and individual freedom. Human life is a rich fabric of historical connections, and we can participate in it only if we understand its development. Our deepest concerns and commitments, Windelband argued, direct our attention toward the singular and the unique. Windelband envisaged historians bringing back to life the persons and events of the past in their full individuality and immediacy (Anschaulichkeit).

The most serious shortcoming in Windelband's view of the idiographic 
approach is probably his assumption that our access to facts is direct and not mediated by theories or standpoints. He is vulnerable to the challenge that what the idiographic scientist tries to study is not an event, but only an event as defined or described in a certain way. One can never exhaustively describe or understand an event or a state of the world. To describe an event at all, and even to claim uniqueness for it, we must first characterize it in a way that picks out the aspects or features that interest us, or that we want to contrast or understand. It is plausible to claim that this characterization depends on general categories, which draw upon a nomothetic approach.

Windelband's approach to the natural and human sciences was endorsed and further pursued by Heinrich Rickert.9 Rickert pointed out that nomothetic and idiographic sciences differ not only in their goals, but also in the conceptual tools that they use. Nomothetic sciences develop general concepts, applicable to a wide range of events or objects, whereas idiographic sciences formulate singular concepts, useful for depicting specific, unique configurations. Rickert also emphasized that the distinction between the nomothetic and the idiographic methods does not coincide with the distinction between the natural and the human sciences: the idiographic method is used also in the natural sciences, for example in Darwinian evolutionary theory, whereas nomothetic methods feature prominently in human sciences such as psychology and economics.

The debate about the legitimacy and methods of the human sciences reached a culmination in the work of Max Weber. ${ }^{10}$ Weber partly resolved the tension between the explanatory and the interpretative perspectives and the distinction between the natural and human sciences. He argued that through the process of interpretative understanding of patterns of social action, practitioners of the human sciences arrive at a causal explanation of sequences of action. Moreover, using "ideal types", they could progress from the study of unique events to cautious generalizations about the common features of institutional patterns in social development. Where other writers distinguished sharply between Verstehen in the human sciences and causal explanation in the natural sciences, Weber saw Verstehen as a necessary part of causal explanations in social science, which are however no less scientific than those of the natural sciences. Weber resolved this tension largely by means of two concepts. To begin 
with, he developed a complex scheme known as "singular causal analysis", in which particular historical events are traced to their causally relevant antecedents. In Weber's account, singular causal analysis is performed by means of probabilistic and counterfactual reasoning, not by using deductions from causal laws. He views history as a complex network of causal relations among particulars, as a scene of alternate processes and possible outcomes that are more or less probable, more or less strongly favoured by relevant causes. The historian's paradigmatic causal question is not whether a particular event necessarily followed upon one or more antecedent conditions, but why a certain historical path or outcome was what it was, and not something else. A cause is not a sufficient condition for the occurrence of the effect, but rather a factor that, in conjunction with other background conditions, is comparatively likely to bring about one outcome rather than alternatives. We explain aspects of the world by means of probabilistic and counterfactual comparisons between what has actually happened and what would have happened in the absence of appropriate causes.

Weber also contributed to the elaboration of the concept of Verstehen. He regarded the interpretative process as an instance of singular causal analysis. Interpretation is performed by means of the hypothetical attribution of rationality to historical agents. We begin by supposing that the relevant agents rationally pursued appropriate ends. We thus tentatively attribute to historical actors a form of instrumental rationality, as well as consistency in motives and beliefs. At first, the rationality that we ascribe to past agents is identical to our own rationality. When we encounter divergences between the courses of action pursued by the historical agents and the behaviour that we expect on the basis of our rationality, we adjust our model of the rationality of the agents. Our aim is to construct a set of motives and beliefs that is adequate to account for the agents' actual behaviour.

The close connection between interpretation and explanation in Weber's thought is further illustrated by his proposal of ideal types as heuristic devices. Ideal types are simplifications or one-sided characterizations of complex phenomena that can be hypothetically posited and compared with the realities that they are intended to represent. Examples of ideal types are models of rational action and patterns or processes attributable to simple causes. In Weber's view, ideal types allow us to ascribe selected 
elements of reality to specified causes, motives, or beliefs, and to make the distinctions and counterfactual comparisons required for the construction of adequate interpretations and explanations.

The debate about the methods of the human sciences in nineteenthcentury German culture produced imaginative and valuable results. According to the interpretative perspective developed in this debate, the chief task of the practitioner of the human sciences is the interpretative or hermeneutic understanding of cultural and social phenomena. Proponents of this approach argue that it is futile to attempt to explain such phenomena by identifying causal regularities; rather, they should be understood. The demand for understanding puts intentionality at centrestage: cultural phenomena are to be understood above all by reference to the intentions, beliefs, and meanings of the agents involved. The emphasis on understanding also stresses the requirement to reconstruct cultural manifestations internally and in their own terms, rather than by reference to causes operating from without.

The interpretative approach has a number of strengths. Most notably, it encourages a positive view of diversity, on both an individual and a cultural level. It is sensitive to the differences between systems of thought and to the advantages that these may offer to their users.

The interpretative perspective also exhibits important shortcomings or vulnerabilities. The first concerns the centrality of texts. The interpretative approach is intended to be applicable to cultural manifestations of all kinds, including actions, artefacts, cultures, and historical epochs. In many ways, however, its paradigmatic object is the text, conceived of as a system of interrelated meanings. The term Verstehen has thereby come to be used mainly to denote an imaginative penetration into historical texts. This emphasis tends to reduce human culture and history to the production and discussion of texts, obscuring the material aspects of human experience.

Second, the theory of Erleben and Verstehen prescribes that practitioners reproduce and relive the experiences embodied in texts and intuitively identify with their authors. This injunction, however heuristically useful, can degenerate into a subjectivist process of empathetic communion of which the results cannot be validated or even imparted to others. The scientific process thereby becomes unanalyzable and mysterious. 
Third, the concentration on historical texts and the worlds of their authors risks elevating past thinkers into authorities that must be studied, subjected to exegesis, and appreciated uncritically, rather than as fellow-contributors to a debate. Notwithstanding its openness towards individual and cultural diversity, the interpretative tradition in the human sciences shows some propensity for dogmatism and intellectual authoritarianism.

Fourth, the emphasis on the individuality of historical protagonists and events does not aid understanding of the relationship between particulars and aggregates, such as the membership of an individual in a group or culture. It also renders the concept of change problematic. Since mechanical causal processes are excluded from consideration, change can take the form only of a teleological unfolding of preexisting potentialities or an emanation of intellectual or spiritual forces. It is in many cases difficult to conduct historical research against such a background.

A further problem affects, in different ways, every form of historicism. If all world views are historically specific, we have no grounds for exempting our own values and beliefs from the contingent flow of historicity. This tends to erode the basis of evaluative and prescriptive engagement with practices different from our own, and to foster a relativist or laisser-faire attitude towards questionable cultural manifestations.

\section{The Dominance of the Explanatory Approach in Twentieth- Century Anglo-American Theory of Science}

The debate between the historical and structural approaches in nineteenth-century German culture ultimately achieved a solution, however incomplete and provisional, with Weber. This solution consisted in recognising that both explanation and Verstehen were legitimate aims of science. The human sciences, which employed Verstehen, were thereby assured of an intellectual space. The debate between the historical and structural approaches was joined again, on very different terms, in the twentieth-century Anglo-American theory of science.

In this connection, the differences between analytical and continental philosophy become very clear. Analytical philosophy places an emphasis on logic, mathematics, and natural sciences. Continental philosophy identi- 
fies more strongly with social, historical, psychological, and literary studies, and recognizes Verstehen as a legitimate intellectual device. Twentiethcentury continental philosophy constitutes, in part, a continuation of the nineteenth-century German debate on the methods and legitimacy of the human sciences. Philosophers in this school, perhaps most notably Edmund Husserl, tackle the problem of the abstractness and idealization of the modern natural sciences with genuine insight and balance. Analytical philosophy, by contrast, tends to take the success of the natural sciences as a given and sees as its task to explain how this success is achieved. It is to this tradition that we now turn.

C.P. Snow asserted in 1959 that the natural sciences and the humanities constituted distinct cultures in modern society. He further claimed that the humanities had acquired a dominant cultural position: whereas a person lacking extensive knowledge of the humanities was not considered cultured, he complained, an understanding of the natural sciences was not a prerequisite for this status. ${ }^{\text {II }}$ Snow's portrayal is gravely misleading. The humanities may be more familiar to and be attributed higher cultural worth by the educated public, and the classic image of the cultured person may be centred on literary and artistic pursuits. In the academy, however, the natural sciences achieved a dominant intellectual position over the humanities decades before Snow wrote his essay, and they retain that position today. Among practitioners of academic disciplines, the concept of science and the standards of scientific knowledge and explanation are defined by reference to the natural sciences. The humanities have encountered growing pressure to justify their claims to scientific status and the specificity of their methods.

The dominant intellectual position of the natural sciences in twentiethcentury Anglo-American thought is illustrated by the tradition's views on the human sciences. Thinkers in this tradition argue typically that the human sciences should adopt methods that closely resemble those of the natural sciences. They focus on two clusters of concepts. The first is explanation. According to many thinkers in the Anglo-American tradition, practitioners of the human sciences should aim to explain events and phenomena, primarily by reference to their causes. These thinkers acknowledge that the causal factors underlying human affairs may be more complex than those of natural phenomena. The explanations provided need not be 
mechanistic or monocausal: they may cite a variety of causal factors, including long-term underlying causes, short-term precipitating causes, trends, and contributing factors. Nonetheless, attention is focused on causal explanation. Second, thinkers in this tradition draw on the concepts of generalization, regularity, and law. Some argue that analysis of data on cultural phenomena reveals historical regularities or transcultural generalizations. Others maintain that the explanation of cultural phenomena could be achieved by appeal to laws of human behaviour. Thinkers in this tradition also envisage that the human sciences could be used, under ideal conditions, to make predictions about human behaviour, analogous to predictions in the natural sciences. The explanatory approach, in most formulations, is naturalist and shows distrust of the emphasis placed by the interpretationist approach upon relations of meaning. ${ }^{\mathrm{I2}}$

The view that explanation can be found only in universal laws and regularities is associated most closely with Carl G. Hempel. According to his influential deductive-nomological model of explanation, to explain an event is to deduce the statement that it occurred from the conjunction of one or more universal laws that cover the event and specific initial conditions. Explaining an event is seen as inferring a statement describing the event from a lawlike statement. Hempel believes that the deductive-nomological model - and its variant, the probabilistic-statistical model - are applicable as much to the human sciences as to the natural sciences. Hempel believes that all accounts used to yield understanding in historiography, for example, are reducible to the deductive-nomological model. This holds for genetic and functional explanations, in Hempel's view, as well as for standard causal explanations. Hempel concludes:

The nature of understanding, in the sense in which explanation is meant to give us an understanding of empirical phenomena, is basically the same in all areas of scientific inquiry; and [...] the deductive and the probabilistic model of nomological explanation accommodate vastly more than just the explanatory arguments of, say, classical mechanics: in particular, they accord well also with the character of explanations that deal with the influence of rational deliberation, of conscious and subconscious motives, and of ideas and ideals on the shaping of historical events. In so doing, our schemata exhibit, I think, one important aspect of the methodological unity of all empirical science. ${ }^{13}$ 
The agonized and painstaking nineteenth-century debate about the legitimacy and specificity of the human sciences is obliterated in this self-confident statement.

The attitude of the Anglo-American theory of science towards the human sciences was sketched by Adolf Grünbaum. He characterizes his interlocutors succinctly:

Dilthey and his followers in the Geisteswissenschaften movement insist on the methodological autonomy of psychology and the social sciences, claiming that intelligent goal-seeking, which is so characteristic of man, calls for a method differing toto genere from that of the physical sciences.

Grünbaum then reviews four objections to the claim that human behaviour can be described and explained by appeal to causal laws. These are the arguments that human individuals are unique, that human behaviour is too complex, that human acts are directed at goals, and that causal laws of human behaviour would eliminate human moral choices. He finds each of these objections inadequate. He concludes that the study of human beings can and should proceed through the search for causal laws, and that claims that the human sciences are distinct from the natural sciences are unfounded:

Strictly empathic understanding may have great heuristic value and sometimes aesthetic value as well. However, from the standpoint of achieving scientific understanding and making the predictions which such mastery makes possible, the empathic method in psychology and in history (Dilthey) is quite insufficient. ${ }^{14}$

Grünbaum hereby sidesteps any queries as to whether prediction and mastery of phenomena are aims appropriate to all scientific disciplines and to all approaches pursued in those disciplines.

Of course, Anglo-American philosophy in the twentieth century also contained alternative voices. Some theorists writing in English advocated a historiographic approach very similar to that of the Verstehen tradition. William Dray is the best known of these. ${ }^{15}$ Another partial exception is represented by Karl R. Popper. Although Popper's views are close to those of Hempel on many issues, he believes that no laws of history exist. Whereas historians rely implicitly on background laws of nature in their 
explanations, these are unavoidably trivial in content, Popper believes: the historian is interested principally in the causal explanation of singular events. ${ }^{16}$ J.J.C. Smart argued that there are no laws in biology, and that biology is therefore a science of a fundamentally different kind from physics. ${ }^{17}$ Smart suggested that the world contains two classes of entities: natural kinds such as chemical elements, which lend themselves to description by universal laws, and historical individuals such as the planet Mars, which lend themselves to description only by singular statements and lowlevel generalizations. We need sciences of both kinds in order to describe entities of both sorts. ${ }^{18}$

Some writers in the Anglo-American tradition also accepted that historical disciplines require suitable conceptual tools, including appropriate models of explanation. According to the narrative model proposed by Thomas A. Goudge, an explanation is a narrative that sets the explanandum into context, conveying an understanding of how it came to pass. ${ }^{19}$ This model of explanation appears to fit the practice in evolutionary biology, economics, and other disciplines. In the narrative model, citing a law of nature is neither a necessary nor a sufficient condition for the success of an explanation. This conclusion is borne out by the fact that the natural historical sciences routinely give accounts of events - the extinction of a species or the formation of a volcano, for instance - that involve no laws but constitute intuitively successful explanations. The narrative model of explanation answers somewhat more closely to the concerns of the human sciences than does the deductive-nomological one. The theory of the narrative model given by Goudge and others is more rudimentary than nineteenth-century treatments of Verstehen, of course, and it is shorn of the intentional dimension of the latter. However, it focuses attention on the individuality and specificity of the event to be explained, and places it in a historical context, unlike the deductive-nomological model.

Notwithstanding these alternative voices, the natural sciences remain the paradigmatic scientific disciplines in the present-day Anglo-American theory of science. The frustration thereby caused to practitioners of the human sciences was well illustrated in the science wars, an acrimonious dispute involving natural scientists, sociologists of science, researchers in the humanities, and others that arose in the mid-I990s. ${ }^{20}$ As many natural scientists saw it, the science wars were provoked by persistent attacks 
by literary and social theorists on the claims of the natural sciences to objectivity and rationality. Some critics of science may indeed have been motivated by a wish to undermine the prestige of the natural sciences; most, however, saw themselves as applying the standard tools of the cultural and social sciences to the assumptions and methods of the natural sciences. $^{2 \mathrm{I}}$

Both of the principal sides in the science wars were guilty of ignorance and lack of comprehension. The sociologists and practitioners of the human sciences often exhibited inadequate understanding of the findings and methods of the natural sciences. Through lack of expertise, they displayed a tendency to sweeping generalization and committed elementary blunders that undermined their standpoint. The natural scientists, for their part, showed equal ignorance of the specificity and traditions of the human sciences, and a tendency to question the legitimacy of these disciplines on the grounds of their difference from the natural sciences.

Natural scientists often - justifiably - insist that outsiders gain expertise in the technical aspects of their disciplines before discussing them. However, they usually feel no reluctance to address issues in the human sciences without gaining expertise in the approaches and methods specific to those disciplines.

\section{Diversity of Approaches in Historiography and ANTHRopology}

Let us now turn from theorists of science to the practice of scientists. Whereas theorists of science often work from abstract first principles and propose clear and coherent conceptual schemes for a discipline, practitioners usually develop a variety of partly unanalyzed, context-specific methods in a pragmatic and even opportunistic manner. Our aim is to ascertain briefly how some of these methods relate to and embody the historical and structural approaches discussed in the theoretical debates.

We start in this section with historiography and anthropology. These disciplines exhibit a wide variety of approaches. We may tentatively arrange historiographic approaches along a spectrum depending on their attitude towards generalization. 
At one extreme we find the genre of microhistory, an attempt to develop an understanding of history through seemingly small, individual episodes. Among the works that contributed to create this genre are Natalie Zemon Davis's The Return of Martin Guerre, a story of everyday life in the sixteenth-century Pyrenees, and Carlo Ginzburg's The Cheese and the Worms, a reconstruction of the mental world of Menocchio, a sixteenth-century Italian miller who was investigated by the Inquisition for his view that life arises in the universe spontaneously like worms in cheese. ${ }^{22}$ In these works, no person or event is regarded as typical or representative of any class: the particular is not made to stand for the general.

A greater willingness to proceed from particular events to general themes is shown by the Annales school. Members of this school combine an interest in long-term historical trends with a concentration on depth and the microcosm. The former is visible in Fernand Braudel's The Mediterranean and the Mediterranean World in the Age of Philip II, which appeared in I949. The latter is evident in Emmanuel Le Roy Ladurie's chronicle of the daily happenings in the village of Montaillou, in southern France, inhabited by some 25 peasants, during a period of thirty years at the beginning of the fourteenth century. ${ }^{23}$

An alternative strategy to bridge the gap between individual historical events and general trends is followed by quantitative social history. This genre sacrifices the qualitative aspects in order to study specific numerical parameters of populations, such as family size, age at marriage, life expectancy, and income.

At the other extreme of the spectrum of historiographic approaches, we find attempts to capture what is described as a supreme principle, essence, esprit or Geist of history. These attempts lead to a kind of philosophical commentary or reflection on human history. In this approach, documentation is subordinated to generality. It provides compact and broad formulations and aims at unearthing the grand principles behind historical occurrences. Indeed, some authors in this tradition set out to describe humankind as a whole rather than individual peoples or cultures. It is exemplified by the works of G.W.F. Hegel, who in his Philosophy of History gives an account of history as the progression in what he called the consciousness of freedom. ${ }^{24}$ Marxist historiography also pursues this style. Historical materialism is an account of history that identifies an underly- 
ing structure in historical events: the dialectic between forces of production (such as energy sources, machines, and production processes) and relations of production (constituted mainly by the pattern of ownership of the productive forces). This dialectic underlies and unifies the entirety of human history. It yields, for example, a succession of social formations: the Asiatic, ancient, feudal, and bourgeois modes of production.

The extremes of this spectrum of historiographic approaches are rarely combined in a single work. One partial exception is Voltaire's Essai sur les mours et l'esprit des nations, published in I769. As its title hints, this work contains the seeds of two approaches to historiography. In one respect, Voltaire emphasizes the mours or customs of nations, which are variable, particular, and plural. In the other, he emphasizes the esprit or spirit of nations, which are unchanging and essential characteristics of peoples. ${ }^{25}$

A similar variety of approaches is found in twentieth-century anthropology. At one extreme, we find structuralism, which Claude Levi-Strauss introduced to anthropology, partly following the ideas of Ferdinand de Saussure in linguistics. Structuralism advocates analyzing large-scale systems, ranging from human languages and cultural practices to folktales and literary texts, by examining the relations and functions of the constituent elements of such systems.

Structuralism is characterized by its willingness to propound general laws accounting for the underlying organizing patterns of phenomena. In literary studies, for example, structuralism has been applied to the field of narratology, or the study of narratives of all forms. Structuralist narratologists analyze the systematic features and functions of narratives, attempting to isolate a finite set of rules to account for the infinite set of real and possible narratives. As a result of its demotion of the person, or subject, structuralism is sometimes regarded as antihumanistic.

At the other extreme, we find functionalism, introduced by Bronislaw Malinowski. This school stresses the purposive nature of institutions in society. The purpose of an institution is derived from the particular culture of that society, which is a unique whole. Institutions can therefore be understood only in terms of their own culture. It is impossible to establish functional equivalence between institutions in different societies; even the cross-cultural comparison of institutions is doomed to failure. ${ }^{26}$

Johan Galtung proposes a new view of the difference between idio- 
graphic and nomothetic approaches. In the view of Weber and others, as we have seen, the two approaches arise from two alternative goals of science, interpretation and explanation. Galtung suggests instead that the choice between the two approaches is determined by the breadth of scope - in Galtung's phrase, the extent of the "contiguous space-time region" that the scientist wishes to treat. ${ }^{27}$ Galtung endorses Windelband's and Rickert's view that idiographic and nomothetic science are complementary. As he puts it, idiographic science provides more realistic explanations of the singular case, i.e., explanations that take into account a larger number of relevant causal factors; nomothetic science, because it surveys a larger scope, can develop categories that are meaningful in a wider context. Thanks to this complementarity, the two approaches can collaborate: nomothetic science can give idiographic science heuristic guides towards particulars of theoretical interest, while idiographic science can provide empirical data to test the hypotheses of nomothetic science.

The dominant research programme in anthropology today is generally known as interpretive social science. ${ }^{28}$ One of its principal practitioners is Clifford Geertz, who is concerned with reconstructing the mentalities and conceptual frameworks of peoples as local and historically contingent creations. The "thick description" that Geertz advocates is description that draws to the fullest possible extent on the categories in which the agents themselves described and interpreted events and actions. Geertz mounts a "critique of conceptions which reduce matters to uniformity, to homogeneity, to likemindedness, to consensus", preferring instead to open things up "to divergence and multiplicity, to the non-coincidence of kinds and categories". ${ }^{29}$

This brief survey of styles of work in historiography and anthropology reveals the following. The practice of these disciplines is more highly varied than the theorists of either the Verstehen school or Anglo-American philosophy of science acknowledge. Nonetheless, the tension between the historical and the structural approaches, and the difficulty of reconciling the two approaches in a coherent manner, are clearly experienced by practitioners. Most of the historians mentioned in this section adopt what I have dubbed the historical approach. They show little proclivity to uncover general and necessary constraints and regularities; although some are interested in identifying historical trends, they regard these as being as con- 
tingent and particular as the events of which they consist. A minority of writers - who perhaps cannot immediately be classed as professional historians, but who are unmistakably engaged in a historiographic project see history as an unfolding of a grand scheme. These writers, including Hegel and Marx, apply the structural approach to their subject. They feel that to the extent that history exhibits any contingent events, these events are what is least important and revealing about the human experience. Regularity and necessity underlie the historical record.

What of anthropology? Some members of this discipline have been willing to posit universal principles of human societies and cultures. However, the dominant anthropological stance today is antagonistic towards such attempts. Instead, practitioners of interpretive social science adopt a relativist attitude, wishing to achieve understanding of the experience of persons and peoples, but not by explaining it. Integration of the historical and structural approaches has not hitherto featured prominently on the agenda of historiography and anthropology.

\section{Historical and Structural Approaches in the Modern Life SCIENCES}

The natural sciences have acquired a dominant position in the present-day system of the sciences, especially in Anglo-American culture, as we saw in section 3; the human sciences have been allocated a subordinate position. The approach is regarded as paradigmatic of the natural sciences, which seeks to provide explanations of events on the basis of universal laws, and is thus seen as defining scientific status. The approach typical of the human sciences, in which one seeks to attain interpretative understanding of particulars, is compared unfavourably with the structural approach.

The dominance of the structural approach not only manifests itself in the tension between the natural and the human sciences, but also affects relations within the family of the natural sciences. The natural sciences are not all alike, as Windelband and other participants in the nineteenth-century debate realized. Some natural sciences make more use of laws of nature than others. The number of laws formulated by a natural science is often taken as a measure of its status and degree of development. This tendency 
found its fullest expression in Comte's hierarchy of the sciences, in which astronomy and physics occupy the summit while lower levels contain increasingly qualitative sciences. The same view is found strongly among natural scientists themselves. The assumption is frequently voiced that a genuine natural science is a law-formulating science, and that branches of science in which few or no laws are formulated are either immature or unsatisfactory.

In his inaugural lecture as professor of Natural Philosophy at the University of Glasgow in I846, for example, William Thomson (later named Lord Kelvin) set out the scope of his subject matter:

In the study of external nature, the first stage is the description and classification of facts observed with reference to the various kinds of matter of which the properties are to be investigated; and this is the legitimate work of Natural History. The establishment of general laws in any province of the material world, by induction from the facts collected in natural history, may with like propriety be called Natural Philosophy. $3^{\circ}$

Similarly, James Clerk Maxwell drew a distinction among three classes of sciences: "abstract" sciences constituted by the various branches of mathematics, "morphological and biological" sciences, and physical sciences, to which he attributed a position intermediate between the other two classes. About the morphological and biological sciences, Maxwell wrote:

Sciences of this kind are rich in facts, and will be well occupied for ages to come in the co-ordination of these facts, though their cultivators may be cheered in the meantime by the hope of the discovery of laws like those of the more abstract sciences, and may indulge their fancy in the contemplation of a state of scientific knowledge when maxims cast in the same mould as those which apply to our present ideas of dead matter will regulate all our thoughts about living things. $3^{1}$

The positivist imagery of a hierarchy of the sciences endured in the twentieth century. C.F.A. Pantin portrays the hierarchy as extending from "exact" sciences at the top to "descriptive" sciences at the bottom:

In our everyday consideration of them, the sciences are apt to be taken as though they 
could be placed in a linear series. Mathematics and physics are at the top and the others are arranged down the rungs of the ladder up which they are proceeding as they become more exact - as in a dice-game. So-called descriptive science, such as taxonomy, stand at the bottom, still waiting for a lucky throw. $3^{2}$

Notwithstanding the widely held view of disciplines steadily climbing the ladder from historical particulars towards universal laws of nature, the aims and methods of the natural sciences exhibit a great diversity. Of most interest in this context is the interplay of and competition between the historical and structural approaches in scientific disciplines. We need to examine the extent to which this interplay falls short of integration, and the reasons for this shortfall.

The interplay between historical and structural approaches emerges in various sciences. One of these is cosmology. On the one hand, cosmologists have a strong sense of natural law and its role in the development of the universe. On the other hand, the fact that we have empirical access to just one universe turns cosmology to some degree into the study of a unique historical individual. In the case of the universe, the distinction between general and necessary features on the one hand and particular and contingent features on the other becomes largely arbitrary. 33 The tension is perhaps greatest in the discussion of the initial conditions of the big bang. In some theories, these are irreducible to laws of nature and must simply be described as historical contingencies; in other theories, the initial conditions of the universe obtained necessarily. The tension between these approaches is reflected in cosmological writings: cosmologists often portray their discipline as the study of the effects of natural laws in the broadest setting possible, but some accounts of the early universe are written in a historical style, and resemble the biography of a historical personage. 34

A second interesting case, on which we will focus in more detail, is biology. The life sciences show great variety, including branches as diverse as molecular biology and phylogenetic systematics. On the one hand, life scientists have formulated a number of statements called "laws", including Mendel's laws and the Hardy-Weinberg law in population genetics; on the other hand, the phylogenetic tree has many characteristics of a historical individual. 35 
In the life sciences, consequently, the interplay between the historical and structural approaches is very evident. Organisms and their forms seem to lend themselves to being studied both as the consequences of laws of nature and as a historical phenomenon. This fact was apparent to one of the protagonists of the nineteenth-century German debate about the methods of the Geisteswissenschaften, Windelband. He argued that organic nature can be both nomothetically systematized and studied as a singular development:

The science of organic nature constitutes the classical example of this phenomenon of transposition. As a taxonomy or a systematic science, it has a nomothetic character, insofar as the invariable types of organisms which have been observed during the last few thousand years may be represented as the nomological form of these organisms. Consider, however, the subject matter of the biological sciences as evolutionary history in which the entire sequence of terrestrial organisms is represented as a gradually formative process of descent or transformation which develops in the course of time. There is neither evidence nor even a likelihood that this same organic process has been repeated on some other planet. In this case, the science of organic nature is an idiographic or historical discipline. ${ }^{36}$

At first sight, one might expect biology therefore to be an especially fertile terrain of cooperation between the historical and structural approaches. The truth is that such cooperation has proved very difficult to implement. As a result, some branches of the life sciences during certain historical periods have applied the historical approach virtually exclusively, whereas others have endorsed the structural approach.

In the twentieth century, the tension between the historical and structural approaches has been strongest in accounts of the morphology of organisms in evolutionary theory and developmental theory. The dominant approach towards morphology has been Darwinian evolutionary theory. In the orthodox interpretation, Darwinian theory regards the diversification of life forms as an irremediably contingent process, driven by random mutations and natural selection. This view of morphology is defended today by, for example, Stephen J. Gould, who argues that evolution would yield very different outcomes if it were ever replicated under similar environmental conditions. Gould proposes a thought experiment to establish this conclusion: 
I call this experiment "replaying life's tape". You press the rewind button and, making sure you thoroughly erase everything that actually happened, go back to any time and place in the past - say, to the seas of the Burgess shale. Then let the tape run again and see if the repetition looks at all like the original. 37

Gould believes that every replay of the tape would yield an entirely different but equally sensible outcome.

Alongside the classic Darwinian approach, there is a long tradition of attempts to uncover systematic and structural principles underlying the morphology of organisms. These attempts were pursued energetically in Romantic biology, and achieved interesting results in the early twentieth century at the hands of biologists such as D'Arcy Wentworth Thompson and Anne Arber..$^{8}$ As Thompson makes clear, he believes in the existence of laws of biological form that largely account for the morphology of organisms in the evolutionary record:

Cell and tissue, shell and bone, leaf and flower, are so many portions of matter, and it is in obedience to the laws of physics that their particles have been moved, moulded, and conformed [ . . ]. Their problems of form are in the first instance mathematical problems, their problems of growth are essential physical problems, and the morphologist is, ipso facto, a student of physical science. 39

In recent years, the structural approach has been defended by researchers in the field of complexity studies, including Brian C. Goodwin and Stuart A. Kauffman. $4^{\circ}$ Writers in this discipline are convinced of the existence of deep structural laws that constrain the emergence and diversification of life surprisingly tightly. They argue that the evolution of organisms, while partly contingent, takes place in a field of possibilities constrained by fundamental laws of nature and by many higher-level morphological principles. These principles produce attractors in gene space, which powerfully constrain and influence the development of species. As a result, the view of evolution provided by Darwinian theory is no longer entirely adequate. Goodwin challenges Gould's interpretation of the "replaying life's tape" thought experiment:

Suppose you reran the Big Bang. What are the chances of getting the same periodic 
table of natural elements, the same ninety-two combinations of protons, neutrons, and electrons? Pretty good, or so I'm led to believe. I think of a rerun of the Cambrian explosion in the same way, not to the same extent perhaps, but as an image. If there are dynamical attractors in the space of morphological possibilities, as I believe, then a rerun of the Cambrian explosion would produce a world much more like the one we know than Steve Gould says. It wouldn't be identical to the one we know, but there may be a lot of similarities. $4^{1}$

The historical and structural approaches cast the similarities of organisms in different lights. In particular, the historical approach attributes evidential significance to the similarity of organisms that, on the structural approach, it does not have. For example, the similarity of fossil fauna and flora in South America, Africa, India, Australia, and Antarctica is cited as evidence for the theory of continental drift. This similarity offers evidential support if organisms develop historically and contingently. If, on the other hand, the morphology of organisms is determined to a large extent by structural constraints, the similarity of fauna and flora on continents separated by oceans loses much of its evidential weight in support of the theory of continental drift.

The outside observer might conclude that both approaches to morphological form are partly valid: organisms are the product both of laws of form and of natural selection. However, it has proved difficult to integrate the historical and structural approaches in the life sciences without falling into traditional oppositions, as the persistence of unproductive "nature versus nurture" debates demonstrates. A more promising recent attempt goes under the name of "developmental systems theory". This approach views ontogeny as contingent cycles of interaction among a varied set of developmental resources, no one of which controls the process. These factors include DNA, cellular and organismic structure, and social and ecological interactions..$^{2}$

\section{Conclusion: Classification and Integration}

The history of the sciences exhibits an enduring debate between the historical and structural approaches. Each approach has an impressive record of 
accomplishment. Our historical survey may lead readers to the following conclusions.

The universe is the product of two elements: a structural element and a historical element. The structural element determines the set of physically possible worlds within which the actual universe finds itself; the historical element determines which of these physically possible worlds, and in what order of succession, the universe comes to instantiate in its development.

The structural element may be identified with the fundamental laws of nature, which impose constraints on the development of the universe and determine what events and structures there may be. The historical element may be identified with a path through this field of possibilities, which determines which of the events and structures allowed by the laws of nature become actual.

For example, the fundamental laws of nature determine which elementary particles may exist and thus determine that, for example, an iron atom is a stable physical structure. However, they do not determine that an iron atom comes to form part of a particular chemical structure: this is determined by the historical development of the universe.

An understanding of the universe requires knowledge of and reference to both the structural and the historical elements determining its development. The development of the universe would seem arbitrary and improbable without full reference to the laws of nature that constrain its possibilities; on the other hand, it would seem underdetermined and inexplicable without reference to its historical trajectory. Together, the structural and historical approaches are capable of giving a complete account of the universe.

These conclusions hold not only for the investigation of the universe in its entirety, but for the study of all objects. The universe exhibits many levels of organization, ranging from elementary particles to human societies and cultures. Each of these levels of organization has its own structural principles, which in part are determined by the principles of lower levels and in part arise as emergent properties. The principles on each level determine the range of possibilities and provide attractors that influence the organization of that level. Within the scope of these principles, historical evolution determines the actual development that a system on a particular level undergoes. 43

Is the view of the world and of science sketched in the previous few 
paragraphs a realistic prospect or an utopia? Structural considerations may encourage the belief that it is the former: historical experience suggests that it may be the latter. On abstract grounds, the proposal that the structural and historical approaches should collaborate in enriching our understanding of the world and in furthering science sounds plausible and sensible. An acquaintance with the history of ideas, on the other hand, cautions that such integration has evaded scientists for the past 150 years. Indeed, the present system of the sciences is to some extent the product of the segregation of scholars into groups that practise one of the approaches to the neglect of the other.

Is it worth redoubling our efforts to realize the integration of the historical and structural approaches? The endpoint is tantalizing: a new ordering of knowledge in which the identity of the present-day scientific disciplines will be subordinated to the integration of structural and historical elements. In some disciplines, such as biology and the human sciences, this will mean that the dominant historical approach will have to be amended and new techniques developed to study structural elements; in other disciplines, such as physics, it will necessitate a re-evaluation of the role of historical development within the existing structuralist framework, from which the temporal dimension has hitherto been largely banned.

This development will have particular consequences for the demarcation of the natural and the human sciences. If it is true that structural elements underpin and constrain creativity in the arts, then no university programme in the human sciences will be complete without a study of the physical, physiological, and evolutionary context in which an art form develops. This study will have to reveal what range of possibilities is open to that art form, before the historical study can explore which part of that range has actually been exploited. The study of the human sciences will thus come to acquire some traits associated with the natural sciences.

\section{ACKNOWLEDGEMENTS}

I thank the Hollandsche Maatschappij der Wetenschappen and the editors of this volume for the invitation to write the present essay. I am grateful to my colleague Herman Philipse for comments on a previous version. 


\section{Notes}

I For an introduction to the German debate on the human sciences leading up to Weber, see Ringer (I997), on which I have drawn in this section. I have also benefitted from Hofstede (i980).

2 Comte (I830-I842), vol. I.

3 On the German historical tradition and educational theory, see Iggers (I968); Ringer (I990); Ringer (I997).

4 Vierhaus (I990).

5 Ritzel (I950).

6 Dilthey (I883); Dilthey (I9I0). For further discussion of Dilthey's view of history, see Ermarth (1978).

7 Simmel (1892).

8 Windelband (I894), p. I75.

9 Rickert (I899); Rickert (I902).

Io Weber (I949).

II Snow (I959).

I2 Accounts of explanation in twentieth-century Anglo-American theory of science are surveyed in Ruben (I993). Barrow (I995) attempts to explain features of the arts by reference to physical principles.

I3 Hempel (I962), pp. 3I-32. See also Hempel (I965), pp. 23I-243; Tucker (I998).

I4 Grünbaum (1952), pp. 665, 668-669.

I5 Dray (I957).

I6 Popper (i960).

I7 Smart (I963), pp. 50-6r.

I8 For discussion of these issues, see Van der Steen and Kamminga (I99I); McAllister (I997).

I9 Goudge (I96I), pp. 70-79; see also Hull (I975). Further on the role of narrative in argument and explanation, see Mitchell (I98I); Wright (I995); Rouse (I996).

20 On the science wars, see Jardine and Frasca-Spada (I997); Brown (200I).

2I On the discipline of social studies of science, see Fuller (I994); Fuller (2000).

22 Davis (I983); Ginzburg (I983). On the genre of microhistory, see also Levi (I99I).

23 Le Roy Ladurie (I978).

24 Hegel (1837).

25 On these two approaches in historiography and their origins, see Kroeber and Kluckhohn (I952), pp. I45-I46. 
26 Goldschmidt (I966); Berry (I969).

27 Galtung (1967).

28 For an introduction to interpretive social science, see Rabinow and Sullivan (I988); Scott and Keates (200I). See also Little (I990).

29 Geertz (I998), p. I07. See also Geertz (I973), esp. pp. 3-32; Geertz (1983).

30 Quoted from S. P. Thompson (I9IO), vol. I, p. 240. On the placing of natural history at the bottom of the hierarchy of the sciences, see Brush (I978).

3I Maxwell (I885), p. 2.

32 Pantin (I968), p. 24.

33 For discussion of the implications of the uniqueness of the universe for cosmology, see McCrea (I970).

34 Weinberg (I977).

35 For a discussion of laws in population genetics, see Ruse (I977), pp. 89-II3. Further defences of the existence of laws in biology are given by Mayr (I982), pp. 37-43; Mayr (I985), pp. 53-54; Ghiselin (1988), pp. 469-470.

36 Windelband (1894), p. I76.

37 Gould (I989), pp. 48 and 287. See also Gould (I999). For further discussion of Gould's historiographical approach, see McRae (I993).

38 Lenoir (I987); Cunningham and Jardine (I990).

39 D. W. Thompson (I942), p. Iо.

40 Goodwin (I994); Goodwin and Webster (I996); Kauffman (I995); Kauffman (2000). See also Ball (I998).

4I Quoted in Lewin (I999), p. 74.

42 An overview of developmental systems theory is provided by Oyama et al. (200I).

43 Elements of this view are to be found in Oppenheim and Putnam (I958).

\section{BIBLIOGRAPHY}

Ball, Philip J. I998. The Self-Made Tapestry: Pattern Formation in Nature. Oxford:

Oxford University Press.

Barrow, John D. I995. The Artful Universe. Oxford: Clarendon Press.

Berry, J. W. I969. “On Cross-cultural Comparability”, in International Journal of Psychology 4, pp. II9-I28.

Brown, James Robert. 200I. Who Rules in Science? An Opinionated Guide to the Wars. Cambridge, Mass.: Harvard University Press. 
Brush, Stephen G. 1978. "Planetary Science: From Underground to Underdog”, in Scientia 72, pp. 771-787.

Comte, Auguste. I832-1842. Cours de philosophie positive. Six volumes. Paris.

Cunningham, Andrew, and Nicholas Jardine, eds. I990. Romanticism and the Sciences. Cambridge: Cambridge University Press.

Davis, Natalie Zemon. I983. The Return of Martin Guerre. Cambridge, Mass.: Harvard University Press.

Dilthey, Wilhelm. I883. Introduction to the Human Sciences [Einleitung in die Geisteswissenschaften]. Translated by Rudolf A. Makkreel and Frithjof Rodi. Princeton, N.J.: Princeton University Press, I989.

Dilthey, Wilhelm. I9ıo. "On the Construction of the Historical World in the Human Studies" ["Der Aufbau der geschichtlichen Welt in den Geisteswissenschaften"], in H. P. Rickman, ed., Dilthey: Selected Writings. Cambridge: Cambridge University Press, I976; pp. 168-246.

Dray, William. I957. Laws and Explanations in History. Oxford: Clarendon Press. Ermarth, Michael. I978. Wilhelm Dilthey: The Critique of Historical Reason. Chicago, Ill.: University of Chicago Press.

Fuller, Steve. I994. "Can Science Studies Be Spoken in a Civil Tongue?”, in Social Studies of Science 24, pp. I43-I68.

Fuller, Steve. 2000. "Science Studies through the Looking Glass: An Intellectual Itinerary", in Ullica Segerstrale, ed., Beyond The Science Wars: The Missing Discourse about Science and Society. Albany, N.Y.: State University of New York Press; pp. I85-217.

Galtung, Johan. I967. Theory and Methods of Social Research. London: Allen and Unwin.

Geertz, Clifford. I973. The Interpretation of Cultures. New York: Basic Books.

Geertz, Clifford. I983. Local Knowledge. New York: Basic Books.

Geertz, Clifford. I998. "The World in Pieces: Culture and Politics at the End of the Century”, in Focaal: Tijdschrift voor Antropologie 32, pp. 9I-II7.

Ghiselin, Michael T. I988. “The Individuality Thesis, Essences, and Laws of Nature”, in Biology and Philosophy 3, pp. 467-474.

Ginzburg, Carlo. 1983. The Cheese and the Worms: The Cosmos of a Sixteenth-Century Miller. Translated by J. Tedeschi and A. Tedeschi. New York: Penguin.

Goldschmidt, Walter. I966. Comparative Functionalism: An Essay in Anthropological Theory. Berkeley: University of California Press. 
Goodwin, Brian C. 1994. How the Leopard Changed Its Spots: The Evolution of Complexity. London: Weidenfeld \& Nicholson.

Goodwin, Brian C., and Gerry Webster. I996. Form and Transformation: Generative and Relational Principles in Biology. Cambridge: Cambridge University Press.

Goudge, Thomas A. I96r. The Ascent of Life: A Philosophical Study of the Theory of Evolution. Toronto: University of Toronto Press.

Gould, Stephen J. I989. Wonderful Life: The Burgess Shale and the Nature of History. New York: Norton.

Gould, Stephen J. I999. "Introduction: The Scales of Contingency and Punctuation in History”, in John Bintliff, ed., Structure and Contingency: Evolutionary Processes in Life and Human Society. London: Leicester University Press; pp. ix-xxii.

Grünbaum, Adolf. I952. "Causality and the Science of Human Behavior", in American Scientist 40, pp. 665-676, 689.

Hegel, G. W. F. 1837. The Philosophy of History. Translated by J. Sibree. New York: Dover, I956.

Hempel, Carl G. I962. "Explanation in Science and in History", in Robert G.

Colodny, ed., Frontiers of Science and Philosophy. Pittsburgh, Penn.: University of Pittsburgh Press; pp. 7-33.

Hempel, Carl G. I965. Aspects of Scientific Explanation and Other Essays in the Philosophy of Science. New York: Free Press.

Hofstede, Geert. I980. Culture's Consequences: International Differences in Work-Related Values. Beverly Hills, Cal.: Sage Publications.

Hull, David L. I975. "Central Subjects and Historical Narratives”, in History and Theory I4, pp. 253-274.

Iggers, Georg. I968. The German Conception of History: The National Tradition of Historical Thought from Herder to the Present. Middletown, Conn.: Wesleyan University Press.

Jardine, Nicholas, and Marina Frasca-Spada. I997. "Splendours and Miseries of the Science Wars", in Studies in History and Philosophy of Science 28, pp. 219-235.

Kauffman, Stuart A. I995. At Home in the Universe: The Search for Laws of SelfOrganization and Complexity. New York: Oxford University Press.

Kauffman, Stuart A. 2000. Investigations. New York: Oxford University Press. Kroeber, A. L., and Clyde Kluckhohn. 1952. Culture: A Critical Review of Concepts and Definitions. Cambridge, Mass.: Peabody Museum of American Archaeology and Ethnology. 
Lenoir, Timothy. 1987. "The Eternal Laws of Form: Morphotypes and the Conditions of Existence in Goethe's Biological Thought", in F. Amrine, F. J. Zucker and H. Wheeler, eds., Goethe and the Sciences: A Reappraisal. Dordrecht: Reidel; pp. I7-28.

Le Roy Ladurie, Emmanuel. I978. Montaillou: Cathars and Catholics in a French Village, 1294-1324. Translated by Barbara Bray. Scholar Press, I978.

Levi, Giovanni. I99I. “On Microhistory”, in P. Burke, ed., New Perspectives on Historical Writing. University Park: Pennsylvania State University Press; pp. 93-II3.

Lewin, Roger. I999. Complexity: Life at the Edge of Chaos. Second edition. Chicago, Ill.: University of Chicago Press.

Little, Daniel. I990. Varieties of Social Explanation: An Introduction to the Philosophy of Social Science. Boulder, Col.: Westview Press.

Maxwell, James Clerk. I885. "Physical Sciences”, in Encyclopaedia Britannica. Ninth edition. Edinburgh: Adam and Charles Black; vol. I9, pp. I-3.

Mayr, Ernst. 1982. The Growth of Biological Thought: Diversity, Evolution, and Inheritance. Cambridge, Mass.: Harvard University Press.

Mayr, Ernst. I985. "How Biology Differs from the Physical Sciences", in David J. Depew and Bruce H. Weber, eds., Evolution at a Crossroads: The New Biology and the New Philosophy of Science. Cambridge, Mass.: MIT Press; pp. 43-63.

McAllister, James W. I997. "Laws of Nature, Natural History, and the Description of the World", in International Studies in the Philosophy of Science II, pp. 245-258.

McCrea, W. H. I970. “A Philosophy for Big-Bang Cosmology”, in Nature 228, pp. 2I-24.

McRae, Murdo William. I993. "Stephen Jay Gould and the Contingent Nature of History", in Clio 22, pp. 239-250.

Mitchell, W. J. T., ed. I98I. On Narrative. Chicago, Ill.: University of Chicago Press.

Oyama, Susan, Paul E. Griffiths, and Russell D. Gray, eds. 200I. Cycles of Contingency: Developmental Systems and Evolution. Cambridge, Mass.: MIT Press.

Pantin, Carl F. A. I968. The Relations Between the Sciences. Cambridge: Cambridge University Press.

Popper, Karl R. I960. The Poverty of Historicism. Second edition. London: Routledge. Oppenheim, Paul, and Hilary Putnam. I958. “Unity of Science as a Working Hypothesis", in Herbert Feigl, Michael Scriven, and Grover Maxwell, eds., Concepts, Theories, and the Mind-Body Problem. Minnesota Studies in the 
Philosophy of Science, vol. 2. Minneapolis: University of Minnesota Press; pp. 3-36.

Rabinow, Paul, and William M. Sullivan, eds. I988. Interpretive Social Science:

A Second Look. Berkeley: University of California Press.

Rickert, Heinrich. I899. Science and History: A Critique of Positivist Epistemology

[Kulturwissenschaft und Naturwissenschaft]. Translated by George Reisman.

Princeton, N.J.: Van Nostrand, 1962.

Rickert, Heinrich. 1902. The Limits of Concept Formation in Natural Science: A Logical

Introduction to the Historical Sciences [Die Grenzen der naturwissenschaftlichen

Begriffsbildung]. Edited and translated by Guy Oakes. Cambridge: Cambridge University Press, I986.

Ringer, Fritz. I990. The Decline of the German Mandarins: The German Academic

Community, 1890-1933. Hanover, N.H.: Wesleyan University Press and University Press of New England.

Ringer, Fritz. I997. Max Weber's Methodology: The Unification of the Cultural and

Social Sciences. Cambridge, Mass.: Harvard University Press.

Ritzel, Gerhard. 1950. Schmoller versus Menger: Eine Analyse des Methodenstreits im

Hinblick auf den Historismus in der Nationalökonomie. Frankfurt am Main: Enz und Rudolph.

Rouse, Joseph. I996. Engaging Science: How to Understand its Practices Philosophically. Ithaca, N.Y.: Cornell University Press.

Ruben, David-Hillel, ed. I993. Explanation. Oxford: Oxford University Press.

Ruse, Michael. I977. “Is Biology Different from Physics?”, in Robert G. Colodny, ed., Logic, Laws, and Life: Some Philosophical Complications. Pittsburgh, Penn.:

University of Pittsburgh Press; pp. 89-127.

Scott, Joan W., and Debra Keates, eds. 200I. Schools of Thought: Twenty-Five Years of Interpretive Social Science. Princeton, N.J.: Princeton University Press.

Simmel, Georg. I892. The Problems of the Philosophy of History: An Epistemological Essay [Die Probleme der Geschichtsphilosophie: Eine erkenntnistheoretische Studie]. Translated by Guy Oakes. New York: Free Press, I977.

Smart, J. J. C. I963. Philosophy and Scientific Realism. London: Routledge and Kegan Paul.

Snow, C. P. I959. The Two Cultures: And a Second Look. Cambridge: Cambridge University Press, I964.

Steen, Wim J. van der, and Harmke Kamminga. I99I. "Laws and Natural History in Biology", in British Journal for the Philosophy of Science 42, pp. 445-467. 
Thompson, D’Arcy Wentworth. I942. On Growth and Form. New York: Dover, I992. Thompson, Sylvanus P. I9ıо. The Life of William Thomson, Baron Kelvin of Largs. Two volumes. London: Macmillan.

Tucker, Aviezer. I998. "Unique Events: The Underdetermination of Explanation”, in Erkenntnis 48, pp. 59-80.

Vierhaus, Rudolf. I990. "Historiography between Science and Art”, in Georg G. Iggers and James M. Powell, eds., Leopold von Ranke and the Shaping of the Historical Discipline. Syracuse, N.Y.: Syracuse University Press; pp. 6I-69.

Weber, Max. 1949. Methodology of the Social Sciences. New York: Free Press.

Weinberg, Steven. I977. The First Three Minutes: A Modern View of the Origin of the Universe. New York: Basic Books.

Windelband, Wilhelm. I894. "History and Natural Science” ["Geschichte und Naturwissenschaft"], translated by Guy Oakes, in History and Theory i9 (I980), pp. $165-185$.

Wright, Larry. 1995. "Argument and Deliberation: A Plea for Understanding”, in Journal of Philosophy 92, pp. 565-585. 


\title{
The Role of Laws and Contingency in History ${ }^{\mathrm{I}}$
}

\author{
Diedel Kornet
}

It was a great pleasure to study James McAllister's essay, not in the least because he discusses the development of the sciences from the perspective of their internal dynamics. Moreover, as a matter of fact, I found myself largely in agreement with his conclusions. But it is my task to start a critical debate, so that is what I will set out now to do by focussing on three main points.

I THE HiSTORICAL ELEMENT DETERMINES THE ACTUAL WORLD NOT ONLY BY CONTINGENT EVENTS AND PROCESSES BUT BY INSTANTIATION OF LAWS AS WELL

The conclusion of McAllister is that

"The structural element determines the set of physically possible worlds within which the actual universe finds itself; the historical element determines which of these physically possible worlds, and in what order of succession, the universe comes to instantiate in its development."

I support the image of the actual universe as one instantiated out of the many possible universes, but it is not clear how this historical element determines it. In the introduction, McAllister states that in the historical approach "the world comes to have the structure that it has as a result of contingent historical events and processes". But it is not true that all historical events and processes are contingent. While general laws (McAllister's structural element) are not bound to time and space, the events and processes that they determine (instantiations of laws, as we call them) most certainly are. Let us take two examples. 
On I January 2002 we witnessed the introduction of the euro. This historical event took place on the organizational level of societies. In their account of this phenomenon, sociologists, economists and political scientists can refer only to a limited number of generalized patterns, because their disciplines have been unable to discover many. Most of their account will contain descriptions of contingent events and processes. The generalized patterns that are available are not powerful enough to predict with any plausibility the date of the next international currency transition.

Our second example concerns the total solar eclipse of II August |I999. This historical event took place on the organizational level of planetary systems. In their account of this phenomenon, astronomers need to refer simply to the law of gravitation of which this event is an instantiation. The same law of nature enables them to predict many further total solar eclipses; the next one will be on 4 December 2002, visible in Australia.

\begin{tabular}{|c|c|c|c|}
\hline & \multirow{3}{*}{$\begin{array}{l}\text { Structural Approach } \\
\text { I } \\
\text { Generalized pattern; } \\
\text { laws and regularities }\end{array}$} & \multicolumn{2}{|l|}{ Historical Approach } \\
\hline & & IIA & $I I B$ \\
\hline & & $\begin{array}{l}\text { Instantiated } \\
\text { generalized pattern }\end{array}$ & $\begin{array}{l}\text { Contingent } \\
\text { events and processes }\end{array}$ \\
\hline \multicolumn{4}{|c|}{ Examples of historical events } \\
\hline 1 Introduction of the euro & & 0 & 00000 \\
\hline 2 Solar eclipse & & 000000 & \\
\hline \multicolumn{4}{|l|}{ Kant, Comte } \\
\hline 3 Physics & 000000 & & \\
\hline 4 Human Sciences & & & 000000 \\
\hline 5 Interpretative persp. & $o$ & 0000 & \\
\hline \multicolumn{4}{|l|}{ Future development } \\
\hline 6 Physics & 00000 & 000 & $o$ \\
\hline 7 Biology & 0000 & 0000 & oooo \\
\hline 8 Human Sciences & $o$ & 000 & 00000 \\
\hline
\end{tabular}


So, the historical element determines which of the physical possible worlds instantiates both by contingency and by instantiated laws and regularities. For a proper further discussion of the position of the different sciences, I denote the structural approach category I (generalized pattern). I introduce two subcategories for the historical approach; category IIA (instantiated generalized pattern), which I have just added to the discussion, and category IIB (contingent events and processes), which is McAllister's original historical approach. For an overview of the categories and the positioning of the two examples of historical events, see the table entries 1 and 2.

2 The Interpretative Perspective of the Human Sciences is NOT AN EXAMPLE OF MCAlLiSTER'S HiSTORICAL APPROACH (IIB). IT FITS CATEGORIES I (GENERALIZED PATTERN) AND IIA (INSTANTIATED GENERALIZED PATTERN) INSTEAD

Kant regarded historical knowledge as purely contingent and disqualified it as scientific for that reason. To the positivist Comte, the maturity of a discipline hinged on its ability to go beyond the description of mere facts by the formulation of laws of nature. The ability of formulating laws, that is using the structural approach in McAllister's terms (category I), was for Kant and Comte the criterion to grant scientific status to disciplines. Physics (positioned in category I) ranked high, and the Human Sciences (positioned in category IIB; McAllister's original historical approach) ranked low (see table entries 3 and 4 ).

It will now be interesting to look into the defence of the $19^{\text {th }}$-century German scholars against the devaluation of the Human Sciences by the criteria of Kant and Comte, as described by McAllister. How did they defend their disciplines against the charge of lack of natural laws? McAllister portrays these German scholars as proponents of the historical approach (IIB). One should therefore expect them to embrace historical contingency and the inability to go beyond the facts, and to show that descriptions are respectable scientific outcomes as well.

But that is not at all what happened. They also wanted to go beyond the mere observed facts, or in other words to escape category IIB in which they were placed by Kant and Comte (see table entry 5). The scholars invoked an 
Interpretative Perspective in which they proposed structural elements as alternatives to laws of nature, and thereby positioned the Interpretative Perspective in the structural approach (I). But they also stressed the importance of focussing on the particular instantiations of those general patterns, and thereby positioned the Interpretative Perspective in the historical approach IIA. It is in this sense that some of the proponents classified this perspective as Historicism. To treat the Interpretative Perspective as an example of his original historical approach (IIB) as McAllister does is not justified.

What is the general pattern invoked by the Interpretative Perspective? As McAllister explains, the Interpretative Perspective puts intentionality at centre-stage. Cultural phenomena are to be understood above all by reference to the intentions, beliefs, and meanings. This understanding is possible by virtue of a presupposed general internal mental pattern (such as rationality) which enables us by means of our empathic epistemological capacity to interpret human actions. Ranke recommends cultivation of empathy; for Dilthey, the human spirit and its acts can be understood only from the inside; Simmel refers to our ability to identify ourselves with others; according to Windelband, we may rely on our informal insight and intuition; and finally, according to Weber, to achieve an interpretative understanding of patterns of social action, we may initially ascribe to others a rationality identical to our own.

It is perhaps debatable whether the internal mental pattern counts as a valid structural element alongside the laws of nature. But valid or not, the Interpretative Perspective, in the campaign to stop scientific devaluation, puts great effort into going beyond the descriptions of mere contingent facts of which they were accused.

\section{The SCIENCES Will ALWAYS DifFeR IN THEIR CAPACITY TO FORMULATE LAWS BECAUSE THEY STUDY DIFFERENT LEVELS OF ORGANIZATION}

In his conclusion, McAllister recommends that each scientific discipline integrate the structural approach and the historical approach. Physics should pay more attention to the historical element and Biology and the 
Human Sciences to the structural element. This suggests the possibility that all of the various sciences could become similar. Is there indeed hope to overcome Comte's hierarchy of the sciences based on their law-formulating capacity for which he, after all, argued on debatable historical, logi$\mathrm{cal}$, and perfectionist grounds?

No, there is not. The potential to formulate general laws and mechanisms will always differ among the sciences for ontological reasons. The objects of study of the different sciences are at different levels of organization. During the development of the universe, these levels of organization emerged in chronological order with increasing complexity. Out of the interaction of elementary particles, stable configurations of such particles emerged, which we now call atoms. From the interaction of atoms, there emerged the next organizational level, that of molecules, the autocatalytic interaction among a number of which in turn gave rise to the level of living systems. Subsequent levels are those of species and societies.

Each level of organization has a fixed number of possible stable configurations (determined by the laws of nature) of which at a particular moment only a number are actualized. At the atomic level virtually all possible atomic configurations (described by the atomic theory) have become actualized: almost all elements of the Periodic Table now exist. At the molecular level, however, far fewer than all possible stable molecular configurations are realized at this moment. The possible stable configurations of atoms are relatively few because of the limited number of logically possible combinations of three kinds of elementary particles within an atom, together with the physical constraint of an upper limit to the proton number. At the level of molecules, the number of possible stable configurations increases enormously because of the many logically possible combinations of the more than one hundred different kinds of atoms within a molecule, many of which are physically stable. If at each subsequent organizational level the number of stable configurations rises with an accelerating number of logically possible combinations, of which many are physically possible, we may expect an ever smaller proportion of actualized entities compared with the number of possible ones.

A decreasing proportion of filled possible configurations at levels of organization of increasing complexity has important implications for the possibility of discovering general patterns. While virtually all possible at- 
oms can be studied and compared in reality, so few of all possible societies have become instantiated that it is very difficult to formulate general statements about them. When only a small number of the possible entities have been instantiated, the attention becomes focussed on why the ones which are there made it, and on the idiosyncrasies of their behavior. It is contingent on which of the possible stable configurations (determined by the laws of nature) have made it in history. Researchers in disciplines studying entities of the higher levels of organization therefore find themselves heavily occupied with describing the historical path of origin of their species or societies and their particular behavior. If only we knew one more form of biological evolution; what a feast it would then become to generalize over living systems.

So the capacity of the different scientific disciplines to formulate laws depends on the level of organization of the objects of their study. A rehabilitation of the Human Sciences should therefore not have to wait for the integrative results of paying more attention to the structural element in the Human Sciences and to the historical element in the Natural Sciences. Though undoubtedly there is a lot to be gained here, as I fully agree with McAllister, the capacity of the Human Sciences to formulate laws is necessarily limited. The simple solution is of course that scientific status should be related not to the level of organization that is studied but to the methods that a discipline develops appropriate to that level.

In this light, the recommendations about the way in which the development of the monodisciplines should take place can be more realistic and, by virtue of the three categories that we now have available, also more subtle (see table entries 6, 7, 8). For Physics, it is more relevant to invest in the historical instantiations of the laws of nature (IIA) than in historical, contingent events and processes (IIB). Biology is a candidate to reach a balanced distribution of attention, for which more investment is needed in studies of generalized patterns (I) and their instantiation (IIA). Human Sciences should invest modestly in the structural element, the formulation of generalized patterns (I), and more in the historical element, that is, in the instantiations of the scarce, available patterns (IIA).

But the real challenge lies in the multidisciplinary integration of the structural approach and the historical approach. To understand the structure of our world, we need to understand the transitions from one organi- 
zational level to the other, for which we need general laws as much as their historical instantiations. But we also need to know how the behavior of an entity at one level is influenced by its constituent parts at lower levels, as well as by the entities at higher levels of which it forms a constituent part. At the level of cells, for instance, to explain programmed cell death (apoptosis) we should understand not only how the molecular mechanism of killing a cell works, but also how the organism of which the cell is a part acquired, for the benefit of its own interests, the capacity to overrule the interests of the cell. Similarly, electrons of atoms that are part of a cyclic molecule or of a biomolecule such as chlorophyll in a living cell behave differently from electrons in free atoms.

At this moment, the Life Sciences form a center of multidisciplinary action. Questions about living systems are now tackled not only by biologists but also by chemists, physicists, mathematicians, computer scientists, and even astrobiologists. In their interaction, levels of organization are crossed incessantly, and their research programs broadly cover each of the structural and historical categories. New educational programs such as Life Science \& Technology, born out of the collaboration between the University of Leiden and the Technical University Delft, train students in a combination of these disciplines from the outset. The new form of science advocated by James McAllister in which the structural and historical approaches become integrated may well develop from this new and fast developing multidisciplinary field.

\section{ACKNOWLEDGEMENTS}

I should like to thank Gerard Nienhuis, Thomas Reydon, and Arno Wouters for profitable discussions.

\section{Note}

I Comments on Historical and Structural Approaches in the Natural and Human Sciences, by James McAllister. 



\section{Science and Society in Flux}

JOHAN VAN BENTHEM

Abstract. Science ${ }^{I}$ is the search for objective systematic knowledge about any topic outside of, or inside ourselves. It is a major cultural component of our modern society - both for its narrower content and for its general attitudes of free thinking and the values of elightenment which it embodies.

This essay discusses some current problems that threaten the functioning of science, in its broad cultural role. These fall under four heading, two internal, two external.

Architecture: We discuss the need for recalibration of the ancien regime in academia, which the rise of 'information and cognition' as a prime example. We make a case for a new matrix organisation making sure that talent and money flow where they do most good for the above functions of science.

Bulk: We discuss the overproduction of scientific information, and the resulting loss of a unified intellectual perspective. Some new mechanisms are proposed for countering this.

Isolation: We discuss the potential interfaces of science and society, making a plea for an activist networking stance, involving more segments of society in intellectual debate.

Ideologies: We point at threats to science arising from current political and religious ideologies, and the need for defending the historical achievements of the Enlightenment. 


\section{INTRODUCTION}

This piece is not quite the same after the events of September II ${ }^{\text {th }}$, 200I. How important is the problem as originally set by the Hollandse Maatschappij today, worrying about the optimal internal organization of the sciences - at a time when we are forcibly reminded of the power of obscurantist mentalities opposed to the central things that science has stood for historically? Some years ago, I met a Kurdish colleague, a Muslim from northern Iraq, who told me about the profound experience of entering the world of science. It was as if he described my own personal history. Entering the world of learning is like a benign religious conversion. It involves learning to think for yourself, rather than accepting things on faith, being confronted with universal truths that transcend cherished national or religious myths, and entering a community not bound in space and time of people of any race, religion, or national background who think likewise. Becoming a scientist is truly acquiring a second, non-parochial identity and joining the world, based on respect for the insights and achievements of others. This may sound overly dramatic to those no-nonsense politicians who view science as the lubricant of modern industry and universities as the research and development division of the nation. It may also seem naive to those who merely want to 'join the West in order to beat it', like contemporary religious fundamentalists using the most sophisticated technologies to spread ignorance rather than light. But in my view, it is these deeper values underlying research and scholarship that are most worth preserving and that ultimately are also most important to the general well-being of our society. Science is not a one-dimensional threat to, or a neutral technological engine of, Western civilization. Well-understood, it is an instrument of liberation - and its values and practices form a crucial defining element of a truly global human culture.

\section{SCience as CUlture}

Not all is well with modern science. Indeed, both its internal functioning and its interactions with general society show many signs of strain. But before discussing the specific concerns of this essay, let us take a prelimi- 
nary tour of our subject. Modern science is a very complex cultural phenomenon, which admits of no simple definition. Its topics range from daily phenomena around us to the most abstruse corners of the cosmos - and its practitioners show an anthropological spread from individual scholars poring over ancient manuscripts to groups of workers in factory-like laboratories. Merely as a point of departure, let me state the aim of science as

the search for objective, general, and systematic knowledge about any subject whatsoever, within or outside ourselves.

The adjectives deserve some brief elaboration. "Objective": we are after knowledge that is accessible to and can be verified in principle by anyone on this planet, transcending personal interests, biological background, or being among the chosen of some religion. "General": scientific knowledge is universal and explains the individual facts of our experience, placing them in a broader understanding of the world. "Systematic": science is a system with constantly emerging internal cross-connections, which forms a source of intellectual dynamics in itself, in addition to the primary challenges of understanding the world and ourselves. In principle, no topic is excluded from this enquiry - though one should agree with our Greek ancestor Aristotle that

it is the hallmark of the educated mind to give no subject more than that intellectual precision which it requires...

The result of scientific enquiry are culture products such as certified information, theories, methods, algorithms, codified in books, papers, machines, or software: transferable cultural heritage. But more important than these is the individual and social process. Science works thanks to a number of individual attitudes of people participating in it (methodical, abstract, objective), as well as a largely transnational social organization which provides guarantees for the right kinds of interaction between its practitioners: criticism, objectification, cooperation across barriers of many kinds. It is this process which is ultimately the crucial concern. Cultural treasures mean nothing if they no longer correspond to a vital practice. 
This description may make science too much of an ideal far removed from our daily practice. The preceding is not meant to suggest that rationality does not exist also in our daily practices of information, decision-making, communication, and acting. Such a separation is totally unfounded and would lead to a dangerous 'isolation of rationality'. All the above features of science are natural extrapolations of general human abilities and natural features of our best behaviour. Humans deliberate, plan, organize, and interact in many rational ways, whose borderline with scientific procedure is often permeable. That is precisely why scientific thinking is a typically human effort, and one which keeps going without artificial pressures. Still, it often requires an effort beyond following the cosier grooves of thought:

think systematically, and even more importantly: think for yourself!

In understanding science, there is also a question of purpose. Why do we do these things? Again, there is a wide range of motives here. Some people do research as a vocation in itself, having been 'touched by the grace' of some talent plus deep love of insight. Others may be driven by the interests of their employers, or of getting rich. This mix of motives is ancient, and it has varied over time. Rather than emphasizing culture production, society nowadays seems to expect science to cure cancer, produce an adequate defense system, and keep national economies performing at ever higher levels in a competitive world. These mixed motives are entirely understandable where funding is concerned, and moreover, they keep science exposed to a wide range of useful external challenges. For instance, many deep issues have arisen in the confrontation of long-term theory and shorter-term technological concerns - witness the birth of thermodynamics in the $19^{\text {th }}$ century, stimulated by the rapid rise of machines in the industrial revolution, and that of 'informatics' in the $20^{\text {th }}$ century, spurred by the stormy development of computers. An active social embedding of science is essential to its functioning as a major cultural activity, but it also makes for some of its most interesting topics of study.

But social value may also depend on more ethereal benefits. I would also like to point to some more esthetic or even emotional aspects of science at its best. Many people are led to it (I myself certainly was) by a desire 
to see eternal truths behind the fleeting things around us, to experience beauty in doing so, and sometimes to have experiences with an intellectual reality that tastes of infinity. In addition, there is a moral appeal to science, which seems one more value in itself. Once one sets the standards mentioned above, the world changes. It becomes hard to believe the 'revelations' handed to us by religions, as the light of reason prevails. Moreover, there is a strong feeling that this 'commonsense' is the same for everyone on this planet, so that science is by its nature opposed to any national or racial barrier. The remarkable historical fact is that modern science is a product of developments in many cultures: Greek, Arabic, Asian, and European. As such, it shows that its commonsense and rationality are not lifeless Western idols of the modern age, but vital historical ideals unifying people across cultures. Moreover, there is no facile multiculturalism here, undermining real achievement. Real science does not put together incompatible 'cultures' under one blanket of uncritical respect, but strives for achievements that shine by a common standard.

Any attempt at reorganizing or steering science in its current social setting should realize the complexity of scientific activity outlined so far, and moreover, it should make an effort to preserve the broader cultural values that it embodies and fosters. These have been created over time, and they have yielded huge side-benefits in addition to insight and profit, forming the best known counterweight for modern civilization against religious bigotry and injustice - and one should never take it for granted that these virtues will continue without support and defense.

\section{Problems, internal ANd external}

The sciences form such a vast field that no simple, more specific characterization can cover their content or the dominant habitus of their practitioners. In many ways, this complex is a vibrant enterprise, producing one spectacular result after another: the success story continues. But there are also a number of observable strains across the width of science, reminding us that we are dealing with a historical achievement whose automatic success cannot be taken for granted. Some of these problems are more internal, others are more external, but all are eventually best understood in the 
context of interactions between science and society. The following set of issues will be the major concerns in this essay.

First, there seems to be a law of diminishing returns at work. In some areas, ever greater amounts of technical sophistication are needed to produce results whose importance does not have the appeal of the past, despite the still passionate rhetoric of the modern high priests. Any concrete example is bound to be controversial. But I myself believe this verdict is true for parts of physics, as one moves down the grain size of the universe, or history, as one moves from studying $n$th rate authors to their $(n+1)$ strate commentators - or, for that matter, my own field of logic, as the embers of the great foundational age are dying. On the other hand, so far, new issues have always come up to fill these voids, and physics, history, and logic certainly have lots of scope for vigorous new themes. Nevertheless, this inevitable dynamic of topics and challenges inside science does create clear tensions. For it challenges the existing intellectual and financial power structure. Thinking in terms of the future of existing fields may not be an enlightening way of getting at the most exciting intellectual phenomena of today! Indeed, here is my first problem:

\section{a straight-jacket: traditional boundaries badly fit intellectual realities}

A second major problem would arise on any principle of organization, however. Increasingly, science fails to produce any coherent intellectual picture altogether:

$b$ complexity: loss of perspective by over-production of information

Both these problems threaten the broader intellectual role of science as a way of giving us an unified perspective on the world which can responsibly influence general culture. Some of these problems are the price of success, but this does not make them less urgent. In addition, there are external problems having to do with the interactions between science and society. One type of problem is still half-internal, involving the increasing grip of society on the workings of science. Organizational and financial policies are not neutral: they influence the intellectual climate in many, sometimes unintended ways. In particular, 
c current project finance generates harmful competition, and threatens the classical ideals of coherence and credit to others; while intellectual property' endangers the disinterest of science.

Thus, even though science encourages intellectual competition (a non-violent form of conflict, to the benefit of all), non-intellectual forms of competition are sneaking in through funding schemes. Governments further national interests, which can be opposed to the non-national goals of science, and 'entrepreneurial universities' repeat the same even more parochially. These problems threaten the cosmopolitan role of science, as a unifying and integrating factor through separate communities.

As a final societal problem, I would mention:

$d$ science is mainly perceived as an instrument, or a superior form of infotainment, to the detriment of its major formative cultural role.

Of course, our educational system is still fed by the universities. But one cannot really speak of a vigorous intellectual climate and public opinion informed by science - and the prestige of creative academic work conforming to scientific standards seems on the wane. I have no causal explanation to offer here. But it does seem relevant that many modern tendencies in society are opposed to the basic ideas of science! In modern politics, emotions of segments of the population rather than well-informed opinions seem to be the basic stuff that one ought to respect and soothe. Feelings of hurt or indignation are treated as irreducible facts. But this form of 'respect' means giving up on the basic ideas of the Enlightenment, where informed and educated opinion counts. An accompanying problem is the relativism in modern political views. If every religion and culture are correct in its own way - a presupposition of our state-sponsored ideology of multiculturalism - we are again giving up a key idea underlying science. For, in an amazing range of phenomena, one finds the opposite. There is an objective truth, or at least a well-argued original individual opinion, to be found provided one makes an effort and becomes informed. This objective truth can be grasped by all human beings, independent of blind appeals to the authority of political leaders, religious prophets, or holy books. When I asked the person mentioned in my Introduction how long the 
Kurdish nation had existed historically, he smiled and asked me. "Which answer do you want to hear? The politically correct one which I am supposed to give as a Kurd, or what I really think?” People who can make that distinction are enlightened! By contrast, it is our duty to scrutinize every claim made by an appeal to raw feelings or other forms of non-objectifiable authority in the harshest possible manner.

Now, this list of problems may seem very pessimistic, rather aptly illustrating a common observation about academics. They always complain about lack of funds, lack of recognition, the general stupidity of others but they do not spend anything like the same energy on their core business: justifying the major investments that contemporary society is already making in subsidizing their private hobbies. Perhaps this essay has the same self-centered plaintive ring. But I do see a difference! I am not complaining about of lack of funding or recognition - and I do not think individual scientists deserve better treatment than other citizens. And society is completely justified in asking for accounts rendered. But even so, I do think that attention to the above problems, emphasizing longer-term general intellectual and moral purposes, will help science perform the most valuable tasks it can for society.

The following sections address the above problems in more detail. Of course, these do not all have the same cause - but they do reflect the fast pace of change in modern society. Therefore, one general issue behind all of them is that of stability. Which structure and modus operandi will be most effective for science in a fast-changing social environment? Several such strategies are already at work around us. One is retreat into subcultures, keeping complexity down by shutting out the larger environment. This happens both in general society and in science. Another strategy is raising 'new people': windvanes without a core, as advocated recently by a Dutch politician, who said we needed evolution to a New Man capable of functioning in an environment offering no stability whatsoever. I myself find the first strategy disappointing, and the second positively obnoxious. Even so, I do not have a panacea to cure all - but I do try to point at some structures and procedures guaranteeing more stability and effectiveness in the current flux of things. 
For a start, let us consider the structure of science as it faces the modern world. Received ideas on the architecture of science have fluctuated historically. In science as in general society, quite recent traditions are sometimes defended with excessive zeal as the eternal natural order of things. The Middle Ages had their old division into Trivium (grammar, dialectic, and rhetoric) and Quadrivium (music, arithmetic, geometry and astronomy). The $19^{\text {th }}$ and $20^{\text {th }}$ centuries introduced such terms as humanities (Geisteswissenschaften) versus sciences (Naturwissenschaften). As for today's landscape, most contemporary Dutch academics have been raised with the threefold division into alpha (humanities), beta (mathematics and natural sciences) and gamma (social sciences) - accepting these as intellectual natural kinds or even genetic subspecies of humanity (people talk about being born as a typical beta). Such divisions form the basis of high-school curricula, and thereby help shape the idea of science and intellectual life, and provide role models for aspiring intellectuals. But this is not a neutral decision of intellectual geography! Subgroups inside these boundaries solidify and develop a sense of superiority versus others - the proverbial arrogance of physicists being a prime and live example. Thus, people with talents that do not fit received boundaries (like this author) become 'eclecticists', 'opportunists', or at best 'inter-disciplinary types'.

In reality, the criteria underlying the modern intellectual topography of the universities are diverse, reflecting many historical accidents. For instance, divisions by topic (nature, economics, history) are run together with independent criteria of method (mathematical or essayistic), which may not be easy to compare in their impact with the former. This point is obvious once you reflect on the current tableau of university disciplines and faculties - and moreover, it will be amply demonstrated by the concrete example of information and cognition in Section 5. Let me just state two claims which we shall return to in more detail below:

a The intellectual realities of science are multi-dimensional, and hence, as a matter of principle, there is no natural fixed architecture for it. 
This means that, just as with cartographic maps of the world, any onedimensional projection into a flat landscape of disjoint faculties is bound to distort the total intellectual landscape. We can only aim for optimal projections, as in cartography, plus additional mechanisms compensating for the remaining distortions, on which more below. In other words, even 'helpful' spatial metaphors of organization should be handled with the greatest care as their tacit presuppositions may be wrong or at least misleading. Moreover, these dimensions are not fixed once and for all. Historically, they are in obvious flux, and hence

$b$ One must recalibrate the organization of science with a certain frequency.

But I advocate this recalibration only for the sake of greater long-term stability. It is not a sign of progress in itself - consider the current reorganizational mania.

\section{A SHOW-CASE FOR REORGANIZATION: INFORMATION AND COGNITION}

Recalibration of basic academic divisions seems appropriate at civilized intervals to give us time to ponder the more permanent trends of the past - say, once a century. Indeed, the $20^{\text {th }}$ century has a striking new intellectual trend that runs right across the existing sciences, viz. the emergence of information and cognition as central themes of enquiry. This trend manifests itself in two ways, internal and external, as so often with important intellectual changes. Here is its internal prong.

Many sciences are seeing the emergence of fundamental themes having to do with how humans, machines, and organizations generate and transform information. This development is happening simultaneously in many disciplines, right across alpha-beta-gamma boundaries. Information flows thanks to the empirical fact that situations are correlated with others and hence can carry information about them, given the physical structure of this world. Cognitive agents take advantage of this, as far as their perceptors reach, and transform these physical structures upward 
into consciously manipulable symbols, or graphics. At the latter end lies the goal-directed use of information that is typical for human behaviour. Thus, information use runs a trajectory from physics to logic. But equally typically, humans organize and modify logical information in larger social structures, adding another level of complexity but at the same time also efficiency. Natural language, the typical human medium for conveying information which developed in our evolution, is at the same time a physical, logical and social phenomenon. Thus, it will be clear that the informationcognition perspective cuts right across established disciplines, drawing them together in new ways along issues concerning the representation, modification and communication of information. The result is a steady growth of insights and techniques, including physical information theory, logical theories of information content and reasoning, computational accounts of intelligent tasks, and linguistic ones of informational structures in human communication.

Even the simplest episode of language use, that of one person asking a question and another person giving an answer, demonstrates all these features at the same time. Just think: what happens when people communicate? Truly understanding even such a simple phenomenon - and we all could do this without any problems - involves a group of fundamental issues:

- What is meaningful information as used by human agents?

- How is it encoded: in language, context, but also visual cues?

- How is this information transmitted during communication?

- What are the complexities of the various processes involved in producing a message, analyzing and transforming it?

- How to model the broader purposes of communication, involving goals, decisions, and longer-term strategies?

Specific disciplines that have something of importance to say about these particular issues include computer science (models of computation, complexity), linguistics (meaningful information, communication), logic and artificial intelligence (reasoning systems), mathematics (information theory for signals), psychology (perception, memory, learning), economics (game theory), sociology (information management in organizations). This range reflects the fact that communication is partly in the heads of participants, but partly also an irreducibly social phenomenon. 
And communication is just one example: one can just as well think of reasoning, learning, or other pervasive topics of this kind. This is no convergence just on paper. Many new conferences and scientific organizations bring together researchers from all these different disciplines, working on shared interests. Significantly also, when TIME magazine published its list of the 20 most prominent intellectuals of the last century, three of those fit perfectly into this trend:

- the mathematician Kurt Gödel,

- the computer science pioneer Alan Turing,

- the philosopher Ludwig Wittgenstein.

This internal scientific trend has its external counterpart in the rapid rise of information technology and knowledge-based production processes. I am not going to elaborate on this aspect, as these phenomena are all around us, starting with the personal computer on which I am typing this very sentence. Suffice it to say that every scientific issue mentioned in this section is made more pregnant and vivid by seeing how it emerges in the setting of electronic communication in all its varieties.

This double aspect is an important engine of progress today, just as it has been for the natural sciences in the past. More narrowly technological and broader scientific issues work together in generating many new fundamental issues for a natural conglomerate of sciences of information and cognition - witness the earlier-mentioned examples of thermodynamics and computer science. Here is a sample of current challenges that come about in this way. These demonstrate a variety of concerns, running from empirical to more mathematical ones. Hopefully, it will be clear that these questions are not just important qua utility, and hence a duty - they are also hugely exciting, and hence a pleasure!

I The enigma which nobody understands. Why is cognition so efficient? (e.g., what has gone on during your grasping of the previous lines of text?)

2 What is the right way of combining external observation and internal reasoning, for instance, when agents engage in planning and acting?

3 What is the comparative content of different information carriers, e.g. symbolic and graphic, and how can they be integrated? 
4 What is efficient social organization for intelligent persons and machines?

5 Which conservation laws of complexity govern information processing?

6 How can we integrate existing major information paradigms, from computational ones (Shannon's channel theory, Kolmogorov complexity) based on the transmission of coded physical signals, to semantic notions of information that are the main concern of logic and linguistics?

7 What are the mechanisms driving major cognitive activities like learning?

8 Emergent phenomena: what new levels of information structure arise with 'bulk activities' like the Internet, comparable to the intrinsic laws for, say, the statistical behaviour of gases over that of individual molecules?

This list is by no means exhaustive. But it does demonstrate a coherent agenda of scientific questions, which admit of substantial answers. Existing fields have already amassed a wealth of relevant notions and techniques. The present period is one of intense intellectual ferment. Last year alone, some to major conferences worldwide brought together computer scientists, logicians, mathematicians, philosophers, social scientists, and economists interested in creating fundamental theories of rational behaviour, cognitive procedures (plans, games), social choice, or various types of learning. In addition to purely academic impact, improved understanding of these phenomena will have clear societal repercussions in education, arts, and commerce.

My conclusions are simply these:

A new category of Information and Cognition science is in the making, driven by both internal and external forces and cutting right across the traditional structure of humanities and sciences.

Moreover, this new intellectual category is of an order of magnitude warranting a revision of the current Entrenched System of disciplines. 
This example of a new category is not unique. In particular, one can extend the more computational and linguistic perspective of this section with the more experimental biological and medical insights of modern neurocognition, emphasizing the actual workings of the human brain. For instance, the above example of communication extends naturally into experimental aspects of brain function. Humans are wonderfully hard-wired for communication, ranging from specialized visual recognition of faces of species members to 'resonance' of motor neurons with a vocabulary of gestures made by others. This broader connection has been sketched admirably in the recent NWO Report "Fruits of Enlightenment", which maps out 'Information and Cognition' in sufficient depth (http://www.nwo.nl/ cognitie) and hence there is no need to repeat that here. Current developments in the life sciences (biology, psychology) are of the same order of magnitude, providing even more support for my second conclusion.

A final comment. The example of Information and Cognition has been highlighted here mainly because it happens to be my own area of activity as a logician. However, because of its relative freshness and links with general developments outside of science, it also naturally ties in with some other recommendations that I would like to make, concerning interactions between science, general culture, and society.

\section{OptimAL ORgANIZATION}

What follows from the above considerations? There is little that is original in my proposal for officially recognizing a new intellectual category. Indeed, many universities in the United States and Europe have already taken the step of setting up faculties or schools of Informatics, that happy phrase covering so much more than computer science in the narrower sense, spanning the intellectual range I have advocated. The Netherlands has been lagging behind in this organizational drive, even though it is a recognized centre of innovation in many relevant disciplines. But it is worthwhile thinking about the more general repercussions of such a move. 


\subsection{Optimizing terminology and removing bias}

The general point of the earlier discussion is that intellectual reality is manydimensional. The idea that all of science can be put into natural disjoint zones is untenable, as groupings will depend on one's criteria. But then, any bias-free discussion must recognize the relative nature of popular terms like 'mono-', 'inter-' or 'trans-disciplinary'. From the viewpoint of the traditional categories alpha, beta, and gamma, for instance, information and cognition are interdisciplinary. But people can be natural wholes intellectually and yet not fit into this, having rather a uniform characteristic that we might call iota. From an iota-perspective, the world changes: marginal groups in the modern university suddenly form a coherent environment, departments from different faculties belong together (e.g. linguistics, computer science, psychology), and the same holds for the many students that come in from high school with just the above combination of interests. This commonality is often overlooked with the blinkers of the Ancien Regime in the universities or our national agency NWO - thereby losing both research opportunities and academic talent. Indeed, having an iota-perspective leads to suspicion in some quarters. I have had to defend myself in mathematics circles for also having a degree in philosophy - or just for being able to write fluent prose. For the record: I like mathematicians! Still, this does show how strong the shibboleths of existing professional groups can be, fortified by many centuries of developing favourite idiosyncracies.

Here is a simpler illustration of how historical accidents determine our language and thinking. There is a little local railroad running from Maastricht to Aachen. It is called an international connection in our train schedule, not for any intrinsic feature but because of some point of history doing little justice to the geography and culture of that region. I emphasize this point because existing powers in academia ignore it. It is in their interest to call all newcomers interdisciplines and then insist on the importance of things like a 'thorough monodisciplinary training', meaning, the unquestioned primacy of their position. Constant alertness as regards these insidious manners of speaking, organizing, and fund-allotment is an imperative. 
At this point, I hasten to say that many universities, our national Research Funding Agency NWO, and even our Academy of Arts and Sciences, the KNAW, are beginning to open up to such broader viewpoints. But the intellectual battle is by no means won.

Even so, new divisions as advocated here are not directed against other disciplines, even though shifts in pecking order and funding must occur. For instance, I myself am convinced that models and methods from $p h y s-$ ics will play a hugely beneficial role in the iota-sciences. But it is much better to have this without importing the current power structure of the physical sciences, with 'reformed' physicists being leaders in informatics. We do not need academic Perestrojka with the nomenklatoera of the Ancien Regime still in place, but rather a genuine revolution with new faces.

Indeed, it may be useful to analyze why established scientific milieus have proved so resilient, even as their intellectual impetus is running out. One reason may be that many students prefer living in groups with fixed norms, defining achievements by unchanging standards and looking down on other academic groups by bonding prejudices, repeated ad infinitum during coffee breaks. Opening up sometimes leads to uncertainty and aggression, just as in the world at large. In this sense, there may still be 'interdisciplinary' minds in a more absolute sense: people who can function without agoraphobia in a more open system - though we all need bounds.

\subsection{Matrix organization}

A many-dimensional structure is typical for many things in life, and one has to choose some mode of organization to do justice to it. In particular, any principle of division generates 'interdisciplinary themes', even if one admits Information and Cognition into the council of the Big Four. The university should have a permanent way of dealing with this. At least two dimensions need to be institutionalized:

There must be a matrix-structure, with mechanisms across faculties taking care of the inevitable boundary phenomena. 
A division into faculties is just one flat projection onto a simplistic onedimensional map of zones. We need another axis of variation to see more of the natural groupings, just as in graphing any complex reality. I do not have further specific proposals to make here, but the matrix structure in the current research and teaching institutes at my own University of Amsterdam offers a promising format. Departments and faculties provide one, long-term dimension of organization. Institutes, reviewed in 5-year cycles, form a second dimension which may cut right across the first - at least in principle - as natural thematic clusters emerge. One example is my own habitat of the 'Institute for Logic, Language, and Computation', which has united research groups from philosophy, linguistics, mathematics, and computer science for a decade now. Of course, one must make sure this two-dimensional freedom is appreciated and maintained - even when it comes at a cost in terms of financial complexity and less well-demarcated bureaucratic turf. (As for the originality of this essay at this point - saying something positive about one's own university should count as a revolutionary innovation in The Netherlands.) Another model that intrigued me was one from Delft University (A.J. Berkhout, 'Universitair Besturingsmodel', December 2000) which takes an architectural engineering approach from systems theory. If nothing else, such approaches are very useful for shaking up entrenched traditions. Finally, the same explicit matrix organization applied to teaching gives us a better way of searching for available clusters of talent in the student population and of interfacing with society.

Once the revision based on the experience of the $20^{\text {th }}$ century has been put in place, however, I have another recommendation to make:

keep whatever system is chosen stable for a long time!

7 QUANTITY OF INFORMATION + PROJECT FINANCE = FRAGMENTATION

\subsection{Information overload and fragmentation}

As we are recalibrating universities, we encounter further problems which affect whatever intellectual geography we choose. A well-known danger is specialization, breaking the unity of science and threatening its impact on 
general culture. This waste of effort and talent is ever-present. The standard response that even the most abstruse pieces of science have always found spectacular applications later in history is a wild generalization from a very small number of success stories! But today's new problems aggravate these long-recognized ones. One insidious new case is a counterpart to the 'information infarct' which already afflicts our general society. There is so much information around that people often absorb none.

The overproduction of information in science threatens the old ideals.

Nowadays, it is impossible for professors to really have an intellectual grip on their field of expertise worldwide and to do justice to what others have achieved. More pregnantly, dissertations used to have the aim of adding something original to the field while doing full justice to existing relevant achievements by others. While still paying lip-service to this ideal of broad scholarship and global fairness, which is slipping between our fingers, the reality that scientists live in is already completely different. Dissertations often contain the minimum number of references needed to avoid criticism from competitors in one's narrower research environment - and researchers often hide in specialized, manageable research communities, without a view on the whole. Thus, the idea of assigning proper credit on a worldwide scale and fairness with respect to others' achievements is under heavy pressure. Here is a side-effect. Universities still maintain the fiction of getting balanced international judgments 'representative of the field' when making senior appointments of professors as high priests of the profession. But despite effusive letters of praise piling up in huge files, who checks that the referees themselves are representative of the field?

I am not claiming any originality for the above observation. A current strategic report from NWO even listed the overproduction problem as the key scientific challenge to be met. Perhaps NWO feels this most acutely as no one in its offices can even try to understand what one year of their financing has actually produced. But worse, organizations like this may themselves be part of the problem:

scientific fragmentation is aggravated by current systems of finance. 
Project finance puts a bonus on making oneself different from others, thereby making research aimed at seeing connections and equivalences less relevant. Indeed, giving integrative lectures explaining how different research programs really do very similar things (as I often do) often meets with a downright hostile reception. Comparability and equivalence threaten people's status and income! Of course, project finance also has some advantages, like being able to shut down unprofitable research lines before they become too entrenched. But the drawbacks of the system merit much more extensive discussion than they normally get.

Thus, we have identified another major problem of current scientific organization. This time, it is not the straight-jacket of old clothes that no longer fit, but rather the patchwork: the fragmentation of science. This phenomenon runs parallel to another fragmentation process. Modern societies are splitting up into minority subcultures of various kinds, and one finds a lot of similar issues as to what should be the role of the universities and scientific organizations in maintaining a 'civil society'.

\subsection{Possible remedies}

Now it might be thought that my beloved information and cognition sciences have some kind of scientific answer to these problems. Aren't we talking about a clear problem of information complexity, solvable by new sophisticated techniques? 'Let science cure science'? But in fact, this problem is a wide open challenge, rather than an area of evident progress. Personally, I even suspect we will eventually hit mathematical incompleteness theorems as to what grasp of complex information can be achieved, comparable to those of Gödel in the foundations of mathematics.

So, what should we do here? If scientific solutions are not readily available, all that remains for now is the exercise of some commonsense. There is obviously some awareness of these matters in the responsible organizations, both universities and scientific associations. For instance, in my own field, there has been a flux of Handbooks, revised every decade, which serve as a kind of longer-term record of what lasting things have been achieved worldwide. But the selection of Handbook editors and authors is currently still somewhat haphazard, so the record is not yet as authoritative as it could be. One could imagine it becoming a prestigious super-star job, regulated by the relevant 
communities through procedures. Likewise, many scientific communities have initiated integrative conferences, such as the TARK meetings on rationality and knowledge, bringing together people from computer science, economics, logic, linguistics, and philosophy. Another example, again in my world, is the ESSLLI Summer Schools on Logic, Language and Information. Initiatives like that should be rewarded. But in practice, one sees the opposite: national and European funding organizations do not fund such integrative events, because they do not fit into their project categories. Finally, in an approach to this problem, several universities have started appointing superprofessors for the sake of greater integration, but one can have doubts as to its efficacy so far, both in the US and in Europe. 'It is lonely at the top', and some super-professors seem to have disappeared with startling suddenness into a communicative vacuum.

My recommendation would be that universities, funding agencies, and grassroots scientific organizations set aside special funds and some of their organizational thinking to integrative initiatives.

Universities should have a core curriculum underlining the unity of science to students, even if this goes against these adolescents' baser grab-the-diploma-and-run instincts. They should also find ways of making sure that professors meet regularly across faculties. One might make it compulsory for full professors to spend two kinds of sabbatical: one in the warm nest of specialization, among one's colleagues abroad, and one in another faculty, with an obligation to communicate and interact with members of another discipline. But our national funding agencies and academy of arts and sciences are in a much better position to make integrative efforts an explicit part of their task, including special calls for integrative projects across fields - and the rewarding of role models. For instance, they would be much better-placed for appointing truly integrative chairs. Their national basis gives them a better platform for seeing and affecting the whole of science. Likewise, they are better placed to set up meeting places like institutes for advanced study and the like. This might also be a useful complementary task for them which is sui generis, as opposed to their more hydraulic task of channeling the taxpayers' money to universities with a minimum of fuss. 
These recommendations require both organizational efforts and a change in habitus among scientists themselves. Looking for larger pictures should become a recognized achievement of great value to us all, not just a sign of advancing years.

\section{INTERFACING SCIENCE AND SOCIETY}

So far, our analysis has been mainly concerned with internal problems of modern science. But scientific developments do not occur in isolation. As pointed out for information and cognition, it is of course no coincidence that scientific flourishing goes hand in hand with technological and social advances. The same holds for problems. Organizational phenomena inside science, such as the above-mentioned fragmentation, are often a reflection of more general social problems. (As the 'Dutch Republic' disintegrates into subcultures, so does what is sometimes called 'the Republic of Letters'.) But the current situation of academic research in society seems rather isolated: with complaints from university leaders taking the place of communication and interaction. The only solution here is a broader vision of what universities should do and an activist perspective on interfaces.

Instead of painting further problems, let me just briefly look at the most important interfaces of the universities with society and propose a forward-looking stance.

Industry Contacts between science and society take many different forms. Let us look at research first. Obviously, there is a good deal of research going on inside industry, whose borderlines with university research are often fluid. In principle, this is a natural alliance which should be fostered. Some government-sponsored research belongs to the same environment. (Incidentally, the emergence of larger businesses and industrial production is itself a very interesting feature of European history, and one which raises lots of fundamental questions of its own concerning social engineering and collective rationality.) But this interface could be much more stimulating and productive, if we see it as an intellectual matter in addition to profit motives. A huge part of the national talent sits inside industry. (It must be, as it certainly does not flow overwhelmingly 
into university jobs.) But then, we will all be better off, both in universities and inside industry, if we create interfaces where these two milieus can meet without immediate business pressures - the way things have happened, or still happen, in research labs like those of Philips or in modern Silicon Valley. Moreover, academic leaders should meet with innovative business leaders, again without time pressures, to talk about developments in their respective worlds, in such a way that real developments take place. These things work better on a personal basis - and indeed, the US, with its more personal approach to things, sees more of these direct contacts than we do in Europe.

Education The other way in which science impacts on society is through our system of general education. We take this for granted, but it is of course a huge cultural achievement that scientific insights make it into a general curriculum for large parts of the population. But here too, universities could do much more in interacting with schools, teachers, and the innovation of curricula. 'Pre-processing' high-school kids may be much more important than teaching students once they have arrived, and this might mean a major shift in the allocation of funds and uses of available didactical resources, even inside the university. These ideas are not new in university circles, but they might be pushed much more effectively, including public recognition of these achievements. In addition to Nobel Prizes, we might give 'Euclid Awards' for outstanding general didactical achievements, remembering that famous Alexandrian schoolmaster of elementary geometry called Euclid, whose works have defined history.

The Press It may be an old-fashioned idea that the press has an educational purpose. It certainly has an undisputed informative purpose, and in that sense, the press should be a natural ally of the universities in spreading intellectual achievements. It is a common complaint in academic circles that the results - say in science supplements of our major newspapers - are haphazard and not a true reflection of what is going on intellectually. I agree that these show lots of biases and do not convey a true picture of scientific activity, making it more inaccessible than need be. But, if so, then meet with journalists, editors, and make sure that the right venues are created! As a result, the press might start reporting on a more regular 
basis about ongoing discussions within the sciences, rather than the staccato of new discoveries. Even more to the point in the setting of what the Hollandse Maatschappij is trying to achieve. Should not the present discussion itself be a typical matter of a debate in which an educated public might participate just as well?

Politics At least Dutch academia has largely written off politics as a partner in intellectual endeavours. Here is the prejudice in a nutshell. 'The Hague' consists of quick-scoring politicians concerned only with appeasing the fleeting emotions of the electorate and how they themselves appear in tomorrow's press commentaries. The result involves spending huge amounts on non-productive higher salaries for pre-school teachers or smothering 'deprived groups' in subsidies whose efficiency is hardly checked - while refusing the most modest sums, by comparison, when it comes to fundamental research and the production of new knowledge. And indeed, in my own modest experience, getting on the same wavelength with politicians is one order of magnitude more difficult than the average communicative challenge. The other way around, one also does not get the impression that the average politician has an accurate picture of science and academics. Nevertheless, this communication gap seems a matter of time, rather than essence.

In fact, I see all the above interfaces as potentially extremely fruitful, and well worth an outreach effort on the part of science. But this takes two major resources:

space, and time!

We need small-scale meeting places, where scientists from universities can mix with people from industry, education, arts, and politics. Small networks of this kind exist, but some of them have ossified. A new élan might come in the form of special centres where people from different walks of life can spend short sabbaticals, interact in the exchange of information, and engage in strategic discussions. Or, we might make it a task of existing academic institutes, setting aside part of their budget for these broader functions. Well, this space problem can be solved easily. 
But we also need a different notion of time. At a recent initiative, the 'Avond van Wetenschap en Maatschappij' - laudable in itself - the difference was illustrated in a striking manner. At one evening in the Ridderzaal of the Dutch parliament, representatives from science, politics, and general culture were supposed to discuss a huge number of major issues and vote on them after some half hour of discussion while disturbed by vaguely irrelevant infotainment from some art academy. No attempt was made to analyze the purpose of the contact or discuss any single issue in detail. This Moulin Rouge approach may be good as a first encounter, but in a sense this is a caricature of what should happen. Serious issues take time, for taking in information, sustained conversation, and subsequent reflection. An expert astride both worlds once told me that academic time is just not available in politics. And the same can often be heard about industry: the agenda of real business leaders does not allow for extended periods of discussion, perhaps even retirement. Now this is what should be questioned. I think it is just a latter-day mistake to think that the best leaders are those whose agendas are full the longest with the greatest variety of problems, and who are always there to address current burning issues. Taking off a day, or a week, or a month to reflect on things may be a much better long-term investment for one's firm or the nation. The ideal of a Dutch minister, for instance, as a quickly burned-up, world-traveling workaholic is a recent one, and it may be just the wrong response to managing an ever-faster modern society. The Kings of Thailand used to retreat into a monastery occasionally to meditate. Why shouldn't our industrial and political leaders retire occasionally to some intellectual environment where they can see things in a broader perspective?

In other words, universities and scientific organizations would be welladvised to devote some of their creative energy to building interfaces with society along all of the dimensions listed above - and the same is true for individual scientists. Intellectual culture is one, and we all share the same interests in maintaining it. In particular, there should be no sharp class distinction between people fighting their battles on the frontier of research or among public discussions in newspapers or perhaps the most crucial cultural battle zone of all: in the classrooms of our schools. 


\section{Summary}

The recommendations made in this essay amount to the following. Science needs to rethink its structure and modus operandi vis-á-vis a fastchanging technological, cultural and political environment. This calls for several actions, beginning with the

Internal structure of science, both in universities and national organizations:

a Recalibrate the current division into faculties, making the major emergent development of the $20^{\text {th }}$ century into a new core category: information Q cognition.

b Create a second dimension of integrating mechanisms across the first level, addressing specifically the major problems of information overload and fragmentation.

Next, equally important are matters of external interfaces of science:

c Create meeting places and times that lead to a lively intellectual interface between universities, industry and politics, where new scientific ideas are not just disseminated in one direction, but also stimulated by flows of informed opinion both ways.

Small networks of people are crucial for these broader purposes, linking up between Academia and other walks of life. The latter recommendation also asks for role models. French prime ministers used to write books while in office, without anyone worrying that this was valuable time taken away from public affairs. Vice-president Al Gore did the same when in active politics - and his book actually contains a lot of interesting reflections on obstacles for interfacing science and politics for those who care about the environment. The Dutch may be more down-to-earth, but should we - and are we? Our greatest political leader was no doubt Johan de Witt, at the helm of the Dutch republic in the mid- I $^{\text {th }}$ century. He did find time to publish innovative scientific works, as well as a wonderful little book "Waerdije" explaining the basics of finance and risk to the educated Dutch public. The latter is considered the start of scientific insurance mathematics: you can see his portrait in academic galleries across Europe. 'Nederland Kennisland' (an almost untranslatable political slogan: 'Neth- 
erlands, knowledge country') will flourish most if we rethink our received, but quite recent views of all actors concerned both inside and outside of Academia.

My original piece started later and ended here. But at the present time, I felt the urge to add a preface and a postface. Sections 2 through 9 were written in optimistic mode - with lots of problems that may be hard but that do not 'cut to the bone'. And one can recognize an energetic optimizing mode to the proposals made in the preceding section. The problems are interesting, people are basically well-meaning, and if we all spend time and energy, things will improve.

But September $\mathrm{II}^{\text {th }}$ reminds me that it would be naïve to take all this for granted. This becomes particularly acute with the following consideration, going back to what was said in the Introduction. I truly feel that there is a deeper level of importance to science as a defining force in our culture. The greatest impact of the Scientific Revolution in the $I 7^{\text {th }}$ century, in my opinion, is not the intellectual advance of knowledge or the spectacular breakthroughs in technology. It was rather the subsequent idea of Enlightenment, the breaking of the power of vested religion and traditions that kept people chained to authority and superstition. The most important advances are those enshrined in the ensuing social life with separation of church and state, civil liberties, and many other features of modern Western society. These things were fought hard for, but eventually we reached what Immanuel Kant called:

\section{the liberation of humanity from their self-imposed tutelage}

from religious books, political leaders, or whatever other unquestioned authorities offered themselves up for dominance. We are allowed freedom of thought, freedom of joining organizations, and freedom of abandoning those opinions and leaving those organizations safely, without being branded heretics or apostates... All these freedoms are constitutive of scientific activity. Inside science, we can state dissenting opinions about any- 
thing and against any authority, including the consistency and tenability of views of authorities or religious dogmas. And these values have spilt over into general society - of course, in conjunction with other beneficial social developments pointing in the same direction. In conjunction with general free-thinking tendencies in Europe, science has made us free! Moreover, this freedom is not just an extra, detachable side-benefit of the enterprise. It can be argued that the relative lack of success of innovative science in parts of the world like the Middle East is precisely because many people try to adopt the technological advantages without the whole package of mentality and history behind it - grafting it onto a political-religious system that does not incorporate these basic values.

Now, many of these accompanying ideals are under pressure today. Science is either seen as an evil force enslaving nature and producing military abominations, or as a mere gadget producing various technological conveniences. More problematically, modern science has its enemies - precisely because of this intellectual liberation. As indicated earlier, I myself see many current tendencies in our society like, in Kant's terms, a 'selfimposed' return to prescientific attitudes. Emotions of small groups in the population are taken as primary realities rather than as issues to be settled by information about historical facts or even statistical data. Dogmas of militant religions diametrically opposed to the basic values of Enlightenment are put under a blanket of 'multicultural happiness', without careful scrutiny and debate. Uninformed irrational myths that are emerging all over the world are not exposed because scientists fear for their travel funds, the loss of local contacts who want abject ritual apologies from Westerners rather than critical views - or the emotional reception by the received opinion in The Netherlands.

All these attitudes undermine our real chances for improving the world. If they had been prevalent in the $I 6^{\text {th }}$ and $I 7^{\text {th }}$ century, we would have had no revolution toward the modern world. All achievements in our history that make us civilized in a modern sense were made because there were people willing to confront religious dogmas and not wrap everything in vague views of everybody's being right in one way or another. This courage seems sadly lacking today, when I look at colleagues exercising all kinds of self-censorship when their financial status or career options are threatened by speaking up. The rhetoric of intellectual independence at universi- 
ties often hides the most timid behaviour in practice. To me then, there is also an activist side to thinking about the future of modern science. How do we highlight the broader values that it brought along, inculcate them in our students, and militantly uphold them against the enemies of Enlightenment?

\section{Note}

I A crucial point of terminology. In the Dutch language, the term 'wetenschappen' covers both the sciences and the humanities, and the term 'science' is used in this broad sense in this essay. Do not just think of physicists tending to large machines, or sociologists waving questionnaires, but also of that philosopher pondering the notion of rational discourse, or that lonely scholar of early Coptic manuscripts! 


\section{Does a New Kind of Science Require a New Kind of Scholar or a New Kind of University? I}

Keith Devlin

Professor van Benthem suggests that the scientific study of cognition and information flow lies outside any of the existing sciences, or indeed any of the generally recognized academic disciplines. This has certainly been my experience after my own research interests moved into that area (from mainstream mathematical logic) in the mid-I980s. Since making that shift, I have not held a regular faculty position at any college or university. My interests simply did not fully accord with my discipline of training, namely mathematics.

For the period I987-89, I had a research appointment at CSLI, the interdisciplinary research center at Stanford that I now direct. I then took a position as a mathematics department chair at a leading US liberal arts college - a wonderful type of interdisciplinary educational institution not found in Europe. Next, I tried my hand as a dean. And now I find myself back at CSLI, this time as its Executive Director. Throughout this I4-year period, I have regularly taught some mathematics courses and written various books on mathematical topics, but my main scholastic interests have been elsewhere, occupying a hitherto unnamed and almost unacknowledged nether-region having connections to mathematics, logic, computer science, linguistics, philosophy, psychology, sociology, communications, cognitive science, management science, and engineering, and which in the near future will, I believe, involve biology as well. In other words, I have been living for some time now in the scientific world Professor van Benthem describes.

The fact that I have been able to do this for so long indicates that the existing university framework does at least allow some individuals to pursue the kind of scholastic agenda he outlines - at least, for a limited 
number of such scholars. Of course, the approach I have followed only works for senior academics, already well established in their original disciplines, who can barter experience and administrative skills in exchange for the freedom to pursue such a risky research agenda. On the other hand, the area we are focussing on is not sufficiently well developed to offer a career path for younger scholars; there simply is not yet enough scholarly depth, nor the scholarly metrics and associated publication outlets, for a young scientist to establish her- or himself as an "information and cognition scientist."

An appropriate academic discipline - a new science - may of course emerge in the future. But my personal view is that it will not. Rather, I think the domain we are looking at is more akin to industry or engineering than science, requiring a combination of different approaches, loosely tied together by modes of operation and codes of practices, rather than the development of a distinctive conceptual framework or a clear research paradigm that defines a discipline.

The similarity with industry and engineering is also apparent when it comes to funding. The traditional research funding organizations rarely, if ever, support the kind of research Professor van Benthem and I are talking about. For even when they establish "interdisciplinary programs", research proposals are evaluated by the criteria of the participating disciplines, a benchmark which truly barrier-breaking research can never attain.

On the other hand, the kinds of problems that lie at the center of the current research into cognition and information flow lie at the very heart of the information and communications technology (ICT) industry. There the aim is not to develop new scientific understanding, but to design and build better IC technologies. And that goal provides adequate scope for funding the kind of research we are talking about.

In this new industrial-academic environment, one obvious measure of progress or success is meeting the companies' goals of product innovation and design. But can this lead to good science? The answer is yes. The nature of the ICT industry is that it requires research that is every bit as challenging and academically respectable as research in, say, chemistry or physics or psychology. Work that fully deserves to be called "science" in the sense outlined by Professor van Benthem. 
Of course, funding is just part of doing science. Scientists also have to publish their results for others to evaluate and perhaps extend. Hitherto, most scholars who have ventured into this interdisciplinary brave new world seem to have taken the route that writer John Brockman has named The Third Culture. ${ }^{2}$ In the absence of an existing evaluative structure to provide certification of merit, Third Culture practitioners step outside the current academic framework of scholarly books, papers, and peer reviewing, and use the open marketplace (and its arguably more demanding metrics) to disseminate their work in the form of academic trade books books written for general sale and marketed competitively for profit by commercial publishers.

Although ostensibly written for a "lay audience" and sometimes referred to as "popular science", such books are in fact largely read, and evaluated, by other scientists. With authors such as Stephen Hawking, Daniel Dennett, Richard Dawkings, Paul Davies, Gerald Edelman, Stephen Pinker, Stanislas Dehaene, Terence Deacon, Roger Penrose, Francis Crick, William Calvin, and Joseph LaDoux, the Third Culture is clearly a major intellectual force. True, most practitioners continue to carry out research and publish within the disciplines they were trained in, but these days it is increasingly their more speculative, interdisciplinary, Third Culture writing that marks the frontiers of scientific knowledge.

In the absence of the standard filter of peer review, Third Culture practitioners use the persuasive techniques of excellent writing to make their scientific case - not to experts in their own particular branch of science but to the entire scientific (and related industrial) community. (Hence the name Third Culture, lying somewhere halfway between the sciences and the arts of C.P. Snow's famous Two Cultures divide.) As a result of the Third Culture, today's scientific action can often be found not in university libraries but on the shelves of Barnes and Noble or online at Amazon.com.

But what of the future? There are limited opportunities for the kind of maverick career path I myself have followed during the past I4 years, and only a handful of practitioners are able to disseminate their work successfully through Third Culture publishing. How will advanced societies such as Europe and the United States ensure the growth and health of future research in cognition and information flow if, as I have suggested, there is 
no single emergent academic discipline that adequately addresses this domain?

At Stanford, we are about to launch a new research initiative, and a highly novel administrative infrastructure to support it, that we think will meet this new need. Its name is Media-X. Media-X is not a single discipline. It is not even a cluster of disciplines. It is the study of the design and use of interactive technologies - interactive media - using whatever methods and paradigms seem appropriate. (The " $\mathrm{X}$ " in the title is meant to be read as a variable that can refer to any of those conceptual tools.)

Formally, Media-X has the status of an "independent research center" that reports to the Stanford Dean of Research (and is not, therefore, part of one of the normal schools such as Humanities and Sciences, Engineering, etc.). Media-X has no permanent faculty. Any Stanford faculty member or researcher can be a member of Media-X. Some will be effectively permanent members; others will be involved for the length of a particular project, or for as long as they desire.

Media-X is not, and is not intended to become, a university department. Rather, it is a highly flexible, virtual enterprise, a dynamic network the stretches across the entire campus. It also provides essential links to outside ICT industries, which are being invited to partner with us in this new enterprise, paying an annual membership fee in exchange for faculty consulting, research collaboration, access to classrooms and students, and rights to intellectual property developed by the program.

Media- $X$ will receive no funding from the university. Rather, the entire program will be supported through the industrial membership fees (which will go to support Media-X research) and one-time endowment gifts to cover the infrastructure support (which, because of the nature of Media-X, will be low - less than $\$ 0.5 \mathrm{~m}$ a year).

The Media-X structure cuts orthogonally across the existing university structure at Stanford - departments, schools, and research centers. As I have observed, the main link that binds the enterprise together is a collection of technologies. The Media- $\mathrm{X}$ vision brings together central information themes - language technologies (e.g. natural language processing, semantics, dialogue systems), human-computer interaction (e.g. information organization, conversational agents, collaborative work environments), engineering (e.g. product design, information sensing, robotics), 
cognitive science (e.g. artificial intelligence, logic, neuroscience, rationality and philosophical foundations) - and it adds the artistic execution of mediated interactions (e.g. computer music, narrative, and the digital art of lighting, character development, and gestures). A for-profit, in-house publishing organization will provide a venue for the dissemination of results that do not fit into existing outlets.

By providing a portal to the Stanford campus, Media-X puts faculty into contact with companies, research labs, and other groups working on the development and use of interactive technology, providing research funding, research projects, and educational projects for use in the classroom. Of course, the decision of whether to become involved in any particular project is up to each individual faculty member. Each year, Media-X will issue a campus-wide request for research proposals in the general area of Media-X. Different faculty members and researchers are likely to be involved from one year to the next.

In view of Professor van Benthem's justified concerns that science should not become the pliant tool of commercial activity, it should be stressed that Media-X is not a research and development contract agency for industry. Unlike the (Media-X affiliated) Stanford Research Institute $(\mathrm{SRI})^{3}$, for example, Media-X will not, as a general rule, engage in contract research. Rather, we will form partnerships with ICT firms, carrying out university-type research, albeit research that is in large part of relevance to, and in some cases comes from, those industry partners. Our goal as a university enterprise is to carry out research and publish the results openly in the scientific literature; product development is left to the industry partners themselves. The intention is that Media-X will be sufficiently large and generate enough funding from industrial member fees that much of the research carried out is of the traditional "curiosity driven" variety, originating with the investigators.

The meta-goal in creating Media-X is, then, to find a structure that will support cross-disciplinary scientific research into cognition and information flow - the general area Professor van Benthem has identified in his essay - using the technological goals of the design, manufacture, and use of interactive technologies to provide the glue that binds the intellectual effort together.

In summary, as Professor van Benthem has correctly observed, the 
massively cross-disciplinary nature of cognition and information flow almost certainly precludes real progress within the existing university framework. But that does not mean we need to dismantle that framework and erect a new one - nor does Professor van Benthem suggest such drastic action. However, both he and I agree that society must find a way to modify the current framework - essentially the framework of the $19^{\text {th }}$ century, although it served us well throughout the $20^{\text {th }}$ - to meet the new challenges of the $2 \mathrm{I}^{\text {st }}$ century, for which it clearly seems inadequate.

Those of us at Stanford involved in the development and launch of Media-X believe that such a program (or perhaps a modification thereof) will provide the appropriate academic structure to fill this need.

For the most part, the intellectual resource for Media-X is supplied by the existing disciplines, housed in standard university departments. A relatively small number of cross-disciplinarians - "Third Culture" scholars will provide the connections that facilitate the various cross-disciplinary collaborations. Ideally, these individuals would be university faculty, occupying the truly "integrative chairs" Professor van Benthem speaks about in his essay. In the current Media-X framework, they are a program overhead and constitute the only significant new cost of Media-X.

If successful, we believe that Media-X will form a model for one aspect of the university of tomorrow, as we enter an era where the main scientific and technological problems that society faces will not be met by any single area of human expertise. With Media-X dependent on industry funding, it seems unlikely that any one country or major geographic region could support such programs at more than one or two universities. But this should be enough to provide an umbrella structure that can legitimize and support such work on a much wider scale.

\section{Notes}

I Comments on Science in Flux, by Johan van Benthem

2 Brockman, J. The Third Culture: Beyond the Scientific Revolution, Touchstone Books (I996).

3 SRI is not officially connected to Stanford University. 


\title{
Appendix \\ The Stanford Media-X Initiative
}

\author{
The Media-X IdeA
}

- Media-X is a Stanford University Independent Center that will coordinate the study and design of interactive technology across campus, bringing together an interdisciplinary group of faculty and students who will influence the next generation of interactive technology relevant to commerce, learning and entertainment.

- Media-X projects will solve problems related to people and technology, including ease of use, natural forms of input and output, social and emotional responses, enhancement of learning, and interaction strategies in business.

- Media-X will organize partnerships with industry, foundations, and government who will collaborate with faculty and students in classrooms and laboratories.

\section{The UnIVERSITY OpPoRTUNITY}

- Media-X will offer financial support, research space, and intellectual forums that support scholarship and teaching related to the design and study of interactive technology.

- Media-X will support education related to interactive technology through the B.S. and M.S. in Symbolic Systems, a growing interdepartmental major, and through programs related to the core academic departments that participate in the Center.

- Media-X will facilitate relationships between the Stanford research community and external colleagues who build, market, regulate, and critique technology. 


\section{The Opportunity for Media-X Partners}

- Media-X partners will have facilitated access to new ideas through participation in campus classes and labs, placement of researchers on campus, participation in Center governance, setting of research agendas, and sharing of intellectual property.

- Media-X offers professional development opportunities for researchers in partner organizations through visits, sabbaticals, project and student mentorships, co-teaching, and research collaborations.

- Media-X partners will establish relationships with Stanford students during degree programs, facilitating student recruiting and knowledge dissemination.

\section{The Media-X Structure}

The launch of Media-X is being coordinated through the Stanford Center for the Study of Language and Information (CSLI). Governance will be through the Media-X Executive Council, a body made up of Stanford faculty and researchers and representatives from industrial partners. The Executive Council will establish program missions, set funding priorities, and award grants. Industrial members will have access to intellectual property generated by Media-X projects. All inventions resulting from projects organized and funded by Media-X will be available to members on a nonexclusive, royalty-free basis. The Media- $X$ portfolio will continue to grow as projects are funded and patents are filed. Members will receive regular notification of filings and will have a fixed period to exercise an option on a particular invention. The Media-X Option Plan assures that member companies will be informed of all inventions, that they will have access to the inventions, and that the access to intellectual property can proceed in a logical and streamlined manner. 


\section{Science for the $2 \mathrm{I}^{\text {st }}$ Century}

ARIE Rip

Aвstract. Science, in its interest in searching for knowledge and trying to make its products robust, can be contrasted with science as an authority, which often relies on traditional ways of knowledge production and disciplinary controls of quality. If authority as such, disciplinary or otherwise, rules, science becomes its own worst enemy. While this is an "essential tension", it becomes tractable in practice, and in a variety of ways.

Science as a mosaic of search practices and a range of modes of knowledge production, embedded in institutions and in society in general, is evolving. Disciplinary boundaries become less important in genomics and nanotechnology, but also in earth and environmental sciences. And the interactions between science and society are changing: relevance to economic and social issues is important, expertise is needed but also contested. Science-as-weknow-it cannot be the final word.

But science-as-we-know-it is itself a product of a long-term sociocognitive evolution, in which some attempts to produce robust knowledge (as in the natural-history mode) were backgrounded and others (as in the experimental and/or controlled-conditions mode) were foregrounded. A historical and philosophical detour allows us to put science-as-we-know-it in perspective.

The important question then is what the further evolution might be. Gibbons et al. have put up a strong diagnosis, of a disciplinary and university-based Mode $\mathrm{I}$ of knowledge production being overtaken by a transdisciplinary, multi-site and fluid Mode 2 of 
knowledge production. Their diagnosis must be nuanced (Mode 2 search practices were around all the time), but also shifted. It is not just a matter of discovery in the context of application (in industry, and with economic goals). The complexities of the natural world are striking back, and this requires a renewed natural-history approach.

Already for this reason, indigenous (and local) knowledge has become important, and creates a challenge to Western-science-aswe-know-it. Underlying world-views are now being articulated, and this raises the question about the world view embedded in Western science. Multi-culturalism is not the answer to this question, but is definitely the site to explore possible answers. The African Renaissance movement, and the official recognition, in New Zealand, of Maori approaches to knowledge production are two of such sites.

Clearly, science in the 2Ist century will not be like science-as-weknow-it. 
Science, in its interest in searching for knowledge and trying to make its products robust, can be contrasted with science as an authority, which often relies on traditional ways of knowledge production and disciplinary controls of quality. If authority as such, disciplinary or otherwise, rules, science becomes its own worst enemy.

This is a strong statement, and I will modify it somewhat later on. But what will remain is the recurrent and unavoidable dilemma between - on the one hand - the need for some order and the reduction of variety that goes with it to be productive in what one does (here, search for knowledge) and - on the other hand - the need to go against that same order to innovate or just to respond to changing circumstances. For science and its institutionalized interest in producing novelties (up to priority races and conflicts), the dilemma is an essential tension. ${ }^{\mathrm{I}}$

The dilemma will continue. But it is made tractable in practice and in a variety of ways. Thus, it is important to trace what happens in scientific practice. History, philosophy and the sociology of science offer important insights here. But there is more to the dilemma than what happens in concrete scientific practice. There are modes and methods of ordering the world and society which have emerged over time, disciplining and enabling at the same time by reducing variety. ${ }^{2}$ This is linked to large historical and contemporary issues of modernity, imperialism and globalization - which will not be discussed as such in this essay but are definitely present as a backdrop.

I will address the essential tension following two complementary and partially overlapping routes:

- One, by having a closer look at science as a mosaic of search practices and a range of modes of knowledge production, embedded in institutions and in society in general. This will allow me to create a broader perspective on science-as-we-know-it: what it is, and what it can be. Such a broader perspective is necessary, because science and the world it lives in are changing. 3

- Two, and following on from this, by positioning science-as-we-know-it not as the final word but as a cross-section of ongoing co-evolution of 
science (and knowledge production and authority more generally) and society. Our practices and institutions are the outcomes of long-term developments and enable as well as constrain further development. This is particularly clear for scientific disciplines as cultural categories and authority structures, but my discussion will be more general.

What are these ongoing changes, and how do they lead to a sense of larger transformations? I will start by presenting five vignettes which together indicate the scope of the changes.

First, the shift toward cross-disciplinary and non-disciplinary research:

(From an interview with Donna Dean, senior adviser, USA National Institutes of Health, The Scientist, Sept. 17, 2001) I think compartmentalization is not as easy to do now in science as it was 20 years ago. And I don't think it's just the fact that I am older and more experienced. Twenty years ago, it was easier to draw a line between biochemistry, chemistry, physics, cell biology, endocrinology, physiology. But now, because of tools and techniques and the genomics revolution, and the skills and abilities that the researchers have, you can't draw sharp lines between the fields. What I see is just a series of overlapping, fuzzy boundaries between and among fields. Probably the only boundary that is not fuzzy is the fact that the person who is trained as a PhD cannot go in and do hands-on work with patients.

Second, the shifting away from traditional positions and roles:

Universities now hire stands on trade fairs, which actually have special spaces for research and technology. The Technical University of Delft, the University of Twente, and the University of Leiden hired $255 \mathrm{~m}^{2}$ space in the Halle für Forschung und Technologie of the Hannover Messe in 1993 (UT Nieuws, 25 March 1993). Scientists, at least biotechnologists, are willing to step out of the traditional system of science and become part of a research centre supported by a big pharmaceutical company, and managed in their style. "You have to cope with the problem of having to justify again and again your research programme. But it's always better than writing research grants!" (Webster, 1994: 133) Actors in the world of science do not behave according to stereotyped views of science. In other words, it is not just a "blizzard of buzzwords" in science policy and science organisation, disapprovingly identified by 
Ziman (1994: 249), that is coming over us. Scientists and science organisations are on the move.

Third, the fusion between science, high-tech and innovation competition, particularly visible in semi-conductors and biotechnology and now also claimed for the presently fashionable label of nanotechnology:

Researchers in Motorola's (a major chip-producing company) R\&D lab in Tempe, Arizona, when exploring possibilities for making thin semiconductor layers even thinner, stumbled on a phenomenon that might be exploited to "glue" gallium arsenide (in which higher speeds are possible) to silicium, the work-horse of the chips industry. A hundred or so researchers spent two years developing this lead, and Motorola took out 270 patents to protect its rights to the new technology. Mobile phones and optical telecommunication are the primary application domains. At the same time, this offers a challenge to solid-state science to understand the how and why of this technical feat. (Based on a news item by Dirk van Delft, NRC Handelsblad 29 September 2001.)

Fourth, the importance of scientific expertise for decision-making under uncertainty, and the resulting pressures for "sound science" - whatever that may be:

US Congressman George E. Brown, Jr. analysed three 1995 hearings convened by the Republican-dominated House Committee, Subcommittee on Energy and Environment, and concluded: "again and again, like a mantra, we heard calls for 'sound science' from Members who had little or no experience of what science does and how it progresses." Brown shows that 'sound science' turns out to mean 'empirical science' in the sense of direct observation rather than models and statistical analysis. Witnesses rejected the use of statistical analysis and models in favor of observational data-even when the use of uncorrected raw data was highly misleading. The epistemic politics involved become clear when Subcommittee members argue that the government should intervene on environmental problems only after incontrovertible direct observations confirm the problem's existence. Brown warns that such a notion of 'sound science' would make it impossible to prepare for environmental harm in advance (Brown 1996). This type of epistemic politics, and the attendant pressures on scientists, returns again and again, and most emphatically when regulation is at issue. 
Fifth, the social contract between science and society is shifting, with new stakeholders becoming important and policy-makers willing to create new spaces.

\begin{abstract}
European Union Commissioner Busquin's January 2000 proposal for a European Research Area can be read as primarily an attempt to shift national science policies to the European level, but also addresses new issues of dialogue with stakeholders and ethical issues of science and technology. 'Science and Governance' is the new concern. In a major European Union conference on this topic in Brussels in October 2000, a Greenpeace researcher was invited to sit (and speak) next to the President of the Royal Society. It is symbolic action, but not without effects. Including effects elsewhere, as when new science and technology initiatives in Japan like the Research Initiative of Technology for Society, by the Ministry of Education, Culture, Sports, Science and Technology, refer to the European Union's approach to support their own venture.
\end{abstract}

These changes are recognized by the actors as well as analysts. What I want to do is to create some distance through a philosophical and historical detour. Rather than addressing the changes as they are being identified here and now, and thus running the risk of ad-hoc responses, I want to locate them in longer-term developments. One can still think in terms of challenges and how to meet them, but we shall then also realize the limits to action that is trying to make a difference. History teaches modesty.

Analysts have come up with strong claims about changes in the organization of science, with university, government and industry overlapping and co-evolving as in a triple helix (Etzkowitz and Leydesdorff 2000) and, more fundamentally, in modes of knowledge production (Gibbons et al. I994, Nowotny et al. 200I). While they tend to define changes in terms of science-as-we know-it, the dynamics they discuss are broader and can help us to develop a broader perspective.

Gibbons et al. (I994) contrast an earlier Mode I (university-based and disciplinary oriented) with a presently emerging Mode 2, which is transdisciplinary, fluid, has a variety of sites of knowledge production including "discovery in the context of application" (e.g. in industry) and new forms of quality control. The separate features they describe are clearly visible, but one might question their overall thesis that these add up to a 
new mode of knowledge production, comparable in its internal and external alignments and eventual stabilization to Mode I (Rip 2000a).

While their diagnosis of changes is useful as a starting point, one must realize that their Mode I is historically located. It emerged in the course of the $19^{\text {th }}$ century and became aligned and locked in after 1870 . However, there was interesting science and knowledge production before the $19^{\text {th }}$ century, and one should inquire into its modes of knowledge production and how these evolved.

Thus, it is important to understand how a Mode I could emerge at all and get a hold on the variety of knowledge production and institutions. To put it briefly, it is a lock-in of dynamics at three levels: ongoing search practices and knowledge production "on location", cosmopolitan interactions of scientists as in conferences and journals, and interaction and legitimation of science in society. The advantage of a lock-in is the creation of a protected space for doing science - in this case, the combination of relative autonomy and disciplinary authority - at the price of accepting the constraints.

One such constraint is the hold disciplines have obtained on the production of scientific knowledge. Another constraint derives from the norms and values which are part of historically evolved regimes. The regime of science, the endless frontier, prepared already in the late $19^{\text {th }}$ century but coming into its own after the Second World War (Bush I945) is still visible in attitudes (like an entitlement attitude towards funding for science) and projections (like the idea of a Golden Age for science in the I950s and I960s, after which things would become worse and worse). These attitudes and projections are of little help in meeting the changes.

Part of the problem (and when recognized as such, part of the solution) are the projections of what science "is", that is, what it should be, on the actual conduct of science. This normative tension will always be present and can work out positively as when it helps to maintain the integrity of science. But such projections might be or become irrelevant, as when they refer to an earlier context, or when the implied view of science is too limited.

The dominance of physics, in particular theoretical physics, and its ideals of explanation in defining what is good science is an example of a too lim- 
ited view of science and in that sense, a limitation. There are hierarchies of sciences with physics on top, there is the strong claim that physics offers insight into the building blocks of the universe and so must be able to explain anything and everything. The scientific picture of the world is then reduced to the physicist's picture of the world. 4 This elite and thus establishment position of physics (recently shared with molecular biology), when generally accepted, reduces the freedom of movement of other sciences. Having grown up professionally as a chemist, and thus located lower in the hierarchy, I can speak from experience.

The other projection is that of the unity of science as a cultural phenomenon somewhat independent of actual philosophical work on the unity of science. In our culture, one can refer to 'science', full stop. Such a reference does away with heterogeneities among the sciences and makes it easy to attribute authority to 'science'. Or even agency, as in the phrase "Science Finds - Industry Applies - Man Conforms" (the theme of the Chicago World's Fair in I933, celebrating "a century of progress"). The existence of the umbrella term 'science' leads to questions about what is and what is not science (is history included? acupuncture? astrology?) and creates a pressure towards unification, up to the idea of philosophy of 'science', full stop.

The term 'science' has a respectable history (though not a well-defined meaning), but its umbrella use is recent and emerges more or less at the same time as when Whewell felt the need to coin the term 'scientist', in the I830s, a period when scientific research was professionalizing (Ross I962). Umbrella terms are not innocent. They have effects, as I indicated. Their force derives from the possibility to project onto them, and the advantage that can be gained by capturing the term for one's own endeavours. To be able to say that your work is scientific and that of your opponent is not puts him in a defensive position.

In this way, 'science' functions as an ideograph. The notion of ideograph was introduced by McGee (I980) to capture the force of terms like 'the people' or 'democracy' which are open (sometimes contested) but have a positive rhetorical value. Van Lente (I993) has shown in detail how 'technology' functions as an ideograph in modern societies. For this essay, it is sufficient to recognize the rhetorical force and in that sense agency of ideographs and write a term in capital letters (TECHNOLOGY or SCIENCE) when 
it functions as an ideograph. Once the ideograph SCIENCE is available, its use cannot be prohibited. In fact, I used the ideograph myself in the opening sentence of this essay - and then compensated by saying I would introduce complexities later on. In particular, there is the contrast between the external usage of an unifying ideograph and the ongoing heterogeneous practices in the various sciences. This is a further example of an essential tension.

The tension is not only between internal practices and external representations. Already within science, there is a tension between the search processes of science-in-the-making, with all their uncertainties, and science-ready-made, often showing the authoritative side of its Janus face. 5 At this level, one can inquire how the vicissitudes of search processes are transformed into knowledge claims with some validity. This is a productive entrance point to discuss the tension and how it is made tractable. In Section 2, I shall develop an argument about the robustness of knowledge which can bridge the gap.

Also, to avoid continuing unproductive ways of doing and legitimating science into the $2 \mathrm{I}^{\text {st }}$ century, one must dig deeper and be prepared to make historical, sociological and philosophical detours. Section 2 continues by taking up that challenge. On that basis I can return, in Section 3, to the possibilities and requirements for science for the $2 \mathrm{I}^{\text {st }}$ century.

This essay is written as a mosaic of observations and examples, comments, general considerations and arguments, drawing on the literature, and for the actual text also basing myself on earlier publications of mine. In this way, I keep the variety of what happens and the heterogeneity of scientific knowledge production visible, while still being prepared to propose patterns in the co-evolution.

\section{A CLOSER LOOK AT SCIENCE AND KNOWLEDGE PRODUCTION}

Structural genomics, one of the exciting frontiers of science in the $2 \mathrm{I}^{\mathrm{st}}$ century (also called proteomics), attempts to produce three-dimensional structures for all human proteins. The UK Wellcome Foundation, one of the big sponsors of genomics research, briefly presented structural ge- 
nomics in the first-quarter issue, 200I, of their Wellcome News. One step is to grow protein crystals to be X-rayed to determine structures. "Salt or sugar crystals are durable and hard, but protein crystals are like fragile cubes of jelly. Growing crystals is something of a black art. Some scientists are well known for having 'green fingers' at growing crystals while others can spend years trying to crystallize one protein."

These 'black arts' of the experimenter are well known, and respected, within science, even if they are not always put up front as in this quote. Their importance in the actual production of knowledge might undermine the claim of universal validity and thus detract from the status and public image of science. And there is often a conviction that one might articulate and explicate the 'black art' so that it becomes transparent and replicable, if one took the time and effort to do so. This does not occur, though, as long as the desired effects can be achieved. ${ }^{6}$

It is not a matter of exorcizing all black art from science, but of understanding how science can produce robust results on location. To get nature to work for us and on our terms, whether in scientific experiments, industrial production, or agricultural and health practices, we have to shape it and use whatever comes to hand. Local and craft knowledge form an integral part of scientific knowledge production and can be the key to its success.

Genomics (and proteomics, metabolomics, and other "-omics") shows another interesting feature of scientific knowledge production which is insufficiently taken up in the philosophy of SCIENCE: the recognition of patterns. Genomics is made possible by the marriage of experimental science and information sciences. But the proliferation of the '-omics' sciences is an indication of a larger shift. As John Quakenbusch expressed it: "it is a shift away from biology as a laboratory science, and hypothesis-driven research, to research where (bio)informatics is needed to link data and find patterns."7 This is actually a return to research approaches in the field sciences and thus to the tradition of what I call, with an antiquated term, 'natural history'. The same John Q. added that genomics, in this way, provides a new perspective: genes are not monocausal sources of phenotypes but work in context, in interaction with their environment. This would then enable holistic approaches to diseases. 
Another interesting aspect of modern science visible in genomics is the increasing role of simulations and modelling, the three-dimensional folding of protein molecules, for example, or modelling of metabolic pathways. The earlier heavy investment in simulations in wind tunnels and water flow simulation labs have been overtaken by the advent of powerful computers and software, but the trend away from the "real" was clear before. Creating a micro-cosmos which resembles the real world but without all of its complexities helps us to do research - even if the results apply only to the micro-cosmos and not to the wider world. Phrased this way, it would also apply to a laboratory; the additional feature of computer modelling is how it introduces dematerialization of science, through rematerialization in computers, software, databases and images.

These developments may revive earlier concerns about the reality of models in science, from the spatial models of molecules proposed by Van ' $t$ Hoff in the I870s to the reluctance of chemists in the I930s and I940s to accept configurational proof of molecules based on physical methods rather than chemical synthesis. With the proliferation of modelling in chemistry, some reflection occurs, but very pragmatically:

The final paragraph of a $\mathrm{PhD}$ thesis on membranes said: "The performed simulations have (..) contributed to the fundamental knowledge of membrane dynamics." And continued: "As a final remark, one should not forget that all the results that are presented in this thesis are simulated. They are not 'real'. One can only hope that they correspond to reality to such an extent that the conclusions are useful also in the real world. But what is reality anyway?" (Marrink 1994, p. 145)

Nominalism about unseen components (as with chemists' ideas of molecular configurations in the $19^{\text {th }}$ century) is relieved when one can manipulate materials based on ideas about these unseen components - this might count as an indirect proof of their existence. The next step, as Wilfred van Gunsteren, Professor in Informatikgestützte Chemie at the ETH in Zürich and close collaborator of гвм in its Blue Gene project, phrased it, is the link with computer-based design: if a simulator can predict the folding and three-dimensional configuration of a protein on the basis of its amino acid sequence, a protein engineer can start designing new enzymes on his computer screen. ${ }^{8}$ 
The tension between realism and nominalism returns with climate change models (and even more so with integrated assessment models), also because various relationships have to be introduced in such models to allow the model to "run" and produce outcomes for various scenarios. The question of the plausibility of such assumptions is backgrounded - until they are contested. For genomics, similar further debates because of backgrounded assumptions might also arise. There is reference to them already within the relevant scientific communities, and with attempts to actually apply genomics findings and techniques, they might come out into the open.

Clearly, a lot is happening in scientific knowledge production which does not agree with a traditional picture of SCIENCE. It is necessary to develop a "philosophy" of science and knowledge production as a composite picture which does justice to the achievements of science in knowledge production without succumbing to traditional authoritative structures and pressures for legitimation linked to SCIENCE. The first step is to create openings by showing the cognitive and material underdetermination of knowledge claims and the importance of processes and trajectories of knowledge development. A variety of modalities of production of robust knowledge becomes visible this way. The actual production of knowledge is located in socio-cultural spaces which enable as well as constrain. The overall picture allows me to consider, in Section 3 , what science for the $2 \mathrm{I}^{\text {st }}$ century might look like.

\subsection{A closer look at robustness of knowledge production in science9}

Consider the intractable problem of formulating knowledge claims with universal validity and proving them when one cannot do more than experiments of limited scope, in certain places and at certain times. Still, an edifice of scientific knowledge has been built on these precarious foundations. Philosophers of science have worried about the strength of the foundations and attempted to specify methodologies for building solid edifices. Karl Popper's critical rationalism, with its sociological complement of "organized scepticism" as a rule in the social system of science, appears to capture important elements of how the productive practice of building the 
edifice actually proceeds. As Donald Campbell has shown, there is a compromise involved, in the sense that scientific communities need what he calls 'tribal norms' to bind them together and make the epistemologically important norms forceful. Competition for reputation would be one such tribal norm (Campbell I979).

The basic point made by philosophers of science and supported through detailed historical and sociological case studies is that scientific knowledge is underdetermined. There is no absolute assurance that later findings and/or new arguments will not undermine present achievements. There are degrees of solidity, of course. But the nature of scientific observation and experiment, and the precarious shift from specific findings to more general knowledge claims, always leave openings for doubt and further checks. Closure of the quest is a practical matter, not a logical step.

Logically, the ceteris paribus problem undermines any attempt at universality of knowledge claims. You know what you have observed in this experiment, here and now. But are the circumstances in another experiment (of your own, of another researcher) exactly the same? You can try to control the conditions and thus make the ceteris the same - but you cannot control for what you do not know about. In practice, iterations between preliminary understanding and first attempts at control often converge to a stable alignment between working experiments and the scientific understanding based upon them (Rip I982, Collins I985). Underdetermination of scientific knowledge claims is not just a philosophical puzzle, there is an element of successful material control and alignment.

The material aspect of underdetermination returns with a vengeance in the issue of how experiments that work do so under specific circumstances. Experiments on the effects of the release of GMO in the soil using a so-called microcosm (Cambrosio et al. I992) tell you a lot about what happens in the microcosm, but not necessarily about what happens in the wider world. When society (and the world) is taken as the laboratory (Krohn and Weyer 1994), it is impossible to do fully controlled experiments. Learning through trial and error occurs but has its risks (when the trials are dangerous) and are epistemologically limited because they follow a particular learning trajectory. The example of the introduction of new medical drugs and the monitoring of effects shows the possibilities as well 
as the limitations (i.e. risks) of the approach.

A further reason for scientific knowledge claims being underdetermined is that to understand what you see, observe, or measure, you need a "theory" of the situation (of the experiment, of the apparatus), somewhat separate from the theory of the phenomena. A striking example, studied in detail by Galison (1987), involves high-energy physics experiments. For new and/or contested observations which do not fit with the present understanding, the direction to go cannot be decided unambiguously: it may be that the theory of the situation is OK, but the theory of the phenomena to be measured/observed is wrong - or the other way around. In the experiments in CERN and other particle accelerator facilities, the background phenomena and apparatus are modelled with the help of a theory of the experiment. The CERN researchers studied by Galison only "found" a new particle when they changed their theory of the experiment. ${ }^{\text {Io }}$

Modelling background phenomena is also important for policy-relevant science, for example, when environmental effects have to be estimated. If the choices involved remain invisible, the pretenses that have gone into the final results will remain underexposed. Criticism from scientists or other involved actors may be necessary. In general, findings should be presented also in terms of the choices made to obtain them. In quality control terminology, one could speak of the 'traceability' of knowledge packages. The general philosophical point here is that knowledge claims are inferences to the best explanation, and the inferential path, with its checks and further considerations, determines the quality of the outcome (Lipton I99I). ${ }^{\text {II }}$

From a general and philosophical concern about the underdetermination of scientific knowledge claims, I have now progressed to consideration of the actual trajectories followed in the attempts to produce more or less solid findings. One can then inquire into the nature of such trajectories, and the de facto requirements made on them, given their history and context.

The first requirement derives from the observation that the definition and pursuit of specific trajectories are often predicated on a partial closure of a broader debate. In a sense, one has to put on blinders to make concrete 
progress - hopefully in the right direction! Thomas Kuhn (I970) discussed so-called scientific revolutions, where epistemic issues are highlighted, and emphasized how a new paradigm emerges and becomes dominant. Epistemic debate is then backgrounded, and 'normal science', with its own kind of challenges, ensues and allows progress to be made until persistent anomalies are thrown up in the course of research within the paradigm and lead to a renewal of epistemic debate. In other words, the closure of broader questions can be opened up again through the work along the trajectory made possible by the closure itself.

The phenomenon of partial closure to make progress is broader than the Kuhnian examples and does not depend on the emergence of a paradigm. The study of and debate about the environmental release of genetically modified organisms (GMOs) provide examples. One issue is that of possible evolutionary impacts, which could not be settled by regular empirical and logical arguments. The two main contending positions are visible in these quotes:

"In contrast to conventional breeding, genetic engineering can transfer genes between species which are widely different in evolutionary terms. However, the greater the evolutionary distance between the species, the lower the probability that they will somehow converge. Therefore, the further genetic engineering moves beyond the limits of traditional breeding, the less reason there is to fear that it could trigger evolutionary processes which end up in species mixtures and a loss of differentiation in the species spectrum." (Van den Daele et al. 1997; 34)

"The fundamental premiss of evolutionary theory is that natural selection (..) operates on genetic alterations (...) to produce evolutionary change. It follows that at least some genetic alterations improve the abilities of organisms to survive, to reproduce, to compete for resources, or to invade new habitats (...). A general assertion that genetic alterations (...) always lower the fitness of organisms is therefore not warranted and runs counter to basic evolutionary principles." (Sharples 1985, quoted in Von Schomberg 1997; 75).

The debate is further complicated by the question of whether genetic engineering is 'special' or just like traditional breeding. The latter suggestion can be used to assuage fears (nothing unusual is happening) but can also be turned around, because "even traditional breeding has not been ecologically trouble-free" (Colwell et al. 1985, quoted in Von Schomberg 1997; 66) 
Partial closure occurred when the regulation of genetic manipulation, and then also of field tests of GMOs, started to use evolutionary distance as a criterion of acceptability. Untoward events may break up the closure, but also societal and cultural considerations - always implicated in epistemic debates. An example would be the spread of GMOs outside fenced-off fields and the consequent concern (and liability) of other farmers, as well as consumers who want GMO-free food. The recognition, by now, that the latter is impossible (as in the usA legislation about labelling, where GMO-free food may contain up to I\% contamination - an example of material underdetermination) will lead to a reconsideration of the evolutionary debate.

The second requirement is the recognition of uncertainty as part of the dynamics of the trajectory. There are varying degrees of tolerance of uncertainty, in general and specifically, in relation to the novelty introduced through scientific research and related knowledge claims. ${ }^{\text {I2 }}$ Uncertainty can be, and generally is, tolerated within a scientific specialty, especially by the 'core set' working at the research front (Collins I985). In this sense, a specialty is enabling, even if there are constraints because of the cognitive, technical and "tribal" norms. These provide, as it were, a protected space in which researchers can live with uncertainty.

However, when knowledge is to be used in professional activities (whether in another scientific specialty, in professional practice, or in preparing policies and decisions), actors want it to be as solid as possible, except in situations when there is an interest in finding an opening for alternatives, and then uncertainties are welcomed. When scientific findings are disseminated to broader audiences, the link with action is absent, or indirect, and there is more tolerance of, or perhaps just indifference to, uncertainty.

One immediate implication is that the pressure to reduce uncertainty and to achieve 'closure' is different in the three contexts - the tribal norms are different for different tribes. One such difference relates to the time horizon for action. Within a scientific specialty, the quest for "the" truth has no definite time limit, even if there may be, in competitive areas, a race to be first. For practical purposes, whether this is getting an instrument to work in an experiment or expert advice contributing to a decision-making process, to have 'solid' knowledge available has to fit time schedules of action. In the public sphere, it is important to enable concerted action, cf. 
interest in consensus conferences, and similar attempts to separate the 'solid' from the still uncertain. Another indicator is the impatience of decision-makers and politicians with the conditional statements of scientific experts and their "on the one hand/on the other hand" vacillations.

To apply the norms of the policy tribe to the work within a scientific specialty may well be counterproductive. And even counterproductive to the goals of the policy tribe itself: the pressure for certainty includes a preference for 'solid facts' rather than theories and models. This creates a problem when anticipatory assessments have to be made for which observation or measurements are impossible by definition. The fourth vignette in the Introduction to this essay, about American Congressmen clamouring for sound science, testifies to this.

The third requirement refers to the process of reaching closure, as increasing alignment and acceptance of the alignment achieved as sufficient to base further work on. The solidity of scientific findings is a matter of alignment of controlled observations and theoretical considerations and the decision that there is enough certainty, for the time being. The process as well as such explicit or de facto decisions can take place within the protected space of a specialty or a discipline, but even then cultural and moral values, interests and circumstances play a role, because these are part of the construction and maintenance of such protected spaces. ${ }^{13}$

The 'state of the art' in a scientific specialty or domain of research reflects the specifics of the earlier sociocognitive processes - a further pathdependency, now at the level of a domain of research. A good example is how the state of stratosphere research in the I960s and early i970s reflected efforts to address concerns about effects of supersonic transport aircraft, which then shaped the possibilities for further research as well as identification of risks. In particular, Rowland and Molina's I974 early warning about possible damage to the ozone layer from chlorofluorocarbons was predicated on data and insights from this trajectory (Callon and Rip I992; Rip I992).

Another intriguing example of how a path was constructed is how the American Department of Energy became involved with human genomics. Because of its earlier involvement in the biological effects of low-level radiation, it had built up a tradition of (molecular) biological research and an 
infrastructure including synchotrons. This led to strong participation in the Human Genome project ten years ago and now to the new and ambitious Program Genomics to Life, focusing on protein complexes that function as molecular machines, and on microbial consortia. As Program Coordinator David Thomassen said in an interview: "DoE has always had the flexibility to fund risky research, more than for example the National Institutes of Health.” I4

There is path-dependent learning involved in and through the alignment processes. Such learning is open-ended, because nobody knows the 'right' answers. It is also collective, rather than individual learning. The notion of repertoire learning is particularly useful here, and this can be illustrated by studies of controversies and their outcomes within science as well as science-related controversies in society. An eventual alignment creates a repertoire of considerations which are difficult to go against. In that sense, the outcome is robust, even if it can be undermined when new arguments, interests, or values unravel the existing alignment.

Robustness can then be explicated as the combination of consolidation and well-articulated alignment. The example of the smoking-health link is instructive to show the importance of the combination of the two. Such a link was implicated in the prohibition of smoking in some USA states in the late $19^{\text {th }}$ and early $20^{\text {th }}$ centuries, the argument being that smoking is what morally depraved individuals do (so it must be prohibited) and will lead to diseases (as punishment for their sins). This not very well articulated alignment broke down in and after the First World War, when the cultural aspects of smoking cigarettes shifted. During the war, citizen groups started to send cigarettes to soldiers because the cigarette was an "indispensable comfort to the men". Moral associations now became positive, the cigarette being identified with "quiet dignity, courage, and dedication above all" (Troyer and Markle I983, p. 40-4I). In contrast, by the I970s, after extended controversies, the smoking-health link had been articulated in great detail, and cultural shifts (for example, the attempt to link smoking with individual freedom) could not undermine the "edifice" that had been constructed.

Turning the tables from a retrospective understanding of controversies and their outcomes, as they occur, to the question of requirements to support the construction of robust knowledge, it is necessary to identify what 
will work again, at other times and in other places. In these examples, robustness is an outcome of interactions and struggles, some of them directed towards traditional scientific robustness, others stemming from values, and again others being part of interest strategies. My claim is that articulation of the quality of alignments is served by such agonistic (and sometimes antagonistic) interactions. They force actors to articulate the merits of their position, to search for arguments and counter-arguments, and to commission special research. (This is a broadening of the Popperian-Mertonian emphasis on fallibilism and organized scepticism, which now appears as a special case within the protected space of an academic scientific community abstracted from many of the vicissitudes of the real world.) Of course, such agonistic struggles can lead to impasses, when parties limit themselves to mutual labelling of the other as contemptibly wrong (as has happened in the debate on nuclear energy and is happening to some extent in the biotechnology debate, where third parties including supermarkets now mitigate the impasse). Within academic science, controversies can similarly become unproductive when insider-outsider or regular-deviant labelling eclipses productive interaction.

Robustness of knowledge is better served by some arrangements than by others. That was Campbell's point about tribal norms, as they function within the academic world. I have broadened his point to include further interactions and processes. The pursuit of robust knowledge remains, but the division of labour in its production may change. For example, the delegation of the production of robust knowledge as well as the assessment of its robustness need not be limited to the relevant scientific and technological communities.

The examples I discussed were mostly about science-as-we-know-it, with identifiable sites and practitioners. The kind of robustness we see then is predicated on these circumstances. The notion of robustness as alignment is more general and can be used to formulate broader questions of knowledge production and assurance of its quality.

\subsection{The richness of knowledge production, in its various modes}

The challenge which has been addressed by modern science is how to transform local knowledge into knowledge valid at other times and in 
other places. Formulated in this way, the challenge is broad and can be taken up by other approaches than science-as-we-know-it. It is what drove Renaissance experimenters; physicists trying to formulate so-called universal laws; professional consultants advising a variety of clients; and Mpemba, a Tanzanian boy making ice cream to sell after school and finding out that putting still-hot milk in the fridge froze faster than cold milk put in the same fridge.

Mpemba's claim and his story, wonderfully told by David Turnbull (I998), has predecessors in Aristotle and Francis Bacon. Bacon's observation that slightly warm water is more easily frozen than quite cold water is cited by Thomas Kuhn (I970, p. I6) as the kind of fact gathered by natural histories prior to the emergence of a first paradigm (which would exclude them) and which "we are now quite unable to confirm". A physicist visiting Mpemba's school, however, conducted a series of experiments confirming the phenomenon and published it, together with Mpemba, in a physics education journal used to publish outcomes from school experiments (Mpemba and Osborne I969). It was then taken up by the UK magazine New Scientist, which received a plethora of similar observations, and resurrected again in 1995 when fluid dynamics physicist Auerbach tried to explain the phenomenon and published on it.

The story of "Mpemba's physics" as David Turnbull phrases it has a number of morals. One is about the risks of projecting findings made under controlled circumstances on to what happens out there, without doing the work of translation. Minnaert's book, Natuurkunde van het vrije veld, originally written in the I930s, is legendary, and rightly so, in having taken up the challenge. ${ }^{15}$ The magazine New Scientist has a tradition of being open to such puzzles. What this shows is the importance of reconsidering too easy claims of establishment physics when faced with accumulated knowledge in local practices.

Three modes of robust knowledge production

Robustness of knowledge production has to do with local search practices becoming linked, their products becoming more or less decontextualized and able to travel to other locations without losing their validity. From this perspective, three main modalities of knowledge production can be distinguished. The importance of introducing the notion of modalities is to cre- 
ate some independence from traditional disciplinary distinctions, which are primarily institutional (see 2.3 ).

The first modality or mode of knowledge production is based on circulation of embodied knowledge and partial articulations and codifications between local practices. This is the main mode of knowledge production in traditional knowledge, in the crafts, and in professional communities, also today, even when there is also strong input from other kinds of knowledge. The importance of clinical judgement in medical practice would be one example.

The second modality can be called "natural history", to honour a venerable tradition. Circulation remains important but may be more extended and consciously sought after, as when Aristotle collected and refined observations and travelers' tales, or $\mathrm{I}^{\text {th }}$ and $\mathrm{I} 8^{\text {th }}$ century amateurs collected specimens, museums and gardens were established, and scholars were hired to study the collections (Westrum I978; Stemerding 1991). The key element is the attempt to recognize patterns which extend over time and place. Since the $19^{\text {th }}$ century, collection, refinement and pattern recognition have become quite sophisticated; geographical information systems (GIS) being one example. In fact, there are good reasons to speak of the rise of a 'new' natural history, as I will discuss below.

The third modality is the production of knowledge under controlled circumstances, in a laboratory and in experimental situations more generally. This starts out as a local practice, and its reproduction in another local practice, say, a laboratory attempting to also build a new kind of laser, is fraught with difficulties which can often only be resolved by visiting the original location and learning relevant skills (Collins I974, see also Collins I985 on replication more generally). The idea is that the phenomena created under such restricted circumstances allow access to background regularities which are valid more generally - at the very least as long as one can recreate the relevant circumstances. ${ }^{16}$

The power of experiment is clear, but the further claim that it allows access to background regularities, up to universal laws, and understanding of the building blocks of the universe (and of society, for that matter) is less easy to defend. The ideology of the scientific experiment and the attendant theory building has become so strong, however, that a special effort is necessary to show the limitations. That is why I had to start discussing, in 2.I, 
the underdetermined character of scientific knowledge claims.
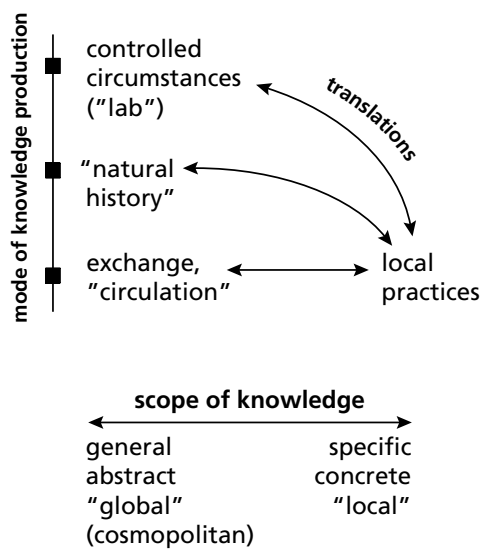

Figure 1: Three modes of robust knowledge production

Figure I visualizes the three modes of knowledge production and adds the observation that the distance to "unrestricted" local practices increases from the first to the third mode of knowledge production. Translations and transformations between the knowledge claiming to transcend local practices and subsequent local practices to which these claims are to be applied are always necessary, 17 but they require more effort going from the first to the second and then the third mode of knowledge production. On the other hand, if these efforts are successful, they can create impressive effects, as when Pasteur, in the late $19^{\text {th }}$ century, demonstrated the power of his laboratory-based vaccine to protect sheep from anthrax - after carefully reconstructing the world outside the laboratory so that it would allow the emergence of this effect (Latour 1983, Latour 1984). In that sense, applying knowledge acquired in a laboratory to the wider world is a form of colonizing the world. Colonialism, in spite of the present and negative politically correct connotations of the word, has some good things to it as well.

There is a trade-off between control over circumstances, gradually increas- 
ing from independence derived from moving across different localities through summation points like musea (Westrum I978) to laboratories, and an easy relevance to real-world situations. Some authors have highlighted the importance of local knowledge over distanced-experimental knowledge, as when Brian Wynne showed how Cumbrian shepherds had more relevant knowledge about after-Chernobyl radiation effects on location than the experts advising on regulatory measures (Wynne I996). On the other hand, this relevance of local knowledge is predicated on local circumstances remaining the same or changing only slowly. An adequate response to rapid and/or larger changes requires an idea of background dynamics and patterns, enduring processes and underlying mechanisms. In other words, local knowledge should not be glorified. But it cannot be automatically assumed that the tradition of Western science-as-we-knowit, in spite of its achievements until now, has all the answers.

\section{A socio-epistemic history of Western science}

Over time, the importance of the controlled-circumstances mode of knowledge production has grown, and at the expense of relevance to concrete and complex situations. Epistemologically, it is a matter of (always partial) reduction of variability and heterogeneity which is conducive to knowledge production, but at a cost of distance from "unrestricted" practices and their complexity. Historically, 'natural history' refers to our attempts to map the world and its development. From a major intellectual thrust (with Aristotle, and the scholars of the I7th and I8th century, and practitioners all along) it became a backwater, pushed aside by experiment-oriented high science.

Since the $19^{\text {th }}$ century, the disciplinary hierarchy in the sciences is based on the claim that lab sciences (and work under controlled conditions more generally) are better in producing valid knowledge than work under non-controlled conditions. ${ }^{18}$ Even if, as Ian Hacking (I992) phrased it, lab science is great, it is about the lab world. This hierarchy is actually a temporary cross-section of a longer evolution over the centuries and may therefore change again. Or perhaps we shall do away with disciplinary hierarchies altogether.

The hierarchy has hybrid origins. The epistemic advantage of reduction of variability was combined with the social and political advantage of 
excluding deviants, that is, actors and approaches not acceptable to establishments. The second half of the $I 7^{\text {th }}$ century is a turning point, when the earlier variety (including reformist and revolutionary approaches) was reduced in order to have a Royal Society in the uk and an Académie des Sciences in France (Van den Daele i997a, I997b). Social distancing strategies and exclusion actions created "high" sciences, linked to establishments (royal or otherwise), and availing themselves of what Thomas Kuhn was to call paradigms, visible in policing actions. "Low" sciences, on the other hand, were open to whatever appeared to be interesting and useful to practitioners in relation to a variety of audiences, from the fairs and markets to the newly emerging industries.

In other words, a socio-epistemic history of science is necessary to show the historical contingency of the present situation - and in particular what I see as an unholy alliance between high science and science as an ideograph, and to show the possibility of transcending these limitations. Figure 2 arranges the variety of approaches and disciplines with the help of two dimensions: one dimension refers to control over conditions, the other dimension refers to societal status and the possibility of background alternative approaches.

Variety of search practices and knowledge production, as defined by knowledge producers

\begin{tabular}{|c|c|c|}
\hline & low science & high science \\
\hline natural history & $\begin{array}{l}\text { Aristotelean “meteorology”, } \\
\text { field sciences }\end{array}$ & $\begin{array}{l}\text { Darwin's evolutionary theory, geo- } \\
\text { physical and cosmological theories }\end{array}$ \\
\hline $\begin{array}{l}\text { restrictedness } \\
\text { (controlling materials } \\
\text { and circumstances) }\end{array}$ & $\begin{array}{l}\text { chemistry, technical sciences } \\
\text { and engineering }\end{array}$ & $\begin{array}{l}\text { From Boyle, Huygens, etc } \\
\text { (in I7 }{ }^{\text {th }} \text { century) onward. } \\
\text { physics, economics, psychology; } \\
\text { now also molecular biology? }\end{array}$ \\
\hline
\end{tabular}

Figure 2

The main diagonal runs from "low" and heterogeneous knowledge production of the 'natural history' type to high science based on 'restricted' circumstances. That is how the history of modern science is often written. It reflects a purification trend, as Latour (1993) would call it, which has a material side to it as well, if one considers for example the capacity to pro- 
duce pure chemical compounds (Rip I982). But it also creates and maintains a specific view of the history of science, which reinforces status differences. From such a point of view, the achievements of high, restricted science justify colonization from the lower righthand corner into the neighbouring boxes, and by now also into the top left corner, for example in present-day meteorology. The scheme should be read not as an argument for three centuries of progress in science, but as reflecting the historical foregrounding of particular modes of knowledge production as (modern) science. There will be débordements, however, and these become visible in boundary struggles and in problems of applying scientific insights in the real, that is, unrestricted world.

The challenge to address the phenomena out there has by now led to new theoretical approaches, as in Prigogine \& Stenger's analysis of "order out of chaos". ${ }^{19}$ And the tradition of 'natural history' has been revitalized through the increasing importance of the sciences of the environment. Measuring, mapping and modelling the world become a scientific challenge in their own right - one might speak of the " $3 \mathrm{M}$ " sciences - and are pursued with the help of the new information and communication technology. ${ }^{20}$ Thanks partly to the competencies acquired from its colonization by high and restricted science, heterogeneous natural history is striking out in new ways, for example pattern recognition in genomics (cf. introduction to Section 2). The new natural history is here to stay.

To restrict or to un-restrict?

There are definite limitations to the focus on restricted circumstances as the only basis for the production of robust knowledge. The well-known physicist (and one-time director of Philips's central research laboratory) Casimir observed that in making experimental arrangements for quantitative measurements, we may eliminate the possibility of new phenomena appearing (Casimir, I983, p. I6r). His example was Lenard's set-up, which was better for certain quantitative studies than Röntgen's, and therefore Lenard did not discover X-rays (Röntgen rays). The point can be formulated generally: by restricting and protecting we become productive, but our backgrounding of the complexities of the material and social world may also limit our opportunities to discover new and interesting phenomena.

Apart from such self-inflicted limitations on discovery, the quest for 
restrictedness creates further problems when the findings of such lab science are expected to apply to the complexities of the real world. The world has to be domesticated before the findings from the lab are applicable. And such domestication may create its own problems. The war against germs, made possible by Pasteur and other's domestications (see Latour I983), has its sequel in the acquired resistance of bacteria against antibiotics, which by now has led to the equivalent of the arms race between men and bacteria. ${ }^{21}$ Given the complexities and contingencies of the natural world, well-intentioned actions may backfire when building on findings from restricted experiments.

One can read my analysis as an argument to unrestrict and perhaps not restrict at all. Such arguments are in fact being made, for example by environmentalists. There is also the interest in the value of local knowledge, as of Cumbrian shepherds after Chernobyl (Wynne i991, Wynne i996), and in indigenous knowledge even if this interest is often in exploiting it for other purposes, as indigenous people increasingly realize.

When Brush (1999) interviewed farmers about nomenclature and preferences for the native potatoes of the Tulumayo Valley in Peru, one response was: "I expect that my potatoes will make you rich". Somewhat disingenuously, Brush continues after this quote in his paper: "The comment was not unanticipated, but it still baffled me."

There is a fine line to be drawn between the recognition of the value and potential robustness of local and indigenous knowledge, and embracing such knowledge as an antidote to the colonialism of Western science. It is indeed important to be able to relativize one's reliance on the Western/ modern tradition and appreciate what happens elsewhere, but one should not go native either. Wynne (I996) as well as Van der Ploeg (I996) wrestle with this issue.To put it briefly, and in my terms: one must require knowledge claims to have validity elsewhere and at other times, even if only in the next valley of the Andes.

Some form of theory or at least pattern recognition is necessary to move findings from one location to another or to apply them to a future situation. It might well be that this always requires a measure of restrictedness. The revenge of natural history cannot then be complete. 


\subsection{Protected spaces, and disciplines as partial ordering}

Nested protected spaces are the distinguishing characteristic of knowledge production in science-as-we-know-it. Protected spaces have material, socio-cultural and institutional aspects. This is very clear in the notion of a laboratory as a place where experiments can be conducted under restricted conditions; these conditions include the disciplining of its inhabitants and the exclusion of unwanted visitors. Field sciences have more difficulties in creating the desired protection, but attempt to create their boundaries as well. Embracing interference is frowned upon in high science.

The effect of protected spaces is the reduction of interference and of variety. In other words, productivity is based on exclusion. This holds for laboratories (and their equivalents) and for disciplinary scientific communities which guard their status.

Part of the work in research practices is to transform the local production of knowledge items into more cosmopolitan knowledge claims - as in a scientific paper. Such claims are addressed to non-local audiences as constituted by a research area or problem area. ${ }^{22}$ These audiences and areas can be hybrid, as was (and is) the case in many sub-areas of chemistry. Research areas, specialties and disciplines offer spaces for cosmoplitan scientific work. They enable at the same time as they constrain. Thus, they offer protected spaces.

Further institutionalization with established journals and, somewhat later, departments or subdepartments in universities will create a recognized specialty, with its own paradigm, cognitive style, and ideals of explanation. The history of the emergence of disciplines and specialties (within disciplines or crossing borders as happened for example with physical chemistry in late $19^{\text {th }}$ century) started in the late $\mathrm{I} 8^{\text {th }}$ century (cf. Hufbauer I982), but disciplines became serious business with professionalization and the revitalisation of higher education in the $19^{\text {th }}$ century, also with respect to research. By the late $19^{\text {th }}$ century, disciplines were dominant institutional categories, sedimented and codified in university departments and library categories.

One sees the features of Mode I here. To count Mode I as a fully fledged regime of scientific knowledge production, it is also necessary that the arrangement of laboratory and field research, disciplines, institutions 
like universities but also some public research institutes like the Physikalische Reichsanstalt in Germany is recognized and accepted by the state and by civil society as the way to do science. In a sense, this is a social contract between science and society. It is definitely a protected space, now at the macro-level, which enables and constrains.

The three types of spaces (micro, meso, and macro) are not independent. And if they are aligned and become nested spaces, they form a lock-in which can be hard to change. This is how Mode I evolved and was reinforced after the Second World War through the advent of new institutions like science funding agencies. The label "Science, The Endless Frontier" (after the title of Vannevar Bush's (I945) Report to the USA President about the role and organization of science in the USA after the war) can be used to characterize much of this regime.

Such a characterization and the underlying recognition of the dynamics involved allow further questions to be raised: could this regime evolve further and eventually transform into a new regime? If Gibbons et al. (I994) are right, a new regime - their Mode 2 - is upon us. Whether they are right or not in their specific diagnosis, regimes do evolve. Recent studies of national research systems have shown general patterns, first in the emergence of a typically modern research system since I870 (Rip and Van der Meulen 1996), then in the way new interactions and institutions have emerged which addressed evolving interaction between science and society (Rip 2002). These studies limit themselves, however, to the organisation of science and science policy. The complete dynamics must include modalities of knowledge production as well.

An important entrance point to understand the complete dynamics is to focus on the link between knowledge production and sponsorship of knowledge production, in particular in Western science. Sponsorship consists of various forms of patronage over the centuries, up to present science policy and university-industry interactions.

To show this, let me go back in time to the European Renaissance. Immediate and bilateral patron-client relationships developed into a triangular scheme, in which the patron needed advice about his sponsorship, say of a painting, a sculpture, or an engineering work, from a knowledgeable third party - in particular, humanist and other Renaissance scholars, who 
might on other occasions profit from patronage themselves.

Galileo at the court of the Medici in Florence was first of all a courtier who offered his work to his patron. As Biagioli (I993) shows in detail, Galileo looked carefully after his "local net" but was also active in building a "cosmopolitan net" with his competing colleagues at other courts - the competition focused on who could offer the more interesting things to their respective patrons - and distancing himself from other, low-brow clients of his patron. Galileo's case has its specificities, but the pattern that is visible is more general.

Such cosmopolitan interactions, while deriving from or at least coupled to local contexts and interests, stimulated the emergence of virtual communities, linked through circulating texts and their contents. The patrons themselves could become invisible when institutions carrying resource mobilisation and the subsequent dispensing of resources emerged. Scientific societies, especially in the eighteenth century, became such a carrier, and the emergence of scholarly journals in the Republic of Letters helped to support "cosmopolitan nets". The influence of patronage games continued in a more global way, as when institutional etiquette was enforced. A striking effect is how the need to appear courteous pushed the struggles among practitioners below the surface presented to the outside (cf. Shapin, 1994). Scientists are tradesmen rather than gentlemen but need to behave and be seen to behave nicely to keep up legitimation.

When the balance shifted to the interactions within emerging and institutionalizing scholarly/scientific communities, concrete patrons were increasingly backgrounded even if they remained indispensable. The professionalization of science in the igth century foregrounded the role of communities of (competing) colleagues in judging scientists, their claims and their promises. This is the birthplace of disciplines-as-we-know-them, and the struggle about status (including attempts to create a hierarchy among the disciplines).

Such a system of science created and maintained protected spaces and enabled further developments. Scientific work became sufficiently independent to relate to and profit from distributed sponsorship: from scholarly societies, various patrons, the state (in particular in France and the German states) and professional practices (in particular in the uk). The I87os mark a further change, with the state coming in as a distant sponsor held 
responsible for the endowment of science; and universities taking up research and scholarship in earnest.

The increased role of the nation-state pushed the idea of a national community of scientists located primarily at universities. Where there had been self-styled spokespersons, it was now a scientific establishment with institutionalized channels for lobbying and advice. This partial lock-in became complete when government funding agencies expanded after the Second World War - because the agencies were captured by the national scientific communities, legitimated by the ideology of "Science, The Endless Frontier". Government science budgets were constructed, and scientists divided the spoils (while voicing concerns about insufficient funding). Funding agencies were the bastion of disciplines, with occasional, and now increasing, guilt feelings about multi- and interdisciplinary work and attempts to respond to new developments.

Disciplines have other important footholds, like graduate schools in the USA and the ensuing possibilities for an academic career; in libraries (in spite of their own good intentions); and in a perverse way in the UK Research Assessment Exercise of the last decade. Thus, disciplines are a partial but important ordering of knowledge production, as well as of the research system and the relationships with sponsors.

This is the history of Mode I, one could say. But it is also the history of the relationships with sponsors of science. A closer look at the variety of sponsorship relations shows that there was always more to science than the regime of Mode I and allows a better view of the dynamics in the so-called Mode 2.

Since the late $19^{\text {th }}$ century, local and state governments and industrial firms have used research and researchers for particular services, as employees and as contractors. But an element of sponsorship was added because of the expectation of general value of the findings (so no detailed specifications) and because the researchers were allowed to further their own reputation and career. This worked out differently in different scientific fields. In chemistry, a productive practice developed in the late $19^{\text {th }}$ century of interactions with industry and other sponsors, including a workable etiquette, which continued into the $20^{\text {th }}$ century. This allowed chemists to accommodate the new challenge of biotechnology in the 
I980s and I990s. Biologists, on the other hand, had no such history of interaction with industry (their practical relations with sponsors were in medical and agricultural sectors), so the advent of biotechnology created transitional problems, with conflicting etiquettes and complaints of naiveté (Rip and Van Steijn I985).

The big charitable foundations, the first of which were established in the early twentieth century, are the nearest equivalent to the earlier patrons of science who could, and would, act according to their own discretion. The Rockefeller Foundation, based in the USA, had a generalized interest in the natural and social sciences, linked to its concern about the future of the urban-industrial society. It has stimulated new developments in biology (including work that paved the way for molecular biology), anthropology and social science from the I930s until at least the Ig6os. Being funded by the Rockefeller Foundation amplified the reputation of the researcher and the research institution.

In addition to such concrete sponsors, one can see the emergence of abstract sponsors: an indirect source of resources because reference to them would support concrete resource mobilisation efforts (especially with the state and with science funding agencies). In the case of chemistry, these dynamics are very clear. The wishes of customers and sponsors were internalized in the field, that is, need not be present as such to have an influence. The functionalities the sponsors were interested in would be realized through the heuristics that made up the paradigm or the regime (Slack I972; Van den Belt and Rip I987). ${ }^{23}$ Instead of Bayer, Hoechst, ICI or Dupont contracting for specific types of research, it was toward the chemical industry in general (and also the medical and pharmaceutical sector) that chemical research and researchers would be oriented, explicitly or implicitly. Since reference to the importance of industry helped to mobilize resources, industry became an ideograph. And the ideograph INDUSTRY played the role of an abstract sponsor.

The reference to INDUSTRY has become increasingly important for science in the late $20^{\text {th }}$ century. Spokespersons for industry (that is, INDUsTRY) are expected to sit on committees, and chairmen of science funding agencies are often required to have some experience in industry, or at least in the private sector. By now, USERS have become important as an ideographic category as well (Shove and Rip 200I). 
There are other such combinations of concrete and abstract sponsors; the MILITARY being a clear and, in the post World War II situation, very important example - even if it cannot anymore be referred to without adding special defence. The ideograph sustainability has become powerful in recent years. NGOS (non-governmental organisations) ranging from Greenpeace to the International Council of Scientific Unions present themselves as spokespersons and are involved in agenda-building for science. Individual scientists and groups develop new approaches (including holistic ones) to link up with sustainability. Being able to invoke SUSTAINABILITY mobilizes symbolic and financial resources, even if it also involves one in the debates and controversies about the environment, global climate change, and issues of expertise and decision-making generally.

Abstract sponsors create a space, and perhaps a protected space, for scientific research and are thus part of the evolving social contract between science and society. They also play havoc with existing disciplinary distinctions. Just as academic disciplines could emerge and stabilize through the backgrounding of sponsors, the "return" of the sponsors introduces dynamics leading to hybrid scientific communities and hybrid forums carrying new or at least modified ways of knowledge production. Patient associations in medical and health research would be a striking further example (Callon et al. 200I).

In this way, I broaden the perspective on present changes beyond the simple diagnosis in terms of a Mode 2 of scientific knowledge production. And there are other elements to be added, which show how the interface between science and society is changing and being articulated further and showing partial institutionalization. ${ }^{24}$ For example, the role of science and technology in wealth creation and contributing to the quality of life is generally accepted (and expected), but there is societal pressure to make the actual impacts of research visible.

Society is now less fatalistic about the impacts of science and attendant risks (as with molecular biology and genetic modification) and wants some technology assessment done (including ethical aspects). And society wants expertise (up to "sound science") even in the face of large uncertainties. Expertise is not limited to what regular science provides.

New stakeholders are becoming important (at all levels of the research 
system). Public scrutiny of science is now a fact of life. It has to do with public understanding of science but, more importantly, with new interactions in the risk society, including a critical appreciation of experts and expertise. It also includes continuing trust in science even if specific developments are being criticized.

The projection of a Mode 2 cannot capture all these changes and challenges. In fact, it may be too early to think of a new regime. Reduction of variety can be counterproductive if it reduces the complexity without understanding what the complexity is about. For that reason alone, it is prudent to entertain heterogeneity, cognitively, socio-culturally and institutionally.

\section{IN PRAISE OF HETEROGENEITY: ABOUT THE FURTHER CO-EVOlUTION OF SCIENCE AND SOCIETY}

Heterogeneity was what we saw when we lifted the homogenising cover off SCIENCE. This then is an argument for maintaining heterogeneity and not being concerned overmuch with a loss of autonomy of science-aswe-knew-it. Pure science, if it ever existed, was a result (and to some extent, a tactic for legitimacy) of a particular institutional arrangement in the $19^{\text {th }}$ century German universities and in the research universities in the USA (and elsewehere) which emulated them.

What we also saw was how Western science, that is science-as-weknow-it as "Westerners", has co-evolved with society - i.e. Western societies. In that sense, its shape and to some extent its contents are historically contingent. The co-evolution continues and with a broader sense of society than before. Science cannot continue its well-intentioned imperialism without adapting to the further heterogeneities. Issues of sustainable development bring out the possibilities and the tensions. As the UK ESRC Science in Society Research Programme (200I) notes:

international environmental negotiations often pit Northern scientists, governments, and NGOS, acting in the name of a global sustainable development agenda that is heavily informed by the earth sciences, against Southern governments and citizen organizations, whose concept of sustainable development is focused on more local needs and local knowledge. 
A tension which has to be made tractable, somehow.

Gibbons et al. (I994) argue that Mode 2 is characterised by an increasing heterogeneity in the cultivation of science. In their more triumphant moments Mode 2 has the future to itself, especially when more and more people listen to their diagnosis. My concern is with the basic richness of knowledge production and the way various "modes" impinge on it. Regimes and institutionalized modes of knowledge production discipline the richness, unavoidably so, but (hopefully) not so as to completely contain it. In combination with a particular institutional arrangement and overall societal legitimation, a lock-in can emerge which limits the co-evolution to specific paths. The academic-disciplinary Mode i of Gibbons et al. (I994) is an example of such a locked-in socio-epistemic constellation, and their Mode 2 might become one.

Lock-ins will always occur, but some lock-ins are better than others. My plea for maintaining heterogeneity, at least for the time being, can then be positioned as a way to escape too rapid lock-ins. Under conditions of uncertainty, it is only prudent to maintain variety. But heterogeneity is valuable in its own right. This is why I highlighted natural history as a way to embrace variety and recognize patterns rather than go all out in controlling the world.

The heterogeneity that is encountered at the moment can be deplored as threatening science-as-we-know-it. But it can also be seen as a kind of melting pot, and one similar in terms of openness and variety to the melting pot of the European Renaissance. If the I7th century represented an unprecedented shift in the socio-cognitive history of science, it is important to look more closely into the nature of knowledge production before that time, in the I4th to I6th century European Renaissance.

For a birthplace of Western science as-we-know-it, it looked messy, unruly, and without clear boundaries between various knowledges. There were the (medieval) universities and travelling humanists, artists and engineers. There were also almanac makers, astrologers, mountebanks and ciarlatani performing tricks at the fairs. Princes and wealthy persons were sought as sponsors, the scholarly work and craftwork to be done were defined in terms of their wishes and aspirations, as well as those of the marketplace. 
One intriguing variety of knowledge production was through so-called 'professors of secrets'. They collected recipes from different crafts and some of their own experience, and sold them at the fairs or to sponsors. The ambivalence in their position is curiously similar to that of biotechnologists and other scientists in commercially important areas. They had to advertise themselves and their knowledge in order to create some visibility. However, at the same time they had to keep their secrets in order to maintain a competitive advantage over other such 'professors' operating at the same market or for the same sponsors (Eamon 1985).

The so-called scientific revolution of the I7th century replaced unruliness with proper procedure (in scientific academies) and started to create boundaries between mechanical philosophy and the crafts (Van den Daele I977a, b). Whether one sees this as an achievement or as de-humanisation (Toulmin I990), the rationalistic mode of knowledge production which eventually emerged has grown out of the fertile soil of the Renaissance. The richness, variety and openness of knowledge production at the time were important for the scientific revolution. And it remained, and remains, important as a backdrop to high science and as a source of renewal.

The recognition of the role of heterogeneity is particularly important to appreciate different cultures: within science, and in the various "trading zones", but also in society in general, at a time when multiculturalism is increasing, and attempts are being made to define an African Renaissance with its own kind of knowledge production, or to have Islamic science differ from Western science. Worldwide, there is an "indigenous Renaissance" (Battiste 2000), and to support indigenous knowledge efforts has become politically correct. While my emphasis on the importance of heterogeneity can be read as an argument for a multicultural scenario, and I would be willing to make such an argument, there is also the idea of a "melting pot" and thus the need to avoid high fences between the cultures.

Productive knowledge production requires some further specification, however, and some closure of epistemic debate. One such provisional closure refers to the status and productive use of expertise, in regulatory science and in attempts to create (precariously) new and authoritative forums. Another provisional closure is the allowance of different cosmovisions referring to different cultural backgrounds: indigenous knowledge 
versus Western science, but also Muslim, Chinese or Japanese approaches to knowledge production. To accept the knowledge claims from the different cultural backgrounds as rightful is politically correct. But such a multicultural scenario has to be checked for how productive its alignments are, that is, how essential tensions can be made tractable.

There are risks when cultural communities take over the quality control that used to be effected by disciplinary communities. The same exclusionary tactics will be involved ("we are the only ones who can judge"), but these tactics will foreground cultural heritage rather than new knowledge production. The multicultural scenario can be traced and evaluated because funding programs and national science policy in a number of countries have special support and funding for indigenous knowledge. Pressures to do so are bottom-up, with the advent of an "indigenous Renaissance" worldwide (Battiste 2000), and top-down, with the political correctness of supporting indigenous knowledge efforts in countries like South Africa and New Zealand.

I shall take New Zealand's funding of Maori Knowledge and Development research as a test case for the multicultural scenario. I shall refer back to some disciplinary tribes within Western science, to relativize the contrast between indigenous knowledge and high science.

High fences might well be raised, and the protected space may become a strong shelter from outside influences. By way of example, I shall present a mini-scenario (with an added twist). There is a special budget in New Zealand's Science Vote for Maori Knowledge and Development, which is translated into dedicated portfolios of the science funding agencies. Maori Development research must be by the Maori, for the Maori, and work from a Maori world view and approach to knowledge (kaupapa Maori). In addition, the conduct of research must adhere to tikanga Maori, customary practices and principles, including the judgment of what looks right. ${ }^{25}$ High-level (non-Maori) science policy officials insist that "Maori worldviews have equal status alongside Western science." In the funding agencies and the research-performing institutions, there is a tendency to go for projects where Maori knowledge of a natural history kind is input for a Western-style research project. From the side of the Maori, there is insistence on a layered view of knowledge with differential access. This justifies 
the limitation of participation to researchers who identify and belong, and general restrictions of access to community and personal knowledge (and the additional issue of communal intellectual property rights).

Does this imply that assessment of research proposals and research results must be done by Maori, and that quality will be defined as following a Maori approach? This will be politically correct, but there will be a danger of a closed-shop. Therefore, "trading zones" are important between indigenous knowledge and Western science, but also between quality-control communities and the wider world. The necessary translations and transformations need not be in place yet, but the challenge to create them is important.

The added twist is the comparison with old-boys' networks in Western science. And relatedly, of "pockets" of research continuing more or less on their own terms, like high-energy physics. John Ziman (I98I) once portayed them as the HEP tribe (joined precariously with the HET tribes). Their kaupapa is more esoteric than that of the Maori, and they have their tribal norms, and tikanga more generally (Traweek I988). In other words, if one condemns Maori-development research, one might also have to condemn high-energy physics.

Closed-shops are protected spaces at the meso-level, which can be maintained as long as the circumstances are right: financial and professional resources for ever more ambitious particle accelerators in high-energy physics, political and cultural resources (and over time, human resources) for Maori Knowledge and Development research.

In both cases, I would want the protection to be partial only and have outsiders, sympathetic or otherwise, involved in assessing the robustness of the knowledge being produced. Support for indigenous knowledge is often argued in terms of overcoming colonialism, while support for highenergy physics is claimed because it extends the frontiers of knowledge (with the implicit imperialism that such extensions are the right of highenergy physics). In both cases, one must have a closer, no-nonsense look at the knowledge production, using the ideas of robustness and variety of modes of knowledge production set out in Section 2 of this essay.

There are other scenarios for science and knowledge production in the $2 \mathrm{I}^{\mathrm{st}}$ 
century. There is the brave new world of biotech, genomics, and nanotechnology. These developments are undoubtedly important. But the promises will be fulfilled (if at all) in a process of co-evolution between science and society - where versions of multiculturalism will be important, as for example currently in the differences in appreciation of genetic modification of plants, animals, and perhaps humans.

There is also the pervasive role of information and communication technologies. In my diagnosis of the situation of knowledge production, the new natural history approaches are the key development for science in the $2 \mathrm{I}^{\text {st }}$ century. Information and communication technologies are not just an important support to the new natural history, but also help shape its contents. One striking phenomenon is how information and communication technologies can address issues of indigenous knowledge, for example in making layered access to knowledge possible.

In all scenarios, a recurrent issue is the quality of the knowledge which is produced and taken up. My analysis in terms of robustness, protected spaces and agonistic interactions allows me to specify, in conclusion, a number of requirements for the processes and arrangements for robust knowledge production. Such requirements could be used to evaluate possible scenarios, but also for real-life developments that invite reflection and action.

Briefly, almost aphoristically:

- Profit from lab science, that is, insights and effects derived under controlled conditions, but without being overwhelmed by its promising possibilities. There is more complexity in the world than can be shoveled away by pushing for controlled conditions.

- Give old and new 'natural history' modes of knowledge a central place in their own right, and to address major issues of environment and sustainability.

- Forget about disciplines as traditionally defined and kept apart and develop a patchwork of partially overlapping domains of knowledge production (which are present anyhow). Include the social sciences and humanities in the spectrum (Rip I995). Domains of knowledge production might be defined in terms of specific approaches and world views, but only when openings for agonistic interaction remain. 
- Instead of going for interdisciplinarity as a goal, develop heterogeneous knowledge management. The present interest in interdisciplinary research is an effect of the hold disciplines have on doing science, and the wish to overcome the hold, rather than there being value in interdisciplinary research as such. A lateral approach would be to start from the possibility to "manage" knowledge and its arrangements and constellations, and develop ways to manage heterogeneous knowledge production. There are intriguing examples, as when indigenous knowledge (of Zulu farming women, of medicine men and women), NGOS, agricultural extension services and research stations, and worldwide agricultural and rural development insights and findings form a patchwork quilt in ongoing attempts to improve subsistence agriculture in a valley in Kwazulu-Natal in South Africa. ${ }^{26}$

- The input from new stakeholders gets regularized, starting with their role as spokespersons for abstract sponsors, say Greenpeace for susTAINABILITY, patient associations for HEALTH (cf. Callon et al. 200I), etc. This is actually a further differentiation and institutionalization of what counts as the interface between science and society. As a mesoand macro-protected space, it can (and should) be evaluated in terms of its potential for robust knowledge production.

- Public involvement more generally based not on so-called public understanding of science, but on public appreciation which includes skills like 'science savvy' and 'scientific connoisseurship. ${ }^{27}$

- There will be links between the levels of the systems of knowledge production, up to partial lock-ins in the form of nested spaces. This can be productive, but openings and interstices must remain.

There is no guarantee that such requirements will overcome the essential tension between search and authority (including the implied authority of existing institution and the social order). But it can make it tractable: productive work is possible, and change is not prohibited.

My storyline has emphasised a three-level dynamic: (i) varying, heterogeneous practices of knowledge production, (ii) meso-level organisations, institutions with their inertia and openings for change, and (iii) possible lock-ins when interactions with environments are (re)structured as a protected space. I then argued for opening up such protected spaces, or at 
least be reflexive about them and keep their boundaries permeable.

This perspective and the suggestions for action are not in the modernist vein, where challenges are identified and actors rise to meet them. It is a reflective approach: looking back, identifying paths taken and their alternatives, trying to see how these may shape the present and the future. And then trying to modulate the dynamics, based on this understanding and on further reflection on their value.

\section{Notes}

I As Kuhn (I977) phrased it and Polanyi (I963) experienced it.

2 See Law (I994) about the search for "root order" as the basic project of modernity itself, and its link with two more ancient traditions: "a monotheistic commitment to a single source of knowledge, and the hegemonic commitment to spread the good news" (quotes from p. 7), and Latour (I99I) about "purification" as the thrust of modernity, while its practices continue to be replete with "hybrid monsters".

3 In this essay, I use 'science' in the Anglo-Saxon sense, where it can be contrasted with the humanities (and with the hybrid category of 'social sciences'). Continental European countries have a tradition of Wissenschaft which encompasses the whole range. When the Royal Netherlands Academy of Sciences (KNAW) wants to indicate the range of scholarly work it covers, it has to use convoluted phrases like RNA of Sciences and Letters, or Sciences and Arts, or Sciences and Humanities. These reflect historical and institutional distinctions. Epistemologically, one can envision new arrangements (Rip I995).

4 In an official study of the US National Academy of Sciences on the future of physics, one finds these claims about physics: "Physics is in many ways the parent of the other physical sciences (..) Well under way (..) is nothing less than the unification of the physical sciences. (..) the basic contribution of physics is the secure foundation on which all this knowledge is built - on understanding, confirmed by the most stringent experimental tests, of the interactions between elementary particles and the ways in which they determine the structure of atoms and molecules. (..) Biology obviously derives part of its nourishment from physics by way of chemistry." (Bromley I972, p. 67 and 69-70). See Rip (I979) for further 
analysis of such reports as one site where the scientific picture of the world becomes visible.

5 The terminology here derives from Latour (I987) and has been taken up widely (also by Nowotny et al. 200I), but the point does not depend on the particular terminology. It has has been discussed under other headings, for example 'context of discovery' and 'context of justification', and their linkages (Böhme, Van den Daele and Krohn I972, Schaeffer 1983).

6 Think also of the 'black arts' of adding compounds and materials to a product formulation to make it actually work, whether with vaccines or herbicides or the composition of the bath in electroplating - these are not mentioned when scientific knowledge is celebrated for its practical powers. For vaccines and the adjuvants necessary to make them work, see for example Turnbull (2000), on the malaria vaccine. For herbicides, see how in an interview with a spokesperson from Monsanto, questions about such additives led to breaking off of the interview (F. Valkema, Chemisch Weekblad, 25 August 200I, p. 3). Electroplating, to be effective, requires the addition of some organic chemicals. But nobody knows why exactly. And firms tend to be protective about their preferred mixes.

7 Quakenbusch, one of the directors of TIGR, The Institute for Genomic Research, in the USA, spoke at the Genomics Conference in The Hague, 6 November 200I, at which the major research funding efforts in this field in the Netherlands were presented. It is more than a data management issue: "Swimming in a rapidly rising sea of data - how to keep from drowning?", as another speaker at the Conference put it.

8 From an interview in NRC Handelsblad, I7 November 200I, at the occasion of Van Gunsteren's NWO-Huygens lecture in The Hague. Van Gunsteren also noted the first simulation of the formation of a membrane from an arbitrary collection of fatty acids in water, this year in Groningen, by Siewert-Jan Marrink and Alan Mark.

9 This section draws heavily on my scoping paper for the ESTO project on Technological Risk and the Management of Uncertainty, commissioned by the Forward Studies Unit of the European Union. A synthesis of the four scoping papers written for this project has been published (Stirling I999), but does not emphasize the points I am using in this essay.

Io Ziman (I978) similarly emphasizes how attempts to exclude disturbing factors still leave the ambiguity of whether the observed effect is real or a result of a "dirty system" (p. 59). Thus, "Physics is the harvest of this Kantian fisherman, whose 
net only catches fish larger than the size of its mesh, and who proudly proclaims as a 'law of nature' that all fish are larger than that size." (p. 30) The additional point is that there are many tribes of fishermen. In another study, Galison analysed the interaction between the experimental physicists, the engineers and the theoretical physicists in high-energy particle accelerator experiments and noted how this resembled a "trading zone" - as between USA soldiers and American Indians in the I9th century (Galison I997).

II The inferential route towards an interpretation or explanation resembles design: there is first an idea, a sketch, related to a notion of why the envisaged artefact would work. Then it must be made to come true, including tests of a prototype. In both cases, something new is created which has to "work". In both cases, also, a path is followed, starting with the original idea, further shaped by initial attempts to elaborate it and by the tests that are done. The original idea might well be modified in the light of such experiences. The eventual, more or less robust knowledge claim or design derives its robustness from the quality of the path that has been followed, as well as from its properties here and now. If the result is still unsatisfactory, one may have to start again, redefine the path as it were. This is a well-known challenge in design. For knowledge claims, the researcher tends to identify with the path s/he has followed, and it is other researchers (especially when they contest the knowledge claim) who go for a different path. The further implication, highlighted in recent sociology of knowledge, is that contesting knowledge claims often cannot be assessed definitively because they are part of different paths, for example, based on different experimental set-ups, assumptions about parameters, etc.

I2 In his study of missile guidance technology, Donald MacKenzie addressed the issue of uncertainties, for example in the guidance system and in the assurance of the missile reaching its target, and showed that tolerance for uncertainty differs across various relevant groups (MacKenzie I990; 370-372).

I3 Some scholars in the sociology of knowledge have emphasized a methodologically relativist approach to truth, but that is not my intention. It would get me entangled, unnecessarily, in what has been called the Science Wars (see Hacking (I999) for an analysis). My aim is to understand better what it is that makes findings and knowledge claims robust.

I4 NRC Handelsblad, 25 August 200I. Information about the Program can be found at http://doegenomicstolife.org/

I5 The book has been translated into English and continues to be reprinted. Of the 
I948, still available edition by Dover Publications (New York), M.G.J. Minnaert, The Nature of Light and Colour in the Open Air, a reader commented on the Amazon website: "still up to date". A new translation with additional photographs appeared in I993 (M.G.J. Minnaert and Len Seymour, Light and Colour in the Outdoors, New York etc.: Springer Verlag).

I6 Philosophically, this is a constructive realist position: regularities are real, but constructed (cf. Bhaskar I975). The construction has cognitive and material aspects, as brought out nicely in J.D. Bernal's aphorism: "Science, in one aspect, is ordered technique; in another, it is rationalized mythology." (Quoted from his Science in History by Rip (1982), on p. 219.) The further point, recurrent in this essay, is that such construction involves a hopefully productive reduction of complexity.

I7 The phrase 'translations and transformations' is an attempt to capture the meaning of the French term "translation" as used in actor-network theory (Callon et al. I986): shifting others (and oneself) in order to transform a situation, with attendant translations ("traduction" in French).

I8 Field sciences cannot give up on local idiosyncracies: "unlike laboratories, natural sites can never be exclusively scientific domains" (Rees (200I), at p. 507, quoting Kucklick and Kohler). And should not give up: "The study of the natural world actually remains highly site-dependent and regional in character." (Williams 2000, at p. 503)

I9 See for example the re-issue of their book, Prigogine and Stengers (1989).

20 Interestingly, as I intimated already, models are a micro-cosmos, in which fragments of high science findings are applied together with ad-hoc, intuitive or experience-based structuring.

2I In I987, Beecham (and other pharmaceutical companies) introduced a product that was expected to reduce the resistance of bacteria against penicillin (Chemisch Weekblad, 2 July I987, p. 272). Come I997, molecular biologists, in their labs, found ways to disarm bacterial resistance genetically - but the problem is whether this will help in the real world, with organisms that multiply very, very fast (New Scientist, 9 August 1997, p. 4). For new pesticides, some regulatory agencies now require an assessment of resistance which might be built up after applying such a pesticide on a larger scale.

22 See Whitley (I984) on the smallest units of scientific organization and Rip (I985) on the transformation of local, non-disciplinary knowledge production into scientific papers. 
23 This way of formulating the point resembles the finalisation and functionalization thesis of the Starnberg group (Schäfer I983) but does not depend on their overall (and physicalist) diagnosis of the development of Western science.

24 In Nowotny et al. (200I), the sequel to the Gibbons et al. (I994) thesis on Mode I and Mode 2, some of these elements are discussed.

25 For in-depth discussion, see Smith (2000). Details of the science funding set-up can be found at the Ministry's website, including a report on a workshop from which I drew my quotes (http://www.morst.govt.nz/creating/maori).

26 This claim is based on ongoing work in a comparative project led by Jan-Douwe van der Ploeg of Wageningen Agricultural University, in which local approaches in agriculture in the Netherlands, Italy and Kwazulu-Natal are studied.

27 'Scientific connoisseurship' is "the capacity to make informed judgements about scientific claims and to judge the competence and credibility of individuals and institutions who are presented as scientific experts or arbiters of scientific expertise" (Economic and Social Research Council 200I).

\section{REFERENCES}

Battiste, Marie (ed.) (2000), Reclaiming Indigenous Voice and Vision, Vancouver and Toronto: UBC Press.

Bhaskar, Roy (I975), A Realist Theory of Science, Leeds: Leeds Books Ltd.

Biagioli, Mario (1993) Galileo, Courtier. The Practice of Science in the Culture of Absolutism. Chicago: Chicago University Press.

Böhme, Gernot, Wolfgang van den Daele, Wolfgang Korhn (I972), 'Alternativen in der Wissenschaft', Zeitschrift für Soziologie 1, 302-316.

Böhme, Gernot, Van den Daele, Wolfgang, Krohn, Wolfgang (I977) Experimentelle Philosophie. Ursprünge autonomer Wissenschaftsentwicklung. Frankfurt a/Main: Suhr-kamp.

Bromley, D.A. (I972), Chairman of the NAS Physics Survey Committee, Physics in Perspective. Washington, D.C.: National Academy of Sciences.

Brown, Jr., George E. (I996), Environmental Science Under Siege. A Report by Repr. George E. Brown, Jr., US Congress, Oct. 23, I996.

Bush, Vannevar. (1945). Science - The Endless Frontier. A Report to the President on a Program for Postwar Scientific Research, Washington, D.C.: July I945. Reprinted, 
with Appendices and a Foreword by Daniel J. Kevles, by the National Science Foundation, Washington, D.C., I990.

Callon, Michel, John Law, Arie Rip (eds.) (I986), Mapping the Dynamics of Science and Technology. Sociology of Science in the Real World, London: Macmillan.

Callon, Michel, Pierre Lascoumes, Yannick Barthe (200I), Agir dans un monde incertain. Essai sur la démocratie technique, Paris: Éd. du Seuil.

Cambrosio, Alberto, Camille Limoges and Eric Hoffman, 'Expertise as a Network: A Case Study of the Controversies over the Environmental Release of Genetically Engineered Organisms', in Nico Stehr and Richard V. Ericson (eds.), The Culture and Power of Knowledge (Berlin and New York: De Gruyter, I992), 34I-36I.

Campbell, Donald T. (I979), 'A Tribal Model of the Social System Vehicle Carrying Scientific Knowledge', Knowledge 1(2) (December) I8I-20I.

Casimir, Hendrik (1983), Haphazard Reality. A Half Century of Science, New York: Harper and Row.

Collins, H.M. (I974), 'The TEA Set: Tacit Knowledge and Scientific Networks', Science Studies 4, I65-186.

Collins, H.M., Changing Order. Replication and induction in scientific practice, London: Sage, I985.

Eamon, W. (I985), 'From the Secrets of Nature to Public Knowledge: The Origins of the Concept of Openness in Science', Minerva, 23(3): 32I-347.

Economic and Social Research Council (UK) (200I), Science in Society Research Programme, downloaded on I7 November 200I from http://www.esrc.ac.uk/ ESRCContent/researchfunding/scisoc.asp.

Etzkowitz , H. and L. Leydesdorff (2000), 'The dynamics of innovation: from National Systems and "Mode 2" to a Triple Helix of university-industry-government relations,' Research Policy 29 I09-I23.

Peter Galison, How Experiments End, Chicago and London: University of Chicago Press, I987.

Galison, Peter, 'Trading Zone. Coordinating Action and Belief,' in Mario Biagioli (ed.), The Science Studies Reader. New York and London: Routledge, I999, pp. I37I60.

Gibbons, M., Limoges, C., Nowotny, H., Schwartzman, S., Scott, P. and Trow, M., (1994) The New Production of Knowledge. The dynamics of science and research in contemporary societies, Sage, London.

Hacking, Ian (I992) 'The Self-Vindication of the Laboratory Sciences', in Pickering, pp. $29-64$. 
Hacking, Ian (1999), The Social Construction of What? Cambridge, Mass.: Harvard University Press.

Hufbauer, Karl (I982) The Formation of the German Chemical Community (1720-1795). Berkeley: University of California Press.

Krohn, Wolfgang, and Johannes Weyer (I994), 'Society as a Laboratory: the social risks of experimental research', Science and Public Policy 21(3) (June) I73-I83.

Kuhn, Thomas S. (I970), The Structure of Scientific Revolutions. Chicago: University of Chicago Press. Second, enlarged edition.

Kuhn, Thomas S. (I977), The Essential Tension. Selected Studies in Scientific Tradition and Change, Chicago: University of Chicago Press.

Latour, Bruno (I983), 'Give me a laboratory and I will raise the world,' in Karin KnorrCetina and Michael J. Mulkay (eds.), Science Observed, London: Sage, pp. I4I-I70.

Latour, Bruno (1984), Les Microbes. Guerre et Paix. Suivi de Irréductions. Paris: A.M. Métaillié.

Latour, Bruno (1987), Science in Action. How to follow scientists and engineers through society, Milton Keynes: Open University Press.

Latour, Bruno (I99I), Nous n'avons jamiais été modernes. Essai d'anthropologie symétrique, Paris: Éd La Découverte.

Law, John (I994), Organizing Modernity, Oxford: Blackwell Publishers.

Lipton, Peter (I99I), Inference to the best explanation, London: Routledge.

Mar, B.W., W.T. Newell, B.O. Saxberg (eds.) (I985), Managing High Technology: An Interdisciplinary Perspective, Amsterdam etc.: North-Holland.

Marrink, Siewert-Jan (I994), Permeation of Small Molecules Across Liquid Membranes. A Molecular Dynamics Study. PhD Thesis, University of Groningen, I994.

McGee, Michael Calvin (I980) 'The 'Ideograph': A Link Between Rhetoric and Ideology', Quarterly Journal of Speech 66 (Feb.): I-I6.

Mendelsohn, Everett, Peter Weingart and Richard Whitley (eds.) (I977), The Social Production of Scientific Knowledge, Dordrecht: Reidel.

Mpemba, E.P. and D.G. Osborne (I969), 'Cool?', Physics Education 4. I72-I75.

Nowotny, Helga, Peter Scott and Michael Gibbons (200I), Re-Thinking Science. Knowledge and the Public in an Age of Uncertainty, Cambridge: Polity Press.

Polanyi, M. (I963), 'The potential theory of adsorption. Authority in science has its uses and its dangers', Science, I4r:Ioro-Ior3.

Prigogine, Ilya, and Isabelle Stengers (1989), Order out of chaos: Man's new dialogue with nature, New York: Bantam Doubleday Dell. Paperback re-issue. 
Rees, Amanda (200I), 'Practising Infanticide, Observing Narrative: Controversial

Texts in a Field Science', Social Studies of Science 31 (August) 507-531.

Rip, Arie (I979), 'Science Policy and the Scientific Picture of the World', in W.

Callebaut, M. de Mey, R. Pinxten, F. Vandamme (eds.), Theory of Knowledge and

Science Policy, Ghent: Communication and Cognition, University of Ghent, 358-377.

Rip, Arie (I982), 'The Development of Restrictedness in the Sciences', in N. Elias, H.

Martins and R. Whitley (eds.), Scientific Establishments and Hierarchies, Dordrecht:

Kluwer, pp. 219-238.

Rip, Arie (I985), 'Interdisciplinarity without disciplines? A view from the sociology of

science', in B.W. Mar, W.T. Newell, B.O. Saxberg (eds.), Managing High

Technology, Amsterdam: Elsevier Science Publishers, I985, pp. I85-I92.

Rip, Arie (I992), 'Expert Advice and Pragmatic Rationality', in Nico Stehr and Richard

V. Ericson (eds.), The Culture and Power of Knowledge, Berlin and New York: De

Gruyter, 357-373.

Rip, A. (I995), 'New Combinations', European Review 3(I), 83-92.

Rip, A. (I997) A Cognitive Approach to Relevance of Science, Social Science

Information, 36(4): 615-640.

Rip, Arie (2000a), 'Fashions, Lock-Ins, and the Heterogeneity of Knowledge

Production', in Merle Jacob and Thomas Hellström (eds.), The Future of Knowledge

Production in the Academy. Buckingham: Open University Press (2000), 28-39.

Also published in Andre Kraak (ed.), Changing Modes. New Modes of Knowledge

Production and its Implications for Higher Education in South Africa, Pretoria:

Human Sciences Research Council, 2000, 56-69.

Rip, Arie (2000b), 'Higher forms of nonsense,' European Review 8(4) 467-485.

Rip, Arie (2002), 'Societal Challenges for R\&D Evaluation', in Phil Shapira and Stefan

Kuhlmann (eds.), Learning from Science and Technology Policy Evaluation:

Experiences from the United States and Europe. Cheltenham: Edward Elgar.

Rip, Arie, and Barend J.R. van der Meulen, 'The Post-Modern Research System',

Science \& Public Policy 23 (5) (Dec. I996) 343-352. Also published in Rémi Barré,

Michael Gibbons, Sir John Maddox, Ben Martin and Pierre Papon (eds.), Science

in Tomorrow's Europe (Paris: Economica International, 1997), pp. 5I-67.

Rip, A. and F.A.J. van Steijn (1985), Effecten van de stimulering van de biotechnologie op de academische cultuur en de mogelijkheden tot kennisoverdracht (Amsterdam: Dept. Science Dynamics, I985). A Report to the Government Office of Science Policy. 
Also published in Maatschappelijke aspecten van de biotechnologie (Den Haag: Staatsuitgeverij, dec. I985) I69-I90.

Ross, Sydney (I962), 'Scientist: The Story of a Word', Annals of Science 18, 65-85. Schäfer, Wolf (ed.) (1983), Finalization in Science. The Social Orientation of Scientific Progress, Dordrecht etc.: D. Reidel.

Shapin, Steven, A Social History of Truth. Civility and Science in Seventeenth-Century England. Chicago and London: Universit of Chicago Press, I994.

Shove, Elizabeth, and Arie Rip, 'Users and unicorns: a discussion of mythical beasts,' Science and Public Policy, 27(3) June, I75-I82.

Slack, Jonathan (I972), 'Class struggle among the molecules', in Trevor Pateman (ed.), Countercourse, Harmondsworth: Penguin, pp. 202-2I7.

Smith, Linda Tuhiwai Te Rina (2000), 'Kaupapa Maori Research', in Battiste, Marie (ed.) (2000), Reclaiming Indigenous Voice and Vision, Vancouver and Toronto: UBC Press, 225-247.

Stemerding, Dirk (I991), Plants, Animals And Formulae. Natural history in the light of Latour's Science in Action and Foucault's The Order of Things, Enschede: Faculteit Wijsbegeerte en Maatschappijwetenschappen, Universiteit Twente.

Stirling, Andrew, On Science and Precaution in the Management of Technological Risk. Volume 1. A synthesis report of case studies. Brussels/Luxembourg: European Commission, I999. A report based on four evaluative survey studies: formal decision analysis and economics (Salo), institutional and regulatory policy analysis (Renn and Klinke), science and technology studies (Rip), risk assessment and environmental appraisal (Stirling).

Troyer, Ronald J., and Gerald E. Markle (1983), Cigarettes. The Battle over Smoking, New Brunswick, N.J.: Rutgers University Press.

Toulmin, S. (I990) Cosmopolis. The hidden agenda of modernity, University of Chicago Press, Chicago.

Traweek, Sharon (I988), Beamtimes and Lifetimes: The World of High Energy Physicists, Cambrdige, Mass.: Harvard University Press.

Turnbull, David (I998), 'Travelling Knowledge: Narratives, Assemblage and Encounters,' draft text for Instruments, Travel and Sciences: Itineraries of Precision in the Natural Sciences, Berlin: Max Planck Institute for the History of Science.

Turnbull, David (2000), Masons, Tricksters and Cartographers, Amsterdam: Harwood Academic Publishers.

Van den Belt, Henk, and Arie Rip (I987), 'The Nelson-Winter/Dosi model and synthetic dye chemistry', in Wiebe E. Bijker, Thomas P. Hughes and Trevor J. 
Pinch (eds.), The Social Construction of Technological Systems. New Directions in the Sociology and History of Technology, Cambridge, MA: MIT Press, pp. I35-I58.

Van den Daele, Wolfgang (I977a) 'Die soziale Konstruktion der Wissenschaft Institutionalisierung und Definition der positiven Wissenschaft in der zweiten Hälfte des I7. Jahrhunderts', in Böhme et al., pp. I29-I82.

Van den Daele, Wolfgang (I977b), 'The Social Construction of Science:

Institutionalization and Definition of Positive Science in the Latter Half of the I7th Century', in Mendelsohn et al. (I977), 27-54.

Van der Ploeg, Jan Douwe, Labor, Markets, and Agricultural Production. Boulder etc.:

Westview Press, I996. Ch. 3, Potato Production in the Peruvian Highlands.

Van Lente, Harro (1993), Promising Technology - The Dynamics of Expectations in

Technological Developments, Enschede: Faculteit Wijsbegeerte en

Maatschappijwetenschappen, Universiteit Twente.

Verran, Helen (2001), Science and an African Logic, Chicago: University of Chicago Press.

Von Schomberg, René (I997), Argumentatie in de context van een wetenschappelijke controverse. Een analyse van de discussie over de introductie van genetisch gemodificeerde organismen in het milieu, Delft: Eburon. PhD Thesis, University of Twente.

Watson-Verran, Helen, and David Turnbull, 'Science and Other Indigenous

Knowledge Systems,' in Jasanoff et al. (I995), II5-I39.

Webster, Andrew (I994) 'University-Corporate Research Ties and the Construction of Research Agendas', Sociology, 28: I23-I42.

Westrum, Ron (I978), 'Science and Social Intelligence About Anomalies: The Case of Meteorites', Social Studies of Science 8, 46I-493.

Whitley, Richard (1984) The Intellectual and Social Organization of the Sciences. Oxford: Clarendon Press.

Williams, Dee Mack (2000), 'Representations of Nature on the Mongolian Steppe: An Investigation of Scientific Knowledge Construction', American Anthropologist 102(3) 503-519.

Wynne, Brian (I99I), 'After Chernobyl: science made too simple?' New Scientist, 26 January, pp. 44-46.

Wynne, Brian, 'May the sheep safely graze? A reflexive view of the expert-lay knowledge divide,' in Scott Lash, Bronislaw Szerszynski and Brian Wynne (eds), Risk, Environment and Modernity: Towards a New Ecology (London: Sage, I996), $44-83$. 
Ziman, John (I978), Reliable Knowledge. An exploration of the grounds for belief in science, Cambridge: Cambridge University Press.

Ziman, John (198I), Puzzles, Problems and Enigmas. Occasional Pieces on the Human Aspects of Science, Cambridge: Cambridge University Press, 93-98. ('A Very Strange Tribe', originally published as Foreword to Originality and Competition in Science: A Study of the British High Energy Community, by Jerry Gaston, University of Chicago Press, I973.)

Ziman, John. M. (1994) Prometheus Bound: Science in a Dynamic Steady State. Cambridge: Cambridge University Press. 


\title{
Redrawing Disciplinary Boundaries - but to What Degree? I
}

\author{
Aant Elzinga
}

First of all, let me say that I agree with the main point of Prof. Rip's contribution, viz., the need to keep an open mind and affirm the plurality of forms of production of knowledge. Science as socially contingent but protected institutional space generates both awe and envy. Indeed, in the balance between search and authority, primacy to the serendipitous nature of the former has to be upheld in the sometimes stifling face of the latter. His demonstration of the historically situated and contingent character of the traditionally dominant image of science, the one that has tended to extrapolate and totalize a small physics-oriented segment in existing knowledge landscapes, is both perceptive and appreciated.

The dominant academic image, as he points out, was largely a projection of a very specific set of conditions and features in particular historical circumstances, reinforced in the $20^{\text {th }}$ century by the advent of logical empiricist philosophers. Later it was found that not even physics lived up to its ideals (cf. N.R. Hanson, P. Feyerabend, S. Toulmin, T. Kuhn). With the emergence of a new (cognitive) sociology of science, combined with interest in policy, attention has been drawn to many other modes of science, among them medical and agricultural, engineering and not least chemical research, where trajectories have involved constant interfoliation with practical pursuits, in so-called contexts of application.

As a counterpoint today to the mainstream image of autonomous academic science traditionally celebrated in the epistemological lens of the analytic philosophy of science, sociologists and policy analysts have come up with the notion of Mode 2 and university-industry-governmental triplehelix complexes. Likewise, interdisciplinarity is played up in retrospective contrast to so-called Mode I monodisciplinary academic science, which in the polemics of the situation is highly schematized, thus paradoxically lending force to the earlier particularism that is to be rejected. 
Arie Rip argues that also these new images of scientific knowledge production have a social epistemology that is rather limited in scope. They are ideologically coloured totalizations of another segment of the knowledge production landscape. In the new metaphors, contexts of application tend to converge with domains of privatization and commodification, even if in the face of criticism some latter-day advocates of the newer images have retreated to a position of wanting to give recognition to non-commercial users, NGOs and representatives of civil society. Still, if one looks more closely, the projection of these new models largely takes events in areas like biotechnology and microelectronics and now increasingly also research into advanced industrial materials as their main reference. Thus, they are caught up in propagating a new particularism while claiming generality. In my estimation they conflate technical characteristics of semiautomation in knowledge production with specific modes of intellectual property and the science-society interface. Arie Rip's words of caution are timely, but they could have been formulated more sharply.

The points that I wish to raise for discussion, and where we perhaps diverge to some extent, are the following:

a What will happen to disciplines in the $2 \mathrm{I}^{\text {st }}$ century?

b Is what we are witnessing today in the advances of computational methods and semi-automated techniques for data processing, pattern recognition and the like really a return to natural history?

With regard to the first question, certainly something has happened in the scientific disciplines. There has been a proliferation of subspecialities, and greater permeability between knowledge domains. In my own university 30 years ago, the physics department had one seminar, whereas today there are 20 parallel seminars in the same but much expanded and differentiated department. Still physics, chemistry, geology, biology, pathology, glaciology, genetics, etc., remain the primary areas in which one is certified as an undergraduate major. The same cores are also relevant in designating PhDs. The major learned societies joined by ICSU, "classes" in academies of sciences and arts, and the workings of the Nobel prize institution continue to do their share in undergirding disciplinary divisions and identities. Job announcements in the journal Science, even when recruiting for positions in bioinformatics and proteonics, most often call for 
a strong core foundation in classical genetics, pharmacology, biology, computer science or applied mathematics. Solid expertise in a primary core discipline also remains in other fields like radio astronomy, geomorphology, oceanography, etc. Here, too, computational methods and vizualization technologies have a strong impact, but without the lucrative monetary profits and hence without the mega-amounts of private funding to speed things up and render them equally visible and talked about as the hybrid domains of biomedicine or nanotechnology.

Arie Rip himself refers to his own background in chemistry in a way that indicates the resilience of residual primary certification and associated professional identities.

Apart from the inertia of institutional arrangements of primary certification, there is a second aspect, onelargely missing in Prof. Rip's account. I have in mind the way the world is; he mentions it in his abstract when he says "the complexities of the natural world are striking back, and this requires a renewed natural history approach". However, in the bulk of his essay there is very little to suggest that the irreductive specificity of systemic (emergent) properties central to different dimensions of the natural world, by virtue of their agency, share in the guilt of reproducing cognitive-social orders in terms of core disciplines. In the $19^{\text {th }}$ century scientists and philosophers spent quite a bit of time trying to classify knowledge on the basis of ontological distinctions. Later, methodological differences were invoked, and in our time functional ties to areas of utilisation of knowledge.

In the $2 \mathrm{I}^{\text {st }}$ century institutional orders of certification and systemic specificities in the ways of the natural world, in the laboratory and outside in the field, will probably continue to influence the recognition of certain broad areas as disciplinary cores.

I see the emergence and development of hybrid fields like bioinformatics, proteonics and nanotechnology as mainly applied and representing technical advances in methods of computation, data processing, analysis. It is a question of semi-automation with human interaction, where pattern recognition is speeded up and done on a scale undreamed of before. This occurs at a conjuncture when we have had over a century of research since the polemics that revolved around natural history fixed on classification and taxonomic work on the one hand and the artificially constraining repertoires of laboratories on the other. But even in the $19^{\text {th }}$ century it was not 
merely a question of either/or. There were at least three lines of thinking: (i) pushing Nature into the laboratory, (ii) moving laboratory experimentation into the field (field stations), and (iii) regarding Nature as such as a grand laboratory. In the second case variables were also restricted and controlled, in association with the work of classification and taxonomy. Whereas natural history might align with inductivist methodologies, laboratory experimentation tended to go in hand with hypothetico-deductive and predictive ideals. Even in the field numeric grids might be placed over natural plots to translate local properties into more general ones.

The classificatory work being done today is more often linked to attempts to extend further analysis of systems at scales from organs, tissues, cells, to the molecular, or in materials science to the atomic levels (nanotubes), and in geology magnetospheric, atmospheric, oceanic, mantel, to fluid-to-solid core systems of the Earth. This represents a further step. The focus on the systemic in this sense appears in systems biology, earth systems science, general circulation models and subsystems in climatology. This is something new. Prof. Rip distinguishes between three historical stages in the development of science, from a crafts mode, to natural history, to concentration on the laboratory. In my historical scheme I would instead present an account in terms of the movement from a crafts mode knowledge production, to taxonomy and natural history, to a focus on processes, and then focus on the systemic, where the latter overlies and frames the earlier heuristic approaches. In analogy with the discussion of the $19^{\text {th }}$ century, there are three parallel thoughts: (i) putting Nature in the computer (simulation, virtual reality), (ii) deploying the computer in the field (automated data collection and assembly, computer-aided observation), and (iii) taking Nature as a computer (both in terms of models informed by communications theories and semiotics, and in terms of constructing bio-computers).

Finally, the problem appears of the essential tension between search and authority when the walls of academic ivory towers are dismantled to let in local practitioners and knowledge practices regarding delicate matters of quality control. The problem is certainly pinpointed in the essay. As an issue it deserves further discussion.

\section{Note}

I Comments on Science for the $21^{\text {st }}$ Century, by Arie Rip. 


\title{
5 Science and Democracy
}

\author{
Herman Philipse
}

ABSTRACT. From the seventeenth century onwards, there has been a spectacular growth of scientific knowledge. Should we expect this growth to continue at the same pace? Would that be possible without an equally spectacular increase in expenditure? How should politicians in a democratic state rationally determine the appropriate level of public investment in scientific research? This prize essay provides tentative answers to these burning issues.

In Section One, an attempt is made to characterise at a meta-level all branches of science and scholarship, not individually, but collectively. Epistemic growth turns out to be an essential characteristic of science. In Section Two, the growth of science is analysed from a historical perspective. What are the prospects of scientific growth in a saturation economy of science? Possible opportunities for, and obstacles to, the future growth of science are explored. The third section is concerned with the rationality of investments in science. Pertinent issues are discussed within the conceptual framework of rational decision theory. What kinds of benefits from science should we distinguish, and how should we value them? Is it possible to predict specific outcomes of investments in research? If this is not feasible, how can it be rational to invest in scientific research at all? The traditional "public good" justification for state investments in basic research turns out to be defective. Are we able to give a better justification? And if so, with which model of rationality can we determine the 
right level of investments in a specific country? By way of an example, the Dutch policy with regard to publicly funded research is analysed. Finally, it is argued that there is an intrinsic relation between democracy and the scientific attitude. Democracies function better to the extent that voters and politicians make up their minds according to minimal standards of scientific rationality. 


\section{INTRODUCTION}

The oldest learned society in The Netherlands, the Hollandsche Maatschappij der Wetenschappen, was founded on 2I May I752 in the city of Haarlem. According to the preamble to its first proceedings, it came into existence because some citizens sought entertainment in performing, imitating, and discussing scientific experiments. Headed by the Lutheran minister Van der Aa, they had formed a small scientific collegium, which now obtained official status, consciously imitating "in the Netherlands the admirable diligence of other Kingdoms and Republics in their support and encouragement of the Sciences and Arts". ${ }^{\mathrm{I}}$

On the occasion of its $250^{\text {th }}$ anniversary, the governing body of the Maatschappij has organised a prize contest, whose contestants have been given a pensum that is neither light nor simple. They are asked to provide:

"A universal characterisation of all branches of science and scholarship ('wetenschap'), such that it may serve as a basis for valuing current scientific activity, and also enables us to formulate new problems and approaches, particularly if these do not fit in with the present-day classification of disciplines. This characterisation - having the nature of a description at a meta-level - will not only contain an enumeration of the elements of science ('wetenschapselementen'), but also indicate the interest groups and professional circles these elements link up with, in order to provide an explanation of the achievements of the past and to explore the opportunities for, and obstacles to, future developments. ${ }^{\text {2 }}$

I do not dare to propose a scholarly interpretation of this text. Rather, I shall briefly reflect on the year I752, focussing on the two "professional circles" united in the setup of the Hollandsche Maatschappij der Wetenschappen: those of science and economics. Two observations on Dutch science and economics in 1752 will give rise to the questions I attempt to answer in this prize essay, questions that, I hold, are elements of the set of possible interpretations one might legitimately assign to the query quoted above.

Learned societies were born late in the Dutch Republic. Indeed, these societies, typical products of the Scientific Revolution and the Enlightenment, had been founded much earlier elsewhere in Europe. The first of 
them was the Accademia dei Lincei, erected in $\mathrm{I}_{0} \mathrm{O}_{3}$ by the Roman Prince Frederico Gesi. ${ }^{3}$ In I6II, Galileo Galilei enlisted as a member, and the participants in the Accademia achieved important epistemological objectives of precision by their use of scientific instruments such as the microscope. However, after the condemnation of Galileo by the Roman Church in I633, the Accademia declined.4 In general, scientific progress in southern countries such as Italy and Spain was thwarted by Catholic conservatism, and learned societies in Northern Europe turned out to be much more effective, particularly the Royal Society in London (I660). 5

Why was the first Dutch learned society founded only in I752, eventhough the Dutch Republic was one of the early and major players in the scientific revolution? Historians point to a number of factors that explain this backwardness, such as the lack of a strong central government in The Netherlands and the local influence of conservative Calvinist ministers. The religious resistance melted away in the eighteenth century when the doctrine of physico-theology enabled believers to reconcile science with faith. ${ }^{6}$ But whatever its causes, the late institutionalisation of science in The Netherlands may have had pernicious effects. In order to discern such possible effects, we have to look at the economic situation of the time.

In the year 1752 the Dutch Republic, though still very rich, had already gone into a slow but steady recession. Its economic growth stagnated, and the Dutch were investing large sums in British and French funds instead of at home. Signs of the downturn were ominous. For example, the output of Leiden fine cloth had fallen from 25,000 rolls a year in 1700 to 8,000 by the late I730s, the output of Leiden camlets fell from 37,000 pieces in I700 to 3,600 pieces by I770, and the Haarlem industry of linen bleaching shriveled in the I730s and ' 40 . The celebrated windmill-driven industrial complex on the Zaan, which produced timber, sail-canvas, ropes and ships, went into a freefall by the I750s, and many of the mills fell still and silent. An index of industrial production in Holland, setting 1584 at Ioo, shows a peak of 545 in 1664, dropping to I08 in 1795. Whereas England was heading towards the Industrial Revolution, around the I750s the United Provinces "abdicated as world leader in trade and manufacture and went into a postindustrial mode".7

Is there some causal connection, one might wonder, between the economic decline of the United Provinces in the eighteenth century and the 
tardy foundation of its first learned society? To put it in more modern and anachronistic terms, could the Dutch Republic have avoided economic decline, at least partially, by investing more, and more timely, in research and development, and by building adequate institutions of research much earlier? Admittedly, the changes in the means of production during the initial phases of the industrial revolution in England were not due to the impact of theoretical science. For example, the impressive improvements in the efficiency and fuel consumption of steam engines between 1698 (Savery) and I770 (Watt) were achieved by trial and error; theoretical understanding came only in the I820s with the work of Sadi Carnot. Yet it has been argued that without the empirical and experimental attitude advocated by Francis Bacon and practised by the members of learned societies such as the Lunar Society in Birmingham, these improvements could not have been realised. ${ }^{8}$

Economic historians are somewhat puzzled by the Dutch degeneration in the eighteenth and nineteenth centuries. But several authors point to a lack of intellectual eagerness in the Dutch. One of them writes, for instance:

The Dutch merchant seemed to be dozing off on the soft cushions offormerly gathered riches and the leaders of industrial business from this period strike us as belonging to the respectable class of slow fat-bellied trade bosses whose brains, suffering from spiritual flabbiness, prevented them from hazarding the leap from the traditional way of doing business. 9

Is it far-fetched to suppose, then, that if in the seventeenth century the Dutch Republic would have founded a scientific institution similar to the Royal Society in London, the official aim of which was "to improve the knowledge of natural things, and all useful Arts, Manufactures, Mechanick practices, Engynes and Inventions by Experiments (not meddling with Divinity, etc.)", its economical fate in the eighteenth century might have been considerably better? ${ }^{\text {Io }}$

This historical issue raises a set of political and philosophical questions of a more general import, on which I focus in the present essay. Scientific research is a costly affair, and especially in the domain of pure theoretical science, its results are uncertain. By what types of arguments 
might justify investments in fundamental research and theoretical science? If results of theoretical science and scholarship are considered as collective goods, how can one legitimise the budgets for producing these goods in a democratic society? What, in general, is the relation between science and democracy? These are timely questions, because governments are faced with many competing demands for public funding. To most politicians and voters, the benefits associated with public spending on health or education are more obvious than those stemming from investment in basic research.

I tackle these issues at an abstract and philosophical level. In Section One, I review three different kinds of meta-descriptions of science, that is, I attempt to provide "a universal characterisation of all branches of science and scholarship", taken collectively. Epistemic growth turns out to be a cardinal characteristic of science. The second section is concerned with scientific growth. It is argued that the exponential growth of science during the three last centuries cannot continue. This raises the issue of whether and how we can optimise scientific growth under the regime of a saturation economy of science. In Section Three, I come to the core issue of the justification of (public) investments in basic or pure research. In order to discuss this issue properly, I introduce the conceptual framework of rational decision theory. Do politicians satisfy the requirements of rational decision theory when they decide on public investments in basic research? One requirement for deciding rationally on this issue is that we adequately establish the value of scientific research by exploring its possible benefits. Such a proper valuation of scientific research is an urgent task, to which this essay is meant to contribute.

\section{What is SCience?}

The question "What is science?" is not itself a scientific question; it belongs to the meta-level of the philosophy of science. Of course, scientists can be, and sometimes have been, philosophers of science as well. But one may be an excellent scientist and a poor philosopher of science, as is shown by the example of Isaac Newton. ${ }^{\text {II }}$ The philosophy of science is at least as old as Aristotle, and the issues it deals with arise from reflecting on 
science: general questions such as "What is a law of nature?", "What types of theoretical unification may we distinguish and what do they accomplish?", or "When is a theory confirmed by its predictions?", and questions concerning particular sciences, such as "Is there an interesting sense in which Newton's Law of Inertia can be considered as a convention?", or "Is it possible to explain the direction of time in terms of entropy?"

Both in Aristotle's epoch and today, the question "What is science?" is important because we want to distinguish between reliable or "scientific" knowledge on the one hand and mere opinions or pseudoscientific views on the other. Its actuality is shown by many facts, such as the popularity of so-called "alternative" medicine, the fact that scientific research is sometimes perverted under the influence of powerful patrons such as pharmaceutical firms, or the attempt by Christian fundamentalists in the United States to dress up the creation myth as a science in order to get it accepted as a legitimate subject in the syllabus of state schools. When the State of Arkansas passed a law that required equal treatment of the theory of evolution and creationism, scientists challenged the constitutionality of the new law in court, and the judges had to ask: What is science?13

To this question three types of answers have been given (a) in terms of statements or beliefs, or (b) in terms of method, or, finally, (c) in terms of cultural processes, research traditions, institutions, and attitudes. Each of these types of answers opens up a field of research of its own, but in order to obtain an adequate conception of what science is, we should combine answers of each of these types. Let me discuss briefly the three types of answers in order to prepare the grounds for the topic of section 2, how we might optimize the growth of scientific knowledge.

\section{a From Foundationalism to a Competitive Model of Justification}

According to the Aristotelian tradition in epistemology, (scientific) knowledge is justified true belief. In his Posterior Analytics, Aristotle (384-322 BC) required the strongest form of justification, proof by logical deduction from true premises, and in order to avoid an infinite regress in the chain of deductions, he stipulated that there be fundamental beliefs which do not stand in need of a justification by deduction because they are self-evidently true. In other words, Aristotle invented the ideal of an axiomatic-deductive 
system, in which the truth of the theorems is guaranteed by the self-evidence of the axioms and the validity of the deductions. Euclid's works on geometry and optics are early attempts to put this foundationalist ideal of knowledge into practice, and the notion of an axiomatic-deductive system exercised a deep influence in European cultural history. During the scientific revolution, Galileo axiomatised his theory of local motions in The Two New Sciences, Newton formulated classical mechanics as an axiomatic-deductive system in his Principles, and Spinoza shaped his philosophy as an axiomatic system in his Ethics. Furthermore, the ideal inspired substantial developments in deductive logic from the I850s onwards.

The definition of scientific knowledge as an axiomatic-deductive system of true propositions remained popular until around I900 - even though it was admitted that many disciplines, such as history, geology, or botany, cannot even aspire to it - but it raised a perplexing epistemological issue, which may be called "the problem of the first principles". ${ }^{14}$ How are we supposed to guarantee the truth of the axioms of a scientific system, if these axioms cannot be justified by deduction from other truths? From the scientific revolution onwards, philosophers such as Descartes, Hume, Kant, and Husserl proposed different solutions to this problem, both with regard to mathematics and concerning the empirical sciences. But these solutions are only of interest to the historian of philosophy. The classical foundationalist ideal of science as an axiomatic-deductive system of true propositions has been superseded by developments in mathematics and in the sciences.

In geometry, the Euclidian axiom of parallels had been questioned by mathematicians already in Antiquity. Since the axiom involves the notion of infinity, it was not considered as self-evident, and attempts were made to prove it as a theorem or to get rid of it altogether. Both attempts failed during more than two thousand years of research, and eventually the strategy of proving the axiom by a reductio ad absurdum of its negation led to the conclusion that alternative consistent systems of geometry are possible, in which the axiom of parallels is replaced by one of its negations. This discovery of non-Euclidean geometries by Bolyai, Lobachevski, Gauss, and Riemann in the nineteenth century eventually led to a drastic revision of the notion of an axiomatic-deductive system in the beginning of the twentieth century. The foundationalist requirement that the axioms be self-evi- 
dently true was dropped, and (pure) mathematics was re-interpreted as a discipline concerned with conceptual (or merely syntactical) deductive systems only, and not with substantial truth in the sense of correspondence with some kind of reality. Instead of wondering how one might account for the allegedly self-evident truth of axioms (if they are not purely conceptual), philosophers of mathematics now focussed on the question of how one is to demonstrate properties of deductive systems such as completeness and consistency, and this issue was solved by (meta)mathematical means. From the first quarter of the twentieth century onwards, the pure mathematician is interested not so much in the substantial truth of the axioms, but primarily in the logical relations between axioms and theorems. ${ }^{15}$

The demise of the foundationalist ideal of knowledge with regard to the empirical sciences occurred at about the same time, but for different reasons. Here, the problem of the first principles had been intractable from the very start, for a simple reason of logic. It seems that the first principles or axioms of the empirical sciences must be empirical judgements of observation, which are, logically speaking, singular or particular propositions (about one item or some items). But from such propositions, one cannot deduce the laws and theories of empirical science, which are, logically speaking, universal (about all items of an open class). Philosophers have proposed three different strategies for solving this problem, all of which have failed. They have argued that perceptual judgements can be universal, because they may be concerned with universal "essences" of classes of entities (Aristotle, revived by Husserl and the phenomenologists), a view which was rejected during the scientific revolution and which was criticised effectively in the twentieth century by philosophers such as Ludwig Wittgenstein and Karl Popper. Or they argued that the empirical sciences are not only based upon statements of observation but also on substantial axioms which are universal a priori, that is, independent of experience, and necessarily true (Descartes, Kant, Eddington). This view has been refuted by scientific revolutions, both in the second half of the seventeenth century and in the first half of the twentieth century, during which axioms that were regarded as necessarily true by Descartes (no vacuum) or Kant (determinism, actual space is Euclidean) were rejected by scientists (Pascal, Bohr, Einstein). 
Finally, a third attempt has been made to save the foundationalist model of (theoretical) scientific knowledge as an axiomatic system of truths, this time by weakening its requirements. If it is logically impossible to deduce scientific theories and laws from singular judgements of observation, they might nevertheless be made probable by inductive support of such judgements. However, specifying the relevant notion of the probability of theories has turned out to be very difficult. Neither the frequency interpretation of probability nor the interpretation of probability as proportion or as a propensity helps us here. We seem to be dealing with mere 'subjective' probabilities, which are degrees of personal conviction, and it is tempting to apply Bayes's theorem to the probability that scientific theories and lawlike statements are true. We would have to assign a prior probability to these theories, which is then modified by experiments and observations in accordance with Bayes' theorem. ${ }^{\mathrm{I}}$

However, Bayes' theorem is too simplistic a model of the justification of theoretical scientific knowledge. It does not tell us how scientists are supposed to assign prior probabilities to theories, and it neglects the fact that in evaluating theories, scientists attach great importance to specific epistemic virtues of these theories, such as explanatory power, simplicity, coherence with established theories, novel predictions, and unification. In order to develop a model of justification that is more adequate to the actual practice of justifying theories in science, we have to depart more radically from the traditional foundationalist models and to acknowledge that, typically, the justification of theories is based upon a comparative assessment of competing hypotheses.

According to such a non-foundationalist and "competitive" model, the justification of theories is relative not only to the data-set available at a given point in history, but also to the rival theories available at that time and to the accepted background knowledge. ${ }^{77}$ We may say that a specific theory $\mathrm{T}$ is justified at time $t$ if and only if it performs better than its rivals in terms of an accepted set of criteria for theory choice, such as predictive accuracy, internal coherence, external consistency with established theories and with background knowledge, unifying power, explanatory depth, and fertility for future research. ${ }^{18}$ As there will be a trade-off between these criteria, the evaluation of theories cannot proceed on the basis of an algorithm such as Bayes's theorem. It is typically a complex value judge- 
ment about which experts may disagree in many cases and over considerable periods of time. Let us call this the model of competitive justification.

If the model of competitive justification is correct, it can never be shown once and for all that specific scientific theories and law statements are justified. In principle, it is always possible that a theory $\mathrm{T}$ justified at $t_{\mathrm{n}}$ becomes unjustified at $t_{\mathrm{n}+\mathrm{r}}$, either because the data-set has been expanded with new findings that were not predicted by $\mathrm{T}$, or because a better rival has been invented in the meantime. This idea is called 'fallibilism' by philosophers of science, and it follows from the demise of foundationalism. The demarcation between scientific and pseudo-scientific ideas now becomes a function of time. ${ }^{19}$

These insights have important implications for our idea of scientific knowledge. Whereas the foundationalist view of scientific knowledge is static in that, once the axioms have been discovered, scientific growth is merely cumulative, the model of competitive justification stresses a more radical kind of epistemic progress as a defining characteristic of science. Progress not only occurs at the level of the data-sets of scientific disciplines, but also at the level of theories, that may be eliminated in favour of superior rivals. Cases of theory-substitution at a fundamental level are often called "scientific revolutions". In principle, there is no limit to theoretical growth in the sciences, and the idea of the 'end of science' is incoherent. ${ }^{20}$ If this is the case, one might conclude that a definition of science in general should not focus primarily on particular beliefs and systems of statements, but rather on the method by which these beliefs are acquired and justified. Is there something called "the scientific method" that can be used to define the scientific enterprise?

\section{b Does "The Scientific Method" Exist?}

The notion of a scientific method may be used at different levels of generality. ${ }^{2 \mathrm{I}}$ At the lowest level, methods are particular devices for obtaining specific kinds of information, and there are indefinitely many scientific methods, such as the litmus test, X-ray crystallography, or carbon dating. Typically, the reliability of these methods can be investigated and explained by science itself, and in the course of scientific progress, ever new methods are developed, such as nuclear magnetic resonance, which was 
pioneered by physicists at Harvard and Stanford Universities who were trying to measure the magnetic moments of atomic nuclei.

At this lowest level of generality, there is a co-evolution of science and methodology, and we may imagine that science has evolved gradually from older practices of acquiring knowledge, such as magic and interpreting omens. To the question of how methods at this level can be justified, we may answer by applying, mutatis mutandis, the model of justification by competition sketched above. Methods, like theories, are justified by competition with rivals, though in the case of methods, the criteria for selection will be different from the criteria used in theory choice. In justifying and choosing methods, we use criteria such as the degree of reliability, precision, technological simplicity, theoretical soundness, and cost. Methodological progress at this lowest level is breathtaking. But none of these methods can be used in a definition of the scientific enterprise as such, for their application is typically limited to one or more specific subdisciplines.

At the medium level of generality are situated methods, the validity of which is not explained by particular scientific theories, even though they cannot be practised in all areas of research. Examples are Mill's methods of experimental inquiry, randomized controlled trials in medical research, or the stylometric method of dating manuscripts and attributing writings to authors. At this level, there is methodological progress as well, but it is slower than at the lowest level, because it depends mainly on logical or mathematical considerations and is not propelled by scientific discoveries. Since these methods cannot be practised in all areas of research and scholarship, they cannot be used to define the scientific enterprise either. Is there a top level of generality at which we might characterise science as such, including the social sciences and the humanities, by means of a methodological canon? May we demarcate once and for all the scientific from the non- or pseudo-scientific by something called "the scientific method"? This is what some philosophers of science have tried to do, such as, notoriously, Sir Karl Popper, but they have not been very successful. ${ }^{22}$

In order to see why this is the case, it is helpful to spell out the criteria of success for such an attempt. In order to qualify as "the scientific method", the proposed method should (I) be distinctive of science and common to all areas of research, including the social sciences and, perhaps, the hu- 
manities; (2) explain the progress and success of science; (3) be a true "method", that is, be applicable in a methodical fashion and not depend mainly upon imagination, intuition, etc.; (4) not depend for its validity on specific scientific theories that might be false, for in that case it would not demarcate science once and for all from other human activities. In other words, the validity of the method should be a priori. ${ }^{23}$

That it is difficult to succeed in terms of these criteria may be shown by the example of Karl Popper. Strict falsificationism, Popper's initial proposal, fails on criteria (I), (2) and (3). Popper's basic idea was that inductive inference can never be justified. He argued that the truth of inductive generalisations and general theories cannot even be made probable on the basis of particular evidence. Logically speaking, however, a general statement can be falsified by a counter-instance, and such a falsification is purely deductive, by modus tollendo tollens. This is why Popper proposed falsificationism as a general methodology of science. According to falsificationism, scientific laws and theories are creative guesses or hazardous hypotheses, which we have to put to the severest possible tests. If they are falsified by these tests, we reject them; if not, they are "corroborated", and we accept them provisionally. A hypothesis which, in principle, cannot be falsified deductively, is "unfalsifiable", and Popper regarded unfalsifiable statements as unscientific.

Falsificationalism clearly fails to meet criterion (I) for, strictly speaking, all statistical hypotheses are deductively unfalsifiable. If a statistical hypothesis says that two-thirds of a population have characteristic $\mathrm{C}$, and if we find that in the investigated sample $85 \%$ of the items possess that characteristic, this is not logically incompatible with the hypothesis, unless we inductively generalise this latter proportion to the entire population. However, according to falsificationism, inductions are not allowed. Falsificationism also fails to meet criterion (2). According to Popper, we should prefer corroborated theories to falsified theories because the former are nearer to the truth than the latter. Hence, falsificationism would explain the progress of science as an increase in "verisimilitude". But if no inductions are allowed, and corroboration is purely a report of our past efforts to falsify a theory, there is no good reason to prefer corroborated theories to falsified theories. For in that case, the fact that a theory has been falsified in the past is no good reason for thinking that it will ever be falsified again 
in the future, and the fact that a theory could not be falsified by experiment $E$ in the past is no good reason for thinking that a repetition of $E$ will not falsify the theory on the next occasion. Hence, falsificationism cannot explain the success of science.

Finally, falsificationism fails as a definition of the scientific methods on account of criterion (3) as well. Popper never thought that there was a method for inventing hypotheses, for invention depends on creativity. Methodology would not play a role in the "context of discovery", but only in the "context of justification". In this latter context, the method of falsificationism would be simple: it prescribes that we look for severe tests and abandon a hypothesis if it has been falsified by a counter-instance. In fact, however, things are not that simple. A testable prediction never follows from a hypothesis on its own; many other premises are needed for deriving it. Consequently, a refutation of a prediction does not deductively falsify the hypothesis. It is a matter of decision which premise is held responsible for the refutation, and there is no clear method for making this decision. Furthermore, in order to establish that a prediction is refuted, we typically need many universal premises. If these cannot be established by induction, as Popper claims, they must be hypotheses. Again, it follows that the hypothesis under testing cannot be falsified by a simple deductive method, for we must decide to accept these other hypotheses in order to conclude that the hypothesis under testing has been falsified. ${ }^{24}$

Later philosophers of science, such as Imre Lakatos and Larry Laudan, have attempted to improve on Popper's falsificationism in the light of these standard criticisms. Reviewing their proposals, however, one will reach the verdict that nobody has succeeded in developing a substantial methodology of science that meets the four criteria formulated above. As one author concludes from a similar line of argument, "there is nothing that can usefully be called the scientific method", although, of course, there is a large spectrum of methods used in scientific research and scholarship. ${ }^{25}$

\section{c The Scientific Forum}

For this reason, some philosophers of science, such as the Dutch psychologist A.D. de Groot, have concluded that we should attempt to characterise 
science primarily in terms of institutions, cultural or social processes, and attitudes, rather than in terms of statements or of method. The basic premises of De Groot's views are the following. First, there is not one substantial methodology for making decisions in all areas of scientific research (including the social sciences and the humanities). But, second, this does not imply that "anything goes", as has been argued, notoriously, by the provocative philosopher of science Paul Feyerabend. The reason is that researchers will reach agreement on decisions by reasonable discussion over shorter or longer periods of time. De Groot introduced the label "the scientific Forum" for all those social processes and institutions in which scientists examine and discuss each others' views, such as learned societies, scientific journals, conferences, public debates, doctorate examinations, and, ultimately, the history of science itself. He claimed that if one catalogues the basic rules and values which the members of scientific fora use in their discussions and evaluations, one gets a "normative minimal methodology" of science, which would be unique in the sense that there is no alternative to this methodology, and which would also describe the core of what we call "the scientific attitude". ${ }^{26}$

As I shall argue in the next section, this institutional point of view on science is fruitful indeed. Yet one may be somewhat disappointed by the "normative minimal methodology" of the ten institutional rules De Groot proposed. Let me mention the most salient rules and values only. A scientific forum is in principle "open" in the sense that anyone who has the relevant expertise can join in. For a forum, only arguments count, and power is irrelevant. Since a scientific forum acquires authority - not power - to the extent that the members agree, its discussions aim at agreement. Unanimity reached by arguments is not only its aim. It is also a criterion for the general public that what the forum agrees upon is justified by science at that moment of time. Finally, unanimity functions as a rule of procedure. If one expert disagrees, the discussion is re-opened. According to De Groot, scientific values such as intellectual honesty, clarity, and objectivity can be derived from the desideratum that the Forum functions adequately. Since in fact it dysfunctions quite often, the minimal methodology of the Forum is not only partially descriptive of actual science, but also normative. ${ }^{27}$

The model of the forum is "democratic" in that arguments count irre- 
spective of the person who advances them. However, it should be sharply distinguished from a very different model of democratic decision-making, which De Groot calls the model of the gremium. Whereas gremia decide by majority vote, fora decide by unanimity based upon arguments. De Groot warns against a "politisation" of science that might result from confusing these two models. ${ }^{28}$ But it cannot be avoided that decisions by scientific fora are sometimes taken by majority vote, whereas the quality of decisions taken by gremia will be optimised if gremia apply De Groot's minimal methodology of science as far as possible. In other words, a democratic state will function better to the extent that decision-makers adopt the scientific attitude as specified by the rules for the scientific Forum, as I argue in subsection 3 e. ${ }^{29}$

The minimal methodology of the Forum has the advantage that because of the very fact that it is minimal, it may be applied to all areas of science and scholarship. Yet it is doubtful whether it can be used as a definition of the scientific enterprise. The reason is that the methodology may and should be applied also outside of the domain of scientific research. We come to the skeptical conclusion that there is not one simple answer to the question of "what is science?" In other words, it is impossible to provide a succinct "universal characterisation of all branches of science and scholarship", which this contest requires. Perhaps this should have been expected from the very start, in view of the great diversity of the different areas of science and scholarship. Yet we have encountered some useful ideas, such as the one that science is characterised by epistemic growth, and the notion of justification by competition. This latter notion has been developed by philosophers of science, but it may be applied, mutatis mutandis, in other domains $(\sqrt{3} \mathrm{~d})$.

\section{Maximising the Growth of Science}

Science is often conceived of as a body of knowledge, a structured system of statements and theories. But we have seen in subsection Ia that this conception leaves out an important dimension of science. What is justified scientific knowledge at one stage of history may be pseudo-science at a later stage, as the example of astrology shows. It follows that growth or 
progress is a cardinal characteristic of science and that growth often occurs by discarding theories.

Historians of science have investigated scientific growth in all its aspects, tracing the succession of theories and ideas, studying the development of methods and practices of research and, finally, charting the history of institutions and expenditure. The spectacular growth of science since the $I 7^{\text {th }}$ century is best illustrated by this latter aspect, because it is open to measurement. A quantitative history of science was pioneered by Derek de Solla Price in $\mathrm{I}_{963}$, and he proposed, as a first "law of growth for science", that science grows exponentially or, at least, that it has grown exponentially from the scientific revolution onwards. Depending on the parameters one chooses, such as the growth of manpower, of journals, of published articles, or of money invested, the crude size of science has doubled in every period of Io to 20 years over the last three and a half centuries.

This "law" of growth for science has interesting corollaries. First, a I5year doubling time extended over three centuries of growth corresponds to an increase of 20 powers of two, that is, a factor of about one million. Thus, in the interval from 1650 to 1950 , indicators of the size of science have increased by the order of a million. Second, the law accounts for a phenomenon which De Solla Price calls "the coefficient of immediacy" of science. During the last three and a half centuries, scientists of each generation have had the impression that most scientific developments occurred during their life time and that they lived in the age in which big science really got started. This effect of immediacy can be explained on the basis of De Solla Price's first law. Assuming that the number of scientists doubles every 15 years, then in any interval of 15 years there will come into being as many scientists as in the entire preceding time. However, at any particular time, the set of co-existing scientists will have as members all scientists produced during, say, an average career period of 45 years. Assuming, then, that for every scientist born before such a period of 45 years, there is one scientist living who was born in the first doubling period, two in the second, and four in the third, we must conclude that about $87^{1 / 2}$ percent of all scientists who have ever existed is alive now. This has been true for nearly all periods during the last three and a half centuries. $3^{\circ}$

Such a growth rate cannot go on forever, because it dwarfs other growth rates. During the last three hundred years, for instance, every doubling of 
the population has produced about three doublings of the number of scientists, but we cannot imagine a human society in which all adults are professionally engaged in scientific research. Given the level of intelligence needed for being a minimal scientist (defined as one who produces only one paper in a lifetime), one might calculate that the number of scientists in the population cannot exceed $8 \%$. $^{\text {I }}$ De Solla Price predicted in I963 that the exponential growth of science would reach its saturation limit within the next human generation. This seems to have happened during the last decades. The investment in scientific research expressed as a percentage of the GDP has been steadily diminishing in many countries. In The Netherlands, for instance, the total investment in Research and Development diminished from $2.2 \%$ of GDP in I987 to I.77\% of GDP in I996.32 In I998, Europe as a whole spent on average I.8\% of GDP on research.

Incidentally, this percentage is low in comparison with Japan $(2.9 \%$ in I998) and the United States (2.8\%), and the gap is growing. In I992, the difference between Europe and the United States in the total expenditure for research was about I2 billion euro; in I998 the gulf had widened to about 60 billion euro. Given the fact that research and development account for $25 \%$ to $50 \%$ of economic growth, the European backlog is a cause for concern in the European Commission. In a recent document, the commission urged the member states to invest more in scientific research and to create a "European Research Space". 33 As De Solla Price wrote in I963, "when a country decides that it can afford to let science grow only at the rate of the national economic expansion, and that the supply and demand of scientific manpower be allowed to tend to equality, this is tantamount to a suicidal withdrawal from the scientific race".34

Leaving aside for the moment these differences between national levels of investment (see subsection 3d), we may conclude that the spectacular exponential growth of science in terms of money and manpower is coming to an end. We enter the phase of a saturation economy of science, in which an optimally efficient deployment of resources becomes crucial, because attempts to increase them exponentially will mostly turn out to be futile. The question is, then, whether and how we can maximise scientific growth in terms of results if growth in terms of money and manpower is slowing down or even negative. In this section, I briefly discuss this issue, focussing on methodology (a, b) and the design of institutions (c). 
Is it possible to speed up or at least maintain the growth of scientific knowledge by improving on methods, in spite of a constant or even lowering level of expenditure? I shall argue that there are good reasons for being skeptical at this point.

As we have seen in subsection $\mathrm{Ib}$, one might study scientific methodology at three levels of abstraction: a lowest level of theory-laden technical inventions; a medium level, and the upper level of a methodology that is valid for all areas of research and scholarship. I shall examine the problem of optimising the growth of science by methodological improvements for two levels only, the lowest level of research technology ( $\mathbb{2 a}$ ), and the upper level of general methodology $(\mathbb{2} 2 \mathrm{~b})$.

At the lowest level, methodological improvements for obtaining knowledge may not only save money, they also cost money. The reason is that methodological advances at this level consist in new technical devices for obtaining information, that is, for expanding our data-set. These devices have to be developed and produced, and the processes of development and production require investments in money and personnel. So our question at this level is a specific one: is it likely that we may maintain or even speed up the growth of scientific knowledge by improving on particular methods for obtaining data, while we are diminishing the level of expenditure or at best keeping it constant?

Answers to this question will have to be formulated in terms of probabilities, and they should be justified by empirical research on the investments in scientific technology over, say, the last three centuries. Instead of doing this type of research, however, I shall discuss an a priori argument for skepticism, which I shall then qualify by reviewing one example of a fairly recent methodological improvement. The argument has been developed by a distinguished philosopher of science from Pittsburgh, Nicholas Rescher, in a little book of I996, called Priceless Knowledge? Natural Science in Economic Perspective. 35

Rescher argues that although there cannot be a theoretical limit to scientific growth, it is inevitable that empirical science will progress ever more slowly for strictly practical and ultimately economic reasons. His argument is as follows. We may characterise the growth of scientific knowledge 
in empirical science in terms of dynamic cycles of equilibrium and disequilibrium between the theory and the data-set. Theorists attempt to capture the regularities they discern in a given data-set by inventing the simplest theoretical structure that accommodates them, which they then project inductively "across the board". However, the regulative idea that theories are universally valid implies an imperative to broaden the range of our experience, to extend the database as far as we can. As the history of science shows, the expansion of the database eventually causes a disequilibrium between the old theory and new data, and this disequilibrium creates the need for new theoretical structures. There is no good reason for supposing that any given theory will be the final one, so that, in principle, the cycle can be repeated indefinitely.

If we define the growth of science primarily in terms of ever better theories, our global question as to the possibilities of speeding up the growth of science in spite of a constant level of expenditure may be answered by settling two separate issues: (I) Can we accelerate the expansion of the data-set while expenditure is constant? (2) Can we speed up the intellectual processes by which theories, in the broad sense of organised epistemic structures, are generated on the basis of a data-set, without increasing costs? Rescher answers both questions negatively. Both the expansion of the data-set and the generation of theories will slow down unless expenditure increases drastically. Let me go briefly into these two issues.

(I) If we interpret science within the framework of the theory of evolution, we may say that initially, the potential data-set of science consisted of the information humans could obtain by using their unaided sense organs in their ecological niche. In other words, humans could explore only their parametric neighbourhood in the parametric space of physical variables such as temperature, speed, pressure, and electric charge. At this "home base" in the accustomed natural environment, humanity could collect data at relatively low costs, thanks to the evolutionary attunement of its sensory and cognitive apparatus. From the $I 7^{\text {th }}$ century onwards, however, further progress was possible only by artificially extending the data-set by means of technical devices that enabled humans to transcend the limitations due to their evolutionary heritage. Henceforth, at each stage of scientific advance, humanity can progress only if it moves even farther away from its 
evolutionary home base in nature. "After the major findings accessible via the data of a given level of technological sophistication have been achieved, further major findings become realizable only when one ascends to the next level of sophistication in data-relevant technology." 36 It is plausible to assume that this "technological escalation" implies an ongoing escalation in the resource costs of significant scientific discovery, because technology will become ever more expensive as we move further away from our natural parametric neighbourhood.

Two further points are relevant here. First, the law of diminishing returns generally applies if we try to approach specific limits in the parameter space of nature. Whenever we attempt to push a technology to the limits of its capacity, aiming at greater vacua, lower temperatures, higher field strengths, or speeds approaching that of light, costs increase exponentially, and less progress is bought for higher costs. Rescher speaks here of a "technology-intensive arms race against nature" and compares the economics of scientific progress with the prices of the series of B bombers, from the old B-I7 of World War II to the supersonic B-I of the I990 era.37

Second, the economics of science differs from that of productive enterprises in business. Whereas business enterprises aim at mass production, and, over time, the ratio of investment cost per produced unit declines exponentially due to economies of scale, the production of new technological devices by the science industry typically aims at novelty all the time, for there is no point in doing a particular experiment over and over again. The science industry usually does not focus on mass production of technological devices, but at pioneering production. As a consequence, the ratio of investment per produced unit has increased exponentially. From these considerations we may conclude that further progress in data technology will be ever more expensive. As a result, scientific progress at the level of expanding the data-set will slow down and, eventually, come to a halt altogether if expenditure remains constant or increases less than exponentially.

(2) What about scientific progress at the level of theory? Here, too, we may assume that growth will slow down, even if the data-set is quickly expanding. It is intuitively plausible that the greater the body of mere information provided by the database, the more difficult it will be to invent patterns of order that obtain in the data-set. Theoretical inventions abound in the earlier phases of 
a new discipline and become ever scarcer in the course of progress. Rescher argues for a law of logarithmic returns that allegedly obtains for the relation between the increase in mere information and the increase in theoretical or significant knowledge. The law implies that an exponential growth of mere information is coordinated with linear growth of significant knowledge. Leaving such pseudo-precision aside and taking the invention of ever new generations of computers into account, we may nevertheless conclude with Rescher that "the more knowledge we already have in hand, the slower... will be the rate at which knowledge grows with newly acquired information". $3^{8}$ This implies that the objective of increasing theoretical knowledge involves everescalating demands on the growth of the database and on investments in theoretical work.

From the considerations under (I) and (2) it follows that it is impossible even to maintain a linear growth of theoretical scientific knowledge while the level of expenditure in technology and manpower remains constant. One might think, however, that this skeptical conclusion is refuted by examples of drastically decreasing costs in research technology. The PCR method in DNA research may be mentioned as an instance of this phenomenon.

The polymerase chain reaction ( $\mathrm{PCR}$ ) method was invented by Dr Kary B. Mullis (La Jolla) and first presented in 1985 , for which Mullis received the I993 Nobel Prize in Chemistry (shared with Michael Smith). By this simple and cheap procedure, for which one only needs a test tube, a specialised polymerase enzyme, the four nucleotide bases, a primer, and a source of heat, it is possible to replicate an individual DNA segment of a complicated genetic material several million times within a few hours. With recombinant technology, this task would have required several days. The PCR method can be applied automatically and with great precision by commercially produced PCR apparatuses. It is a revolutionary new instrument for basic research, such as determining genetic and evolutionary connections between different species, or the human genome project, and for applied biomedical research: diagnosing viral and bacterial infections (HIV, for example), localising the genetic alterations underlying hereditary diseases, and forensic research. 39

Yet my feeling is that such counter-examples do not refute Rescher's skeptical argument. Research costs may decrease locally because of technological inventions while, globally speaking, Rescher's conclusion re- 
mains true. Indeed, it is plausible to assume that this is the case, although the skeptical argument must be tested by empirical research..$^{\circ}$ Let us accept for the sake of discussion that, other factors remaining equal, it will be impossible even to maintain the present rate of scientific growth without substantially increasing investments in research technology. Let us further assume that, globally speaking, a substantial increase in expenditure for basic research is unlikely. Are there any other factors the manipulation of which might speed up scientific growth under these conditions?

\section{$b$ The Principle of Proliferation}

If such factors exist at all in the domain of scientific method, and if Rescher's skeptical argument is valid, we have to look for them at the higher levels of methodology. At these levels, methodology is not theory-laden and does not consist of technologies. In principle, one might imagine that here improvements of method might yield accelerated scientific growth without substantial increases in expenditure. Are there any proposals for methodological improvement at these levels that will accomplish this feat?

I shall discuss one example of such a proposal only, the "Principle of Proliferation" (PoP). My reasons for discussing the PoP are twofold. First, this principle supposedly belongs to the general methodology of science and scholarship. Hence, if introducing it accelerates epistemic growth, it will do so globally, perhaps in all disciplines. Second, the principle has been proposed by a member of Popper's school in the philosophy of science, Paul Feyerabend. According to Popper and his pupils, the aim of normative methodology is to optimise the growth of science. As Popper said, "the central problem of epistemology has always been and still is the problem of the growth of knowledge".4I Feyerabend explicitly introduced the PoP as a methological rule that promotes epistemic growth, and as far as I know, no other independent rules have been proposed with this objective in general methodology during the last decades. For this reason, we may safely assume that his proposal is representative for the entire domain of general scientific methodology in the sense that if the PoP turns out not to be a reliable rule for accelerating scientific growth, as I shall argue, probably no other new methodological rule will be found that satisfies this requirement. 
Feyerabend first presented his argument for the PoP in I963 as an attempt to improve on the methodology of logical positivism. ${ }^{42}$ He reproached logical positivism for stimulating a dogmatic attitude in the sciences because of the methodology of inductive confirmation it advocated. Feyerabend argued that in order to be a good empiricist, we should not attempt to confirm a specific theory as well as possible by empirical tests, but rather develop alternative theories and test the rival theories against each other, given the data-set. This methodological rule is called the PoP. Since it takes time and investment to develop alternative theories up to the point that they yield solutions to actual scientific problems, Feyerabend also advocated a second methodological rule that is a corollary of the PoP: the Principle of Tenacity (PoT). This principle prescribes that we stick to alternative theories under development in the face of considerable difficulties.

One might say that Feyerabend endorsed the competitive model of justification which I sketched in subsection ra and added PoP and PoT as methodological rules to this model. His argument for these embellishments was derived from one particular example, Brownian motion. According to Feyerabend, the Brownian particle is what Wilhelm Ostwald had called a perpetual motion machine of the second kind, so that its existence would refute the phenomenological second law of thermodynamics. Feyerabend argued, firstly, that the relevance of Brownian motion to the second law would never have been grasped if scientists had merely attempted to "confront thermodynamics with the facts", as the logical positivist methodology prescribes. Rather, it was because scientists considered an alternative view, the kinetic theory, which explains Brownian motion, that they saw its relevance to the second law of thermodynamics. He claimed, secondly, that without the kinetic theory, it would have been impossible to see that Brownian motion refutes the second law. Feyerabend concluded that proliferation of theories is indispensable for the progress of science, because, in general, empirical difficulties for one theory are only discovered in the light of an alternative theory.

Are PoP and PoT sound methodological rules that will speed up the growth of theoretical science in spite of stagnating investments, if applied consistently? There are four reasons for being skeptical at this point.

First, one may doubt the physics of Feyerabend's argument. For instance, it is dubious whether Brownian motion could be considered as a 
perpetuum mobile of the second kind, which refutes the second law of thermodynamics. Second, Feyerabend's argument contains the fallacy of hasty generalisation. It may be true that sometimes an empirical anomaly for a theory can be discerned only in the light of an alternative theory, but this is not generally true. For instance, the phenomenon of black body radiation was known long before Planck derived his formula for blackbody curves in I900, and it was seen to be incompatible with traditional physical theories such as classical thermodynamics and electromagnetic theory. What typically happens in the history of science is that scientists only start to develop an alternative to the existing theoretical paradigm after anomalies have been piling up for some time, as Kuhn has argued in The Structure of Scientific Revolutions. 43

This common practice is more rational than Feyerabend's PoP, which prescribes that alternative theories must be developed in all disciplines at all stages of scientific progress since, allegedly, anomalies cannot be discovered without an alternative theory. It is more rational - and this is my third reason - because the costs of developing alternative theories are huge, at least in those disciplines in which theories are complicated structures that embody mathematically formulated laws and in which reliable measurement is possible. Applying Feyerabend's PoP and PoT will not speed up scientific growth in spite of stagnating investments; rather it will slow down growth because large sums are wasted on irrelevant theoretical work. Even worse, universal application of PoP and PoT may create intellectual chaos, as is shown both by the later development of Feyerabend's philosophy and by disciplines in which theoretical proliferation abounds, such as clinical psychology.

In I96I, Feyerabend had argued that there is no logical or epistemological difference between scientific theories and so-called myths, such as the doctrine of witchcraft. These myths have had observational success, like scientific theories, because they created their own interpretation of experience. Yet there is an important difference between believers in myths and scientists, Feyerabend held at that time. The former adopt an attitude of complete and dogmatic acceptance, whereas good scientists have an attitude of criticism concerning their theories. 44 By introducing PoP and PoT into scientific methodology, however, Feyerabend undermined his earlier distinction between science and myth in terms of attitudes. This under- 
mining mechanism explains the extremist multicultural and post-modernist ideology of his later years. If tenacity is a legitimate attitude for developing alternatives to accepted scientific views, which is prescribed by PoP, we should mitigate our critical attitude with regard to attempts at constructing alternative theories. Hence it may seem that "anything goes" in intellectual matters. In a paper called "How to Defend Society Against Science" (1975), Feyerabend concluded that accepted "science is just one of the many ideologies that propel society". Accordingly, he advocated "a formal separation between state and science" and argued that in a future society, scientists should be "more than balanced by magicians, or priests, or astrologers". 45

What is wrong with PoP and PoT is that they are not methodological rules at all, and this is my fourth argument. Methodological rules proper should be applicable in all circumstances, or at least in a set of situations that may be specified in advance. This is not possible with regard to theoretical proliferation and tenacity. Sometimes it is advisable to develop an alternative to existing theories, and sometimes it may be worthwhile to display tenacity, but quite often, it can only be assessed by hindsight whether specific instances of proliferation or tenacity have been good or bad for the growth of science. As PoP and PoT are the only proposals for new methodological rules that have been put forward in general methodology during the last few decades, the prospects for speeding up scientific growth by introducing a superior general methodology are grim indeed.

That PoP is not a sound methodological rule may also be shown by academic disciplines in which abundant proliferation of "theories" causes stagnation rather than growth. The Dutch psychologist and philosopher of science A.D. de Groot, to whom I referred earlier, has argued that in psychology theoretical proliferation is a symptom of a dysfunctioning scientific forum. Because developing a new "theory" or starting a new therapeutic school yields more status than patiently testing the existing views or expanding the data-set, the number of theories has become too large. Serious researchers are unable to make a rational choice between all the schools and sects. As a consequence, the average quality of the field sinks: bad ideas survive for too long, and good ideas go unnoticed. In such a situation, critical examination of existing ideas is a more important task than developing new ones, and further proliferation is counterproductive. 
A similar situation obtains in philosophy, but fora that are appointed to review the quality of research, such as the vsnu committees in The Netherlands, often prefer theoretical proliferation to critical evaluations of existing theories. ${ }^{4} 6$

It is improbable, then, that we will be able to speed up or even maintain the global growth of science in a period of stagnating investments either by improving on research technology or by introducing new rules of method. If methodology does not help us here, are there other means? Could we promote scientific growth by re-designing our research institutions and universities, for example?

\section{c Institutional Design}

There is no doubt that the foundation of new institutions, or re-designing existing institutions, may speed up local scientific growth considerably. In his lectures on the development of mathematics, Felix Klein devoted a section to the foundation of the École Polytechnique in Paris (I794) because, due to the stringent admission policies and the exceptionally high demands put on the pupils, this school brought France to the forefront of mathematics in the first half of the $19^{\text {th }}$ century. 47

The importance of institutional design is also stressed by De Groot, who argues that institutional improvements such as quality assessments of research may strengthen the proper functioning of the scientific forum. De Groot lists seven conditions for a sound scientific development, most of which have to be met by institutional design and funding: (I) scientific institutions must offer an attractive career to talented and ambitious students (2) who have to be trained properly. Furthermore, scientific research (3) must produce a percentage of useful results (4) that have a reasonable life-span, such that (5) the best results are preserved whereas inferior and insignificant products of research are eliminated (6) by means of a valid procedure of evaluation and selection. A proper functioning of all these sub-processes yields (7) the social prestige of scientific research, that is essential for its public and private funding. 48

It is not always easy to decide whether specific new institutions create opportunities for, or rather obstacles to, the growth of science. Let me discuss briefly the Dutch example of so-called research-schools, introduced in 
The Netherlands during the last decade of the $20^{\text {th }}$ century. These schools are meant to be both graduate schools and centres for excellent research, with an independent budget responsibility and with links to universities. According to the committee that advised the Dutch government on these schools in I990, presided over by Dr. A.H.G. Rinnooy Kan, the objectives of founding the schools were, inter alia, to promote cooperation between universities, to strengthen research management, and to raise the external visibility of research in order to attract more external funding. ${ }^{49}$ Some II5 schools have been formally approved of by $2001.5^{\circ}$

In order to meet the first of these objectives, to promote cooperation between universities, research schools should have a "federal" organisation, assembling excellent researchers working in several universities. As the universities were supposed to provide nearly the entire budget of the schools, each federal school would have to drain the budgets of the participating universities. Furthermore, it should have a strong management (second objective) and a high external visibility (third objective). But these requirements do not fit in with another aim of the Dutch government. Impressed by the market ideology, the Ministry of Education wants to stimulate competition between universities, and a competitive mechanism has been installed in the model for funding these institutions. Obviously, the objective of inter-university cooperation and that of inter-university competition contradict each other, because they imply antagonistic strategies for budget management. In order to compete, universities have to protect their individual budget responsibilities, whereas inter-university cooperation in federal research schools requires that research budgets be transferred to these schools.

As a consequence, organisers of research schools are facing the following dilemma. ${ }^{\text {I }}$ If they prefer a federal school, they discover that its autonomy and budget will be undermined by competition between the participating universities. If, however, they prefer a local school within one university only, they will wonder what its surplus value is compared to a local research institute with a graduate programme. It seems, then, that founding research schools in The Netherlands runs the risk of causing a waste of time and money, and this is due to conflicting government objectives. An exception is formed by those few schools that have been able to obtain considerable external funding, either within the framework of the so- 
called "In-depth Strategy" or from non-governmental organisations. ${ }^{52}$ According to a recent evaluation, most research schools have had some positive effect on the quality of graduate programmes, but it is debatable whether they have contributed positively to the quality and output of research.53 The considerable cost of overhead in terms of time and money must be subtracted from the investments in research proper.

The greatest institutional challenges are faced by the European Union as a whole. While the university systems in the United States and Japan have the shape of a quality pyramid, with a few outstanding institutions at the top, most European countries have egalitarian and state-dominated systems that all differ from each other. If Europe really wants to compete with the best American universities, it will have to create a European university and research space. The European Committee is not blind to this necessity, but the measures it proposes, such as creating networks of existing national research institutes, are modest in relation to its objectives. 54 What is needed to favour the creation of top universities and research institutions comparable to Harvard, Princeton, MIT, or Caltec is to privatise at least half of the European universities and give the best of them the freedom from national restrictions and the generous funding needed for pursuing the road to the top. If this is not feasible, one might perhaps create international top universities in Europe by building a number of new and highly selective European institutions situated "above" the existing universities. However, neither of these strategies will succeed without huge investments.

The gist of my arguments in section 2 is that in order to maintain the growth of science, ever greater investments in money and personnel are needed. What justifies such investments? Which types of arguments and models of justification are appropriate if we want to legitimise a specific level of expenditure? What level of public expenditure should a democratic state such as The Netherlands aspire to? These questions are the topics of Section 3, in which I focus on the justification of basic research within the political framework of a democratic state. In order to discuss these issues properly, I shall first introduce the conceptual framework of rational decision theory. 
A decision to invest a determinate sum in scientific research is justified for an actor, be it a democratic government or the board of a company, if this decision is a rational one in the context in which it is made. But what is rationality? When is a decision rational? These questions are the topic of rational decision theory, as pioneered by John von Neumann and Oskar Morgenstern in their classic study Theory of Games and Economic Behaviour.55 I shall briefly introduce the conceptual structure of this theory in order to define a framework for the discussion on investment in basic research in this section.

Rational decision theory is a normative and mathematically formulated theory. It would be a mistake to suppose that actual human beings deliberate rationally in conformity with the theory. On the contrary, psychological research has revealed that human thinking and decision-making are fundamentally flawed and limited processes. ${ }^{56}$ This discrepancy between actual decision-making and the ideal of rationality specified by rational decision theory raises some interesting problems. How should one characterise the shortcomings of actual decision-making in the light of the ideal of rationality specified by decision theory? Which of these shortcomings are avoidable in a determinate situation? And which limitations of rationality are intrinsic to specific kinds of decisions? By answering these questions, we might attempt to spell out a model of optimal rationality for a specific type of decision, such as the decision by democratic states to invest in fundamental scientific research.

In subsection (a), I introduce the basic terminology of rational decision theory, as it was re-formulated in terms of subjective expective utility by Leonard Savage in I954, and in (b) I specify the kinds of benefits that may result from investing in basic scientific research. 57 Under (c) I discuss an essential limit of rationality with regard to investments in basic theoretical science: the paradoxical fact that natural science, being our most powerful predictive tool, is itself unpredictable as far as its content is concerned. Apart from this essential limitation, there are also accidental and avoidable limitations of rationality, and politicians display such avoidable irrationalities. This is the reason that in subsection (d) I discuss into some detail the cost-benefit rationality of government investments in basic research, 
drawing on the recent SPRU review of the literature on The Relationship Between Publicly Funded Basic Research and Economic Performance of $1996.5^{8}$ I sketch the outlines for a new justification of public investments in research. Since the actual rationality of the Dutch governmental decisions is low in this domain, I also propose a model of justification for improving it. Finally, I argue (e) that the scientific attitude is intrinsically related to a properly functioning democracy, so that a major objective of education in a democracy should be to promote the scientific attitude in all citizens.

\section{a Decisions and Mistakes}

A decision may be defined as a choice of conduct in a complex situation in which there is more than one possible course of action under consideration. Rational decision theory assumes that the decision-maker can form expectations, formulated in terms of probabilities, concerning the future outcomes of each course of action, and that he is able to assess these outcomes on an evaluative continuum reflecting personal values and current goals.

The empirical implementation of decision theory presupposes that both probabilities and the subjective valuation of outcomes can be expressed in numbers. Probabilities are quantified on a scale between zero (impossible) and one (certain), and subjective values of each possible outcome are expressed in another conventional scale, assigning, say, -Ioo to the worst possible outcome and +roo to the best possible outcome. Psychologists and economists have developed a great number of scaling methods to solve the measurement problems of how these numbers might be extracted from people's thoughts about decision situations.

The best decision for a subject in a given situation may now be calculated in three steps. First, the situation must be modeled as a decision tree, in which for each possible option in that situation all possible outcomes are mapped. Second, numbers are assigned to the probabilities and the subjective values of these outcomes. Finally, the best decision, defined as the decision that leads to the highest expected utility, is calculated by summarising the utilities of each option, where the utility of an outcome is defined as its probability multiplied by its value. In other words, a decision is 
rational if the expected utility of the option chosen from the option set in a situation is greater than that of all other options. Rational decision theory has the form of an axiomatic deductive system. What Von Neumann and Morgenstern proved is that whenever the axioms of their system are satisfied, a numerical measure can be assigned to each possible outcome, and the options can be ordered in terms of their expected utilities. As a consequence, it can be calculated what the most rational decision is in each situation.

In principle, decision theory may be applied in two fundamentally different ways, the behaviourist and the mentalist manner. It is applied behaviouristically if the actual choices people make are interpreted as revealing their values or preferences, and these revealed preferences are interpreted as implying utilities. This application is favoured by economists, but it is inadequate if we want to use decision theory in order to make up our minds about which option we should prefer in a given situation. For such a use, decision theory should be applied mentalistically: we must ask ourselves how we value outcomes and how to estimate the probabilities of these outcomes. We may also use the theory mentalistically in predicting the decisions of other people. We ask them to make judgments about their values and subjective probabilities, and we combine these judgments in accordance with the axioms of decision theory. We then derive predictions concerning the decisions these people will make.

I am not introducing the conceptual framework of decision theory in order to assign determinate numbers to the expected utilities of specific options for investing in scientific research to calculate the most rational decision. Even if this could be done in principle, the outcomes of the relevant measurements would depend on the details of individual situations. My objectives are more abstract and philosophical. The framework of decision theory is helpful in specifying the kinds of mistakes one might make in actual situations that ask for a decision and in attempting to prevent such mistakes. In general, five types of mistakes may be distinguished: (I) an inadequate analysis of the relevant situation resulting, for instance, in the omission of relevant options, (2) mistakes in the assessment of probabilities of outcomes, (3) overlooking possible outcomes of options, (4) insufficient reflection on one's own valuation of outcomes, and (5) making contradictory choices. I briefly illustrate (I), (2), (4) and (5). In the next 
subsection, I shall focus on (3) as applied to the problem of investing in basic research. 59

I. Few people possess to a high degree what Robert Musil once called "a sense of possibility" (Möglichkeitssinn). Indeed, the protagonist of his main novel, Der Mann ohne Eigenschaften, was an exception in that he had an acute sense of possibilities, whereas most people are dominated by a sense of "reality", that is, by habit. As a consequence, we often neglect possible courses of action in a given situation. Empirical decision theorists discovered that in everyday situations, people have a general tendency to focus on a few salient possibilities to which they are accustomed, ignoring all the others. ${ }^{60}$ Another example of mistake (I) would be to overlook the fact that decisions are only concerned with future courses of action that have future effects (costs and benefits). Often one commits the fallacy of "sunk costs", that is, one enters surreptitiously costs made in the past into the analysis of the decision situation. This happens, for instance, if one refuses to sell shares on which one has made a great loss in the past, even though the probability of future gains is lower than on other shares one might buy. It is a fundamental rule of rationality that decisions should be based upon future consequences only.

2. The most important examples of (2), mistaken estimations of probabilities, are due to biased sampling or to neglecting base rates. Biased sampling may occur in many ways. Since we remember our successes better than our failures, we will overestimate the success rate of our behavioural routines. Examiners in entrance examinations may think that they are doing a good job if the students they selected succeed, but they forget that data about the rejected applicants are not available. A state may pride itself on the high productivity of its publicly funded research and conclude that more investments are not needed, but overlook the fact that this productivity is due to accidental circumstances that will disappear soon. ${ }^{6 I}$ Furthermore, we systematically overestimate the frequency of salient events and morally negative occurrences. For instance, numerous people cancelled their air travel arrangements after the terrorist attacks of II September $200 \mathrm{I}$ and decided to go on holiday by car. They forgot that the probability of a traffic accident remains much higher than that of a plane crash staged by terrorists. Similarly, a cost-benefit analysis of scientific research is often biased negatively by too much attention paid to spectacular risks of scien- 
tific developmens, in genetic engineering, for example.

Neglecting base rates also has many manifestations. One is the effect of what is called "anchoring". Because of our limited attention channels, we often focus on one item of evidence that "anchors" our estimate of probabilities or averages, and such information considered early in the judgement process tends to be overweighted in the final judgement. If asked what is the average price of a textbook, students presented with an expensive sample will come up with a higher estimate than students presented with a cheap item. Another way to neglect base rates is overlooking the regression effect. Regression toward the mean is inevitable for scaled variables that are not perfectly correlated. If someone performs exceptionally well on one occasion, it is probable that he will perform less well on the next occasion, that is, his performance will regress toward the mean of his or her performances. By making a non-regressive prediction of the next performance, one commits the fallacy of overlooking the regression effect. Teachers commit this fallacy if they argue that praise of pupils for an unusually excellent performance is counterproductive, because pupils will perform less well next time.

3. Mistakes of type (3), overlooking possible outcomes of choices, are particularly relevant to the issue of investments in basic research. In my view, politicians tend to underestimate the benefits of scientific research in two ways: they focus exclusively on the economic benefits, and they fail to appreciate the diversity of economic benefits of publicly funded research. For this reason, I shall discuss these issues more amply in subsections $3 \mathrm{~b}$ and $3 \mathrm{~d}$. Let me briefly illustrate mistakes of types (4) and (5) before coming to them.

4. Nothing is more difficult than to determine what we really value in life, and mistaken decisions are often due to insufficient reflection on our valuations. An example of such a mistake (4) would be the decision by a factory owner in a small town to introduce automation in his factory. Although automation increased his profits because many workers were made redundant, in fact it turned out that the owner's real utilities in running the business had little to do with the profit he made. His greatest satisfaction was derived from providing employment to many people in his community. Applied decision theorists question decision-makers at length about their values and about their estimates of probabilities. I hold 
that Dutch politics stands in need of such applied decision-theoretical advice with regard to its valuation of scientific research in relation to other public goods, in particular social security.

When the Dutch laws of social security were introduced, such as the law on unfitness for labour (WAO), it was never anticipated that huge numbers of people would profit from them. Nor could politicians anticipate that the generous social security system of The Netherlands would make it into one of the most attractive countries in the world for "refugees". Politicians should not be blamed for this lack of foresight (although, if they had possessed it, they would have voted against the proposed laws), because all human actions have unintended effects. They must be blamed, however, for not systematically searching for unintended effects and for not sufficiently reconsidering the laws in the light of these unintended consequences.

If the Netherlands spends too much on social security, it under-invests in scientific research, as I shall argue in subsection 3d-4. Hence, I plead for a re-evaluation of these domains of public spending. There are many causes for the present distortion of political valuations. First, whereas social security spending has a short-term objective, aiming at alleviating the present material needs of citizens, investing in basic research has longterm positive effects: it is crucial for an economy that remains competitive in the long run. But democratic politicians usually focus on the short term and do not anticipate the future beyond the next elections. Second, politicians commit the fallacy of focussing on salient negative examples, neglecting base rates and overall effects. One well documented case of personal misery has more influence on the decisions of politicians than statistics and long-term economic predictions. Furthermore, it is often overlooked that the positive performance of the Dutch economy during the last decade of the twentieth century has been caused by non-sustainable policies, such as low salaries and consensus between social partners ("poldermodel"). In the long run, such a positive performance must be based upon an increase of productivity caused by investments in research and technology. Finally, if large numbers of people profit from social security, politicians who propose to curb the system risk losing votes, whereas no votes are lost by economising on fundamental research. ${ }^{62}$

5. The fifth type of mistake consists in making contradictory decisions. 
In the literature on decision theory, such mistakes are illustrated by incoherent betting behaviour that might turn a subject into a "money pump". With regard to government policies, however, it is more typical that decisions are contradictory in relation to each other because of incompatible objectives. The example of Dutch research schools showed that these institutions often cannot meet the requirement of a substantial independent budget responsibility because the objective of inter-university cooperation is in conflict with the objective of competition between universities. Another and more damaging contradiction exists between the official ambition of the Dutch government to turn the Dutch economy into a knowledge-based economy ("kenniseconomie") and its attitude with regard to investing in research.

Dutch policy-makers seem to think that a substantial increase in government spending on research is not necessary. In the relevant documents, one may discern two arguments to this effect. According to the first, the relatively low level of investment in research and development in The Netherlands is not due to the level of public spending but to the low level of investments by the private sector, because Dutch public spending is at the average level of the OECD countries. The second argument says that The Netherlands might shift its attention from home production of scientific knowledge to using knowledge produced elsewhere in the world, that is, it might focus more on "diffusion" of knowledge than on research. ${ }^{63}$ I shall argue in subsection $3 \mathrm{~d}$ that these arguments are mistaken. They show that Dutch policy-makers have alarmingly little insight into the real economic benefits of research and the mechanisms of knowledge diffusion. Let me first say a few words on the benefits of scientific research in general.

\section{$b$ Benefits of Scientific Research}

To the extent that governments attempt to justify public spending on scientific research, they do so mostly on the basis of economic arguments: investing in research pays off in economic terms. But this point of view is too narrow. By overlooking non-economic benefits of research in science and the humanities, governments commit the mistake of neglecting possi- 
ble utilities of choices (see subsection 3a-3).

Scientific research in the broad sense of the term yields at least four different types of benefits: (I) economic, (2) knowledge needed for noneconomic action, (3) purely cognitive and cultural benefits, and finally (4) attitudinal benefits. The first sentence of Aristotle's Metaphysics reads: "All men naturally desire knowledge”. Humans do so for two reasons: knowledge is needed for successful action or production, and acquiring knowledge is a joy in itself. Broadly speaking, benefits of types (I) and (2) are means to successful action or production, and benefits of types (3) and (4) are ends in themselves. Let me briefly discuss these four types.

I. According to a document published in the year 2000 by the European Commission, "25 to 50 percent of economic growth is due to scientific research and technology". ${ }^{64}$ In view of this information, which I shall qualify and discuss in subsection $3 \mathrm{~d}$, the Commission is raising the alarm concerning the research conditions in Europe. As I mentioned in section 2, the average investments in research and development within the European Union amount to about $\mathrm{I} .8 \%$ of the GDP, versus $2.8 \%$ in the United States and $2.9 \%$ in Japan, and the gulf is widening quickly. Many other indicators are equally alarming. The percentage of scientific researchers working in industry in terms of the workforce as a whole is much less in the European Union (2.5\%) than in Japan (6\%) or the United States $(6.7 \%)$. The European trade balance for technological products has shown a deficit of about 20 billion euro a year over the last ten years. The number of European post-doctorate students in the United States is about twice as high as the number of American post-doctorate students of a similar level in Europe. Finally, the attitude with regard to science among the American public is more positive that that of Europeans. With the entrance of Eastern European states in the Union, the balance between Europe and the United States will deteriorate further, for the average level of investment in research in the candidate countries is even lower than it is in the European Union. For these reasons, the European commission pleads for a fundamental discussion on the necessity of investing in scientific research.

The Dutch state spends more on scientific research (in terms of percentage of the GDP) than most small countries in the European Union, such as Greece, Portugal, and Ireland. But it invests considerably less than France, Germany, Finland, and Sweden. There is no reason for compla- 
cency at this point for a country that aims at developing a knowledge-based economy, as I argue under (d).

2. Scientific research is also needed to inform action and production outside the economic sphere, both public and private. Fundamental research with military objectives comes to mind as a prime example, but a great many other examples are available. Medical research may have economic benefits, but its primary aim is to enhance human health. Scholarship in the humanities, such as history and cultural studies, may be essential to the success of foreign politics. Research on religions such as Islam is indispensable in order to stimulate multicultural discussions in Western countries, that are needed for the social integration of minorities. Research on the ecosystem Earth, in which many different disciplines play a role, is necessary in order to prevent environmental disaster. If one adds up these and many other non-economic benefits of research, one may conclude that, taken together, they are more important than the purely economic benefits. For this reason it is surprising that both the European Union and individual countries focus primarily on economic benefits whenever they want to justify public investments in research.

3. Apart from being a means to other ends, scientific research is also an end in itself, both for the individual and for humanity as a whole. Aristotle argued in book X of his Nicomachean Ethics that the highest form of human happiness consists in the activity of Theoria, the disinterested contemplation of truth. Indeed, according to Aristotle, speculative and disinterested scientific activity is the highest of the Virtues and the ultimate aim of human life. Aristotle defended this noble ideal of humanity against competing conceptions with trenchant arguments and scorn. With regard to those who hold that pleasure and amusement are the ultimate aims of life, he wrote that "to make amusement the object of our serious pursuits and our work seems foolish and childish to excess: Anacharsis' motto, Play in order that you may work, is felt to be the right rule". ${ }^{65}$

Aristotle's noble ideal has been obscured by Christianity, a religion whose plebeian origins have been obvious to acute observers such as Friedrich Nietzsche, but it was rediscovered during the European Enlightenment. Today, the ideal is in danger of being lost again, because of the vulgar materialism of modern culture. On the one hand, it would be completely justified for modern states to enable as many people to lead the life 
of scholarship and scientific research as they can afford. ${ }^{66}$ On the other hand, it is unlikely that politicians will ever feel the force of this argument for investing in research. The reason is that the intellectual pleasures of research and their superiority to most other pleasures are obvious only to those who have devoted their life to the search for truth, and politicians are mostly not among them.

As far as humanity as a whole is concerned, the advancement of science has freed the thinking part of mankind from the fetters of religious superstition and wishful thought, and it has deeply changed man's view of the world and of his own place in the universe. The intellectual superiority of Western culture in relation to cultures that have not produced the selfcorrecting tradition of scholarship and scientific research is obvious to each serious student of comparative cultural history. From the point of view of intellectual and spiritual life, science in the broad sense of Wissenschaft is the greatest adventure mankind has ever undertaken. It is an aim in itself of humanity, and to consider science as a mere means to economic life is as degrading to science as to the human being who considers it thus.

4. Finally, scientific research has important attitudinal benefits. Taking part in the activity of scientific research and scholarship teaches us that all our convictions are fallible and that it is a pleasure to be corrected by others. Researchers learn to practise the virtues of objectivity, criticism, impartiality, and intellectual creativity. In subsection ze, I shall argue that these virtues are not only essential to science but also beneficial to democratic society at large.

In this subsection I have argued that the greatest benefits of science and scholarship, that is, those benefits that are not subservient to economic aims, are usually overlooked in discussions on the justification of investments in science. Many of the purely economic benefits are neglected as well in such discussions, as I shall argue in subsection 3d. Before coming to this issue, let us review a serious problem for those who want to invest in scientific research, the problem of unpredictability.

\section{c The Problem of Unpredictability}

A decision cannot be rational unless the subject has listed all the relevant outcomes of choices and has reflected carefully on the valuation of these 
outcomes. We have seen that with regard to public investments in scientific research, both of these necessary conditions for rationality are rarely satisfied. Politicians tend to overlook the utilities of research and undervalue scientific research in relation to other public goods, such as social security. What should we think about a third important necessary condition for rationality, the proper assessment of probabilities of outcomes?

Investors in scientific research are sometimes discouraged because the outcomes of research cannot be predicted, with any probability whatsoever, as far as their content is concerned. This problem of unpredictability has been aptly characterised by Henri Poincaré, when he wrote: "Do not, therefore, expect any prophesy from me: had I known what one will discover tomorrow, I would have published it long ago, to secure priority" ${ }^{67}$ Although the problem of unpredictability is trivial and its solution quite obvious, it is useful to spell it out, because an insufficient appreciation of the problem may lead to unrealistic expectations and demands of investors in scientific research.

Science is our most powerful predictive tool, and in Western culture it has replaced older methods of foreseeing the future, such as astrology, reading omens, or religious prophesy (even though these outdated methods survive as folklore in popular culture). It may, therefore, come as a surprise that science cannot predict itself with regard to its future content. In general, there is no reason why one would not be able to predict the knowledge which someone else will possess at a later date. I can predict, for instance, that students of physics at the University of Leiden who pass their propedeutic exams will have mastered classical mechanics and the calculus at a specific level. But is it possible for a person to predict the knowledge he will possess at a later date if he does not possess that knowledge now? Similarly, will the scientific community be able to predict the content of new theories or experimental discoveries which it has not yet invented or made? The supposition that it can leads to a contradiction. In order to predict at time $t_{\mathrm{n}}$ that the scientific community will invent a specific new theory $\mathrm{T}$ at time $t_{\mathrm{n}+\mathrm{r}}$, we would have to have that new theory $\mathrm{T}$ at our disposal at time $t_{\mathrm{n}}$, so that it cannot be a new theory: it must be known already at $t_{\mathrm{n}}$. Hence, prediction of the content of new knowledge is logically impossible.

A similar but slightly more complicated argument shows that it is log- 
ically impossible to predict the future acceptance of an empirical theory that we now do not yet accept even though it has already been invented. In order to do this, it would be necessary to predict events, on the basis of our presently accepted theories, that are not yet observed but which, when observed, would provide sufficient evidence for the as yet unaccepted theory and would motivate its acceptance for that reason. But the supposition that this is possible also leads to a contradiction. The reason is that events predictable on the basis of theories we now accept will count, if observed, as evidence for these theories and not as good reasons for accepting a new theory which we do not now accept. Of course we may simply calculate the observable consequences of a new theory and accept it if these consequences materialise. But in that case, we are not predicting that they will indeed materialise. ${ }^{68}$

One may object that these arguments are irrelevant to the demands of investors in scientific research. What these investors want to predict, the objection says, is not the content of new theories of discoveries but the likelihood that there will be results, irrespective of the content of these results. It is doubtful, however, whether investors would be satisfied by such empty predictions. If they invest in research because they expect a technological spin-off, for example, they will want to assess the probability of results of a certain kind. And in order to predict results of a certain kind, one has to predict at least the global content of new discoveries.

It would be interesting to investigate empirically how able scientists are in predicting the global content of new discoveries. The anecdotal evidence we have is not very promising, however, for as far as we know, the record in science forecasting of even the most qualified experts is poor. For instance, shortly after the publication of Frederick Soddy's I930 book Science and Life, in which the author speculated about the possibility of atomic bombs, the Nobel laureate in physics Robert A. Millikan wrote that "the new evidence born of further scientific study is to the effect that it is highly improbable that there is any appreciable amount of available subatomic energy to tap". ${ }^{6}$ Fifteen years later, on 6 August I945, Hiroshima was destroyed by an atomic bomb, that killed 70,000 people. 70 By way of a conclusion, I quote Nicholas Rescher as he writes: "Since we cannot predict the answers to the presently open questions of natural science, we also cannot predict its future questions, for these questions will hinge upon 
those as yet unrealizable answers...". $7^{\text {I }}$ And if we cannot predict the future questions of science, we are unable to predict even the kind of answers, if any, that scientists will provide to these future questions.

The problem of unpredictability may seem to preclude any rationality of decisions to invest in scientific research, but this is an illusion. Although we cannot predict the outcome of particular research activities and, indeed, cannot predict that there will be an outcome at all at a given time in the future, statistics over large aggregates of research activities show that, globally speaking, scientific research pays off, even in purely economic terms (see under d). If one calculates, for example, the total amount of capital generated by the invention of the transistor, one will probably find that this single invention paid for all research in the world for many years. ${ }^{22}$ Yet it remains true that the problem of unpredictability has serious implications for the rationality of local investments in scientific research.

One implication is that investments should not be over-specific. If we assume that the problem of unpredictability is more serious with regard to fundamental investigations than in applied research, we must conclude that in fundamental research larger aggregates must be funded and that the decision of which research proposals receive funding must be left to the scientists working in the field. A second implication is that we cannot leave the funding of basic research to private players in the market. Since the aggregates to be funded must be large, they will not be sufficiently specific for receiving funding by private companies. This implication brings us to an issue to be discussed in the next subsection: why should there be public funding of scientific research?

Another implication is that it is not easy to foresee which specific type of research institution will be most profitable in the future. In the explanatory memorandum of the present prize contest, the governing body of the Hollandsche Maatschappij der Wetenschappen raises questions such as: Will a different taxonomy of scientific disciplines favour the growth of knowledge? Should we invest in deepening disciplinary research or rather in broadening research in the sense of making it interdisciplinary? Could it be that the traditional classification of disciplines in natural sciences, social sciences, and humanities is an obstacle to further growth of knowledge? 
The answer to all these questions is the same, to wit, no answer. Because we cannot predict future knowledge, we simply cannot know in advance what kind of research institution is most profitable in the long run. The wisest course is to build different types of institutions in the Western world and just see what happens. Here, as elsewhere, the model of justification by competition is the best one we have. A comparative evaluation of research institutions has already yielded some interesting conclusions, one of which I shall mention in subsection $3 \mathrm{~d}$.

I stress the importance of the problem of unpredictability here because in Western societies the attitude with regard to public funding of research has changed in the last quarter of the twentieth century. After the Second World War until well in the I980s, most governments in industrialised countries endorsed the model for basic research advocated in 1945 by Vannevar Bush, the US presidential science adviser. According to this model, governments fund basic research, and this will yield, at some time or other, contributions to national wealth, health, and security. The attitude towards expected benefits from science was relaxed, as should be the case if one takes the problem of unpredictability seriously.

But after the I970s, public expenditure came under strain, and the further "democratisation" of Western societies led to demands for greater public accountability. In The Netherlands, for instance, it was argued that scientific research should produce more social benefits ("maatschappelijke relevantie"). It seems that in most OECD countries, a new political consensus for science is emerging according to which governments will invest in basic research only if it generates more direct and specific benefits.73 This new political mentality will be harmful to the long-term cultur$\mathrm{al}$ and economic interests of these countries, because it endangers investments in fundamental research the results of which cannot be predicted.

\section{d Public funding of basic research: the economic argument}

As we saw in subsection $3 \mathrm{~b}$, scientific research has at least four different types of benefits, and the economic benefit is only one of them. One might argue with reference to each of these benefits that scientific research should be publicly funded, but in this section I focus only on the economic argument for public investment in fundamental or basic research. My pri- 
mary question is, then, (I) why exactly should basic research be publicly funded, if one focuses on its economic benefits?74 Using, among other documents, the I996 review by the Science Policy Research Unit of the University of Sussex (SPRU) of the existing literature on The Relationship Between Publicly Funded Basic Research and Economic Performance, I shall also answer three other questions: (2) What types of economic benefit of fundamental research can be distinguished? (3) Can we measure the economic benefits of basic research? (4): How are we to determine the proper level of public investment in basic research?75

I The mechanism of the market can function efficiently only if the consumption of an item of the relevant category by one consumer rivals the consumption of that same item by another consumer and if consumers can be excluded from consumption of the relevant goods. If the conditions of rivalry and excludability are satisfied, we speak of purely individual goods. However, if one or both of these conditions are not satisfied, allocation of the relevant goods will be inefficient. If there is no rivalry, the marginal costs per extra consumer are zero, whereas consumers will not be prepared to pay a price that is substantially higher than the marginal costs per consumer. And if there is no excludability, consumers will not want to pay a price at all, that is, they will want to be free riders, and no producer for the good will be found. Economists distinguish various kinds of collective goods depending on which conditions are violated and to what extent, and in principle it may be rational for national states to produce collective or public goods.

According to the traditional argument for state funding, basic research should be considered as a public good. This is because the main product of research allegedly consists in codified information that is costly to produce but virtually costless to transfer, to use, and to re-use. In other words, with regard to the products of scientific research, there would be no rivalry. In that case it is economically efficient to make the results of basic research freely available to all potential users by publishing them in a publicly accessible form. As a consequence, there will be no incentive for private producers to fund basic research, because they cannot appropriate the economic benefits of its products. It follows that basic research must be publicly funded. $7^{6}$ 
This "public good" argument presupposes that the only, or the main, utility of basic research consists in publicly accessible publications of results, and that no cost is attached to the use of these results: one could just read the publications. If this is so, there is neither rivalry nor excludability. Because there is no excludability, consumers will want to be free riders, and in the private sphere no producer of basic scientific knowledge will be found. It does not follow, however, that it is rational for a particular state, such as The Netherlands, to fund basic research. If the argument is correct, states can be free riders as well, using the information produced by research funded by other states, without seriously investing in research themselves.

This seems to be the point of the observation made by the Dutch Central Planning Office (Centraal Planbureau) quoted in subsection 3a, according to which The Netherlands should shift its focus from producing scientific research to "diffusion" of research. In this context, "diffusion" is simply a euphemism for using knowledge which others have produced without paying for it. In the same manner as a small country such as The Netherlands underinvests in its military protection because it profits from the military of large allies, it might underinvest in scientific research and profit from the investments made by other countries.

There are, however, two problems with this Dutch use of the traditional argument for public investment in basic research: the use is not quite decent, and the argument is invalid. Let me focus on the problem of invalidity. It is neither the case that the products of scientific research can be used and re-used without costs, nor that the main utility of basic research consists in publicly available publications.

Many authors stress that it requires a substantial research capacity to understand and use scientific knowledge, both by individuals and organisations. Hence using this knowledge is not at all without cost; it is impossible without an expensive research capacity of the user. At the personal level, the reason is that many epistemic capacities are tacit and can only be acquired by extensive training. Personal interaction is often necessary for transferring knowledge, and in many cases, the best method for transferring knowledge from one organisation to another is the physical transfer of the skilled individuals who possess this knowledge. At the level of research organisations, information is exchanged mostly between laborato- 
ries that have something to offer to each other. It follows that if a country does not have a substantial research capacity, it will be excluded from this type of scientific communication.

Furthermore, scientific research typically has a great many benefits that are available only to the countries that fund it, as we shall see under (2). It has been suggested that published information is not even the most important product of scientific research. Although publications are an important source for learning about research, one of their functions is to signal the presence of tacit and technical knowledge in specific research groups, which may be exploited through personal contacts. It follows that economists who adhere to the traditional argument for public funding of research, including the economists of the Dutch Central Planning Office, are mistaking a pars pro toto, since they assume that the publicly accessible publications are the main products of research.77

If the traditional "public good" argument for state funding of basic research is partly based on mistaken assumptions, this does not imply that no public funding of fundamental research is needed. On the contrary, as the SPRU review says, "numerous studies over the last 25 years have indicated that market forces lead to sub-optimal investments in basic research"..$^{8}$ A better rationale for public funding of basic research may be given by adding two lines of argument to the traditional case for considering research as a "public good". One line is based upon the problem of unpredictability. Since the lack of predictability is a serious problem for investors in basic research that can be solved only by investing in large aggregates of research over long periods of time, states will have to contribute substantially to the funding of basic research. The second line of argument consists in drawing attention to the great number of local economic benefits of investing in basic research. Scientific knowledge is embodied in individuals and organisations, and the main benefits of research flow through training and networks. Public funding is indispensable to provide training and to sustain a nation's access to international networks.79

2 If publicly accessible publications are not the only and not even the main economically relevant benefits of basic research, what other economic benefits can be distinguished? On the basis of an extensive study of the literature, the SPRU review lists five other economic benefits: 
- In the process of basic research, new instruments and methodologies are invented. Transfer of these new technological methodologies to industry often opens up new industrial possibilities and dramatically changes the pace of technological advance. Good examples are computers, the Internet, and gen-technologies such as the polymerase chain reaction (PCR) method discussed in subsection $2 \mathrm{a}$.

- Skills acquired by people involved in basic research, particularly graduate students, yield great economic benefits as individuals are transferred from basic research into industry. They carry with them substantial tacit knowledge and master the codified knowledge of their field.

- By participating in fundamental research, individuals also acquire the general capacity to analyse and solve complex problems outside of their specialty. This capacity is essential for management and often proves of great benefit to firms and other organisations confronted by complex problems.

- Without a substantial home capacity for scientific research, a country cannot access international networks of experts and information. This observation holds for all domains of basic research separately, and it raises painful issues for small countries. If a country such as The Netherlands decides to focus on some domains only, neglecting others, it will lose access to top networks in these other domains.

- In some cases, basic research leads to the creation of "spin-off" companies that profit from the epistemic capacities of academics. ${ }^{80}$

The relative weight of these different benefits turns out to vary with the scientific field, technology, and industrial sector. As a consequence, no simple model can capture the relation between basic research and its economic benefits. It is clear, however, that the traditional argument for public funding of research needs to be corrected and supplemented. There are many more benefits than the traditional argument assumes, and these benefits are often "local" in the sense that they come only to the countries that invest in basic research.

It has been argued by a number of authors, for instance, that epistemic spillovers from geographical proximity are much more important than the traditional argument for public funding allows for. The local technological 
infrastructure turns out to determine the capacity for industrial innovation, especially if university research and development is closely associated with industrial research and development. In other words, geography is an important influence on the process of innovation, because investments in human and technological capacities at specific places create "locational advantages".

These local spillover effects also show up in co-author and citation behaviour. Hicks et al. (1996) have shown that even though the Japanese share of the world total of scientific publications is between $8 \%$ and $13 \%$, $88 \%$ of the joint papers by a Japanese author involve a Japanese collaborator and only I $8 \%$ a foreign partner. This proves that not all partners in the world are equally attractive, for in that case there would be only between $8 \%$ and $13 \%$ joint papers with a Japanese partner. Similarly, Narin and Olivastro (I994) found that across all major countries there is a systematic bias favouring one's own country in the degree to which companies cite scientific papers in their patents. People prefer partners who are spatially closer and more similar in language, culture, and history. ${ }^{8 \mathrm{I}}$

From these considerations, we may draw two conclusions. If the Dutch government wants to be a free rider in research, focussing more on the diffusion of knowledge than on its production, it will discover that by economising on production, the Dutch will lose the capacity to profit from the diffusion of knowledge produced elsewhere. ${ }^{82}$ A recent OECD study from June 200I on the relation between research and productivity concludes that since "countries which spend more on R\&D take more advantage of foreign technology, free riding (waiting for other countries to develop the new technology and just trying to imitate when it is ready) would be ineffective". ${ }^{83}$ The second conclusion is concerned with institutional design. If a substantial benefit of fundamental research consists in skills acquired by graduate students, universities should have a major share of fundamental research, and posts for graduate students should be made attractive. ${ }^{84}$ Furthermore, because of local spill-over effects, research laboratories of industries should be situated in the vicinity of university research centres.

3 Can we measure the economic benefits of fundamental research? In principle, there are three methods for doing so that complement each other: econometric studies, surveys, and case studies. Econometric studies 
typically rely on large databases and use statistical techniques in order to assess the economic rates of return (annual profit rates) to research on a macro level. Surveys have been used to estimate how much basic research contributes to specific products and processes, whereas case studies focus on particular sectors of technologies. Each of these methods has advantages and specific problems. For example, case studies provide detailed insight into mechanisms of knowledge diffusion, but their results cannot be generalised.

There are many difficulties in measuring fundamental research and its contribution to economic welfare. First, there is the problem of tracing the transfer of information from basic research to particular technical innovations. Such transfers are not priced or sold, and thus they are not accounted for in any bookkeeping, and they are neither excludable nor rival. Second, it is misleading to estimate to what proportion basic research contributes to technological developments merely by computing the sums invested in it, which are very small in relation to the investments in applications and commercialisation. The development of classical mechanics by Newton did not require much investment, but its long-term contributions to economic welfare are astronomical. Yet no other reliable methods of measurement exist for estimating the economic benefits of publicly funded research. The example of classical mechanics brings us to a third difficulty: most estimates of the economic benefits of fundamental research take only short terms (up to fifteen years) into account, whereas the influence of deep theoretical discoveries is often great in the long run and unpredictable.

Two other factors contribute to the likelihood that the economic benefits of publicly funded basic research are generally underestimated. The data on research and development used in American studies include a large component of military research, in which the economic return is low. 85 And much econometric research depends on data provided by the staff of industrial research organisations, who may be under pressure to show that their own research is contributing to the success of their corporation. As a consequence, they will play down the contribution by publicly funded research. We may conclude that in the many studies that intend to assess the economic benefits of publicly funded basic research, these benefits are probably underestimated rather than exaggerated. 
Nevertheless, the rates of return associated with publicly funded basic research found by these studies are very impressive. According to the numerous publications analysed in the SPRU review, rates of return on publicly funded research vary between $20 \%$ and $83 \%$, depending on the sector and industry. Moreover, in a study of one thousand of the largest US firms during the I970s, Z. Griliches found that corporations spending a larger fraction of their R\&D on basic research were more productive and had a higher level of output in relation to their measured inputs. ${ }^{86}$ According to the 200I OECD study on the relation between research and productivity growth in I6 OECD countries, an increase of I\% in public research generates $0.17 \%$ in productivity growth, whereas I\% more in business R\&D generates $0.13 \%$ in productivity growth. The authors conclude that "the effect of government and university performed research on productivity is positive and significant, and outweighs the cost of public research". ${ }^{8}$

E. Mansfield has attempted to measure the rate of return on academic research in the USA over a fifteen-year period. On the basis of a large number of (debatable) assumptions, he concluded that this rate of return is $28 \% .88$ The real percentage must be even higher, because Mansfield only investigated seven industries, a limited period of time, and benefits within the United States and did not include indirect benefits such as skills, the production of new tools, etc. Since this rate of return is much larger than the rates of return generally expected from capital spending, one might wonder why private corporations do not invest more in basic research. The answer is to be found in the problem of unpredictability: since the results of basic research are unpredictable, corporations tend to underinvest in basic research, especially if they are obsessed with shortterm shareholder's value. This is why I suggested that the problem of unpredictability is one of the two pillars of a sound justification of public funding of basic research.

4 It should be possible for a state, in principle, to determine the optimal level of public investments in basic research according to the framework of rational decision theory. But in fact, this is not what happens. Governments commit all of the mistakes I listed in subsection (a) above. In fixing the budget, they are dominated by habit and invested interests, because a very small percentage of the budget (around $\mathrm{i} \%$ ) is open to re-allocation. 
As a consequence, most possible courses of action are not taken into consideration. Deliberation on values and aims is often ad hoc and more attuned to tactical considerations (elections) than to the long-term interests of the country. Furthermore, it is surprising that the Dutch government has never even attempted to calculate the rate of return on public investments in basic research in The Netherlands, in order to compare it with the rates of return on other public investments, such as infrastructure. ${ }^{89}$ As a result, decisions on national priorities in economic politics, such as the choice between investing in a privatised telecommunications company $(\mathrm{KPN})$, for example, and investing in research, are partly determined by pressure groups and relations of political power instead of primarily by long-term national interests.

It would be unrealistic to hope that politicians will ever make up their minds according to the prescriptions of rational decision theory. For this reason, I propose a rule-of-thumb model of sub-optimal rationality for determining the proper level of investments in basic research that can be handled easily by politicians. The structure of this model is that of justification by competition, as explained in section I. Let us assume that countries want to compete in terms of national wealth. Let us further assume that, because of local spill-over effects, Griliches's results for big business holds for countries as well: if they spend more on basic research, they will produce more wealth, other factors being equal. $9^{\circ}$ These assumptions seem to be endorsed by the Dutch government, since it aims at transforming the Dutch economy into a "knowledge-based economy". ${ }^{\text {I }}$

According to the model, politicians first have to fix the economic targets for their country: how high do they want it to be in the world hierarchy of economic performance? Given the second assumption, one may derive a level of investments in basic research for the country as a whole from the overall economic target, using research funding of relevant other countries as a benchmark. Third, the public part of these investments has to be fixed. Finally, one corrects this public share as a function of non-economic objectives. For instance, a country may want to maintain or develop a specific cultural trademark. France is a good example of such a country. If the cultural aims of a country include a high profile in scientific performance, the level of public investments in research should be adapted accordingly.

It is interesting to note that most governments do not even use a model 
of suboptimal rationality in order to determine the level of public investments in basic research. The SPRU review concludes from an analysis of research policies of the US, Germany, France, The Netherlands, Japan, and the Asian Tigers that: "there is no evidence that other countries [than the UK] use systematic criteria in determining the level of funding for basic research. Certainly, there has been no attempt to link that level to the magnitude of economic benefits that basic research generates"..$^{2}$ Let us now apply the proposed model of suboptimal rationality to The Netherlands.

The official ambition of The Netherlands is "to belong to the leading group of Europe" in economic performance. 93 The Dutch government explicitly draws the conclusion that it should aim at creating "an excellent infrastructure for research" and at belonging to the "world top" in research and innovation.94 This would imply, I suppose, that the Dutch overall level of investment in basic research as a percentage of the GDP must be higher than the average level of the OECD countries $(2.2 \%)$, say, at the level of the US (2.8\%). In fact, however, it is lower than the average level of the OECD countries, as the Dutch government acknowledges. Gerrit Zalm, the Dutch Minister of Finance, argued in the opening address of the academic year 2000-200I at the University of Leiden that the culprit here is not so much the Dutch state, which finances a relatively high percentage of the total investments in research (39.I \% against 35.6\% in Germany and $30.6 \%$ in the US), but private corporations, which invest only I.I\% of the GDP in research, as against 2.I \% in the US. Although the government intends to invest more in research over the coming years, the increase will not even bring The Netherlands up to the average OECD level of investments in terms of percentage of the GDP. 95

We may conclude that the Dutch government is promising more than it is prepared to pay for, and this will harm the economic interests of the country in the long run. The government is behaving irrationally in that its actual choices do not accord with its official aims. Zalm's argument to the effect that the Dutch state invests enough in basic research and that private corporations should do more is superficial in light of the SPRU review. In the past, industries funded basic research in their home countries. Today, however, there is a tendency to invest in countries with the best local research facilities. Industrial underinvestments in research in a country may 
then be interpreted as a symptom of non-competitive national facilities. As the authors of the SPRU review conclude, the key issue is not so much whether the benefits from basic research are substantial - they are - but "how best to organise the national research system to make the most effective use of them". $9^{6}$

If The Netherlands really wants to create "an excellent infrastructure for research", it should design facilities in universities and other state institutions that can compete with the best infrastructures in the United States. To this end, the government should investigate to what extent the relatively low local level of corporate investments in basic research is due to deficiencies of the Dutch research environment, and redesign this environment accordingly. Since this is a huge task, which may require that the Dutch abandon some of their dogmas in university politics (no entrance examinations, an egalitarian system of institutions, a national system) and increase their investments substantially, it is advisable that in the next government there will be a cabinet minister for scientific research. As I argued in subsection 2c, many problems can be solved only at the European level, so that The Netherlands should effectively promote an international European and hierarchical system of universities.

\section{e The Scientific Attitude}

One of the main non-economic benefits of training in scientific research is that the trainee acquires a scientific attitude. I shall round off this essay by arguing that a rudimentary version of the scientific attitude is indispensable to mature citizens of well-functioning democratic states. Acquiring the scientific attitude should be one of the main objectives of education in democratic countries.

In order to evaluate the democratic calibre of national states, it is useful to distinguish between the institutional and the functional aspect. One question is: to what extent does a country have democratic institutions, such as a division of powers, free elections, an independent judiciary, and so on. For each country, one might try to design an optimal set of democratic institutions, taking the history of that country into account. Quite another question is: to what extent do the existing institutions function democratically? For instance, there may be free elections, but if the elector- 
ate can be manipulated easily by clever advertising strategies, the democracy in that country - the US, for instance, or Russia - is dysfunctioning. Or if there is a gentleman's agreement between the major parties of a country not to fight elections over a specific issue that is crucial for the future of a country, such as the issue of immigration in The Netherlands, this democracy is not functioning well, however honourable the motives of these parties may be (to prevent discrimination against immigrants). Countries may be democratic from the institutional point of view and quite undemocratic from the functional point of view.

My thesis is that a democracy cannot function well unless enfranchised citizens and politicians predominantly adopt a scientific attitude when fixing their beliefs. 97 Only if citizens are able to make up their minds rationally will politicians be motivated to discuss important issues in the open on the basis of pertinent arguments. Without such a public discussion of political issues, decision-making by politicians will be neither optimal nor fully democratic, and elections will be won on the basis of advertising strategies instead of by political merit. The system of free elections presupposes that voters are able to make up their minds and determine their standpoint with regard to political issues. How do people do this? And how should they do it?

Generally speaking, adult human beings prefer having a fixed standpoint to being in doubt. Often, however, it is more pleasant not to think at all about issues than either to doubt or to have a point of view. The reason is that having a point of view involves the risk that one clashes with other people who are of a different opinion, or with the facts if they are brought to one's attention. Psychologists call such clashes "cognitive dissonance", and they have discovered that people can bear cognitive dissonance only to a limited degree. So we might raise the following question: what is the optimal method for making up our minds, assuming that the cognitive dissonance we are able to tolerate has an upper limit? Roughly speaking, three strategies may be distinguished.

The first strategy is that of individual obstinacy. An individual determines a standpoint or has acquired it by education, and sticks to it whatever may come. The advantage is obvious, for the discomfort of doubt is excluded. But the costs of this method in terms of cognitive dissonance are huge: one easily clashes both with the opinions of others and with the 
facts. In order to reduce these costs, humanity has practised a second strategy since time immemorial, the method of collective obstinacy. If everyone endorses the same opinion on an issue, interpersonal clashes of opinion are excluded, and a certain piece of mind is guaranteed. Whoever holds a different view will be liquidated or converted to the common doctrine by subtle or less subtle means.

This is the method of most so-called world religions and of all dictatorial regimes. What has been written in The Book or decided by The Party is absolutely true, and doubting it is sinful. The Curia or the Politbureau has the monopoly on interpreting The Book, and discussions on interpretative issues cannot be public because a loss of authority will be the result. The method of collective obstinacy also has more moderate manifestations. Quite often, people adopt a view because their peer group endorses it. Opinions may be articles of fashion, and they are acquired together with other elements of a lifestyle, such as dresses with a prestigious label or cigarettes of a specific brand.

Again, the advantages of this method are clear, because cognitive dissonance caused by differences of opinion between people is excluded. But still, the costs are too high. The method is not truth-indicative, so that clashes with the facts cannot be avoided and will occur unexpectedly and unmethodically. There is a superior strategy on the market, that was invented by the Greeks in Antiquity and practised by other civilizations during short periods, and that has become dominant among the members of the Western intellectual elite from the seventeenth century onwards: the scientific method (in the minimal sense specified in subsection Ic). The method of collective obstinacy may still flourish with regard to opinions about other-worldly issues, where the facts, if any, are beyond human grasp and have no causal power in this world. If more mundane matters are at stake, the third method of the scientific attitude is to be preferred.

When we fix our beliefs by the scientific method, cognitive dissonance is not excluded. Our opinions may clash either with those of others or with the facts. But cognitive dissonance is made tolerable because clashes of both types are subjected to methodical rules. Whoever has the scientific attitude will consider his or her opinions as tentative hypotheses that are fallible and have to be tested. If this is the case, it becomes interesting to learn what others think, and one will try to test one's views in critical dis- 
cussion. Furthermore, who is right concerning the facts cannot be decided by counting votes, but only by investigating those facts. This is why in the scientific tradition ever more sophisticated methods for factual investigations have been developed.

The scientific attitude involves specific virtues, such as curiosity, modesty with regard to one's own views, intellectual creativity and perseverance, methodical scepticism, and tolerance concerning dissenters. These very virtues are vices according to those who prefer the method of collective obstinacy. Usually, the moral calibre of the world religions is praised, even by agnostics and atheists. But one will not find these intellectual virtues defended in their Great Books. On the contrary, Jesus said, for instance: "Every plant which my heavenly Father has not planted will be rooted up" (Matthew I5:I3), and in the Koran it is written: "Whoso believes not in God and His Messenger, We have prepared for the unbelievers a Blaze"..$^{8}$ Because the intellectual virtues are essential to a well-functioning democracy, science and not religion should be regarded as the highest spiritual good in a democratic state. It is no wonder that in countries where the attitude of collective obstinacy prevails we find misery and cultural stagnation, whereas economy and humanity flower in the democratic and scientifically minded West.

I hold, then, that a democracy cannot function well unless the scientific attitude prevails both in citizens and in politicians. This does not imply that each citizen should fix an opinion on all issues by means of the scientific method: nobody disposes of sufficient time to do this. Having the scientific attitude enables citizens, however, to engage in critical discussions if this is necessary and ask pertinent questions. Nor do I think that politics can be reduced to science, for in politics, conflicts of interest and extrascientific values play an important role. But even in determining our interests or in deliberating on values, a scientific attitude of open-minded discussion with dissenters is essential to the functioning of a democracy. Finally, I do not advocate that all citizens should aim at a career in research or participate in scientific training at an advanced level. Yet it is necessary for a well-functioning democracy that all citizens receive some training in the scientific attitude at school and learn to discuss critically.

We may conclude that in view of the attitudinal benefits of scientific research, scientists and scholars must be held in high regard in a democra- 
cy: they are supposed to excel in virtues which each citizen should possess to some degree. Moreover, a democratic state ought not to fund religious schools if in these schools the attitude of collective obstinacy is propagated. Rather, the scientific attitude should be taught to pupils as early in life as possible. Although in its sophisticated forms the scientific attitude can only be the product of a prolonged training and experience in research, its fundamentals can and must be part of high school education.99

\section{Notes}

I Cf. Klaas VAN BERKEL, "The Legacy of Stevin. A Chronological Narrative", in A History of Science in The Netherlands, ed. by Klaas van Berkel, Albert van Helden, and Lodewijk Palm (Leiden: Brill, I999), p. 84. For a history of the Maatschappij, see J. A. BIERENS DE HAAN, De Hollandsche maatschappij der wetenschappen 1752-1952, reprint with a supplement I952-I970, Haarlem: Tjeenk Willink, I970.

2 The original Dutch text reads: "Een universele karakterisering van alle takken van wetenschap, dusdanig dat deze een basis biedt voor het waarderen van de huidige wetenschappelijke activiteit, en daarnaast mogelijkheid geeft nieuwe probleemstellingen en benaderingswijzen op te stellen, onder meer wanneer die niet zouden passen in de thans gangbare discipline-indeling. Deze karakterisering - naar haar aard een metabeschrijving - zal niet alleen een opsomming van wetenschapselementen bevatten, maar tevens aangeven bij welke belangengroeperingen en beroepsgroepen die elementen aansluiten, om daarmee een verklaring te bieden voor de verworvenheden uit het verleden en de kansen en obstakels voor toekomstige ontwikkelingen te verkennen".

3 At least this is what most historians tell us. But there were earlier Renaissance academies such as the Accademia degli Affidati in Bologna (1548) and the Accademia Secretorum Naturae in Naples (ca 1560 ). Cf. Lewis PYENSON \& Susan SHEETS-PYENSON, Servants of Nature. A History of Scientific Institutions, Enterprises and Sensibilities (London: Fontana Press, I999), p. 83.

4 Cf. Ezio RAIMONDI, "Scienziati e viaggiatori", in Storia della Letteratura Italiana, vol. 5, edited by Emilio Cecchi and Natalino Sapegno. Milan: Garzanti, I967. Cf. also Giuseppe OLMI, "In essercitio universale di contemplatione e prattica: Frederico Cesi e l'Accademia dei Lincei”, in his L'inventario del mondo: Catalogiazione della natura e luoghi del sapere nella prima età moderna, Bologna: Il 
Mulino, I992. The Church of Rome rehabilitated Galileo after nearly 400 years. Clearly, it has some difficulties with admitting its errors, a capability crucial for scientists.

5 The British historian Hugh TREVOR-ROPER has argued that the CounterReformation blocked progress in the Southern countries for the next three hundred years. See "Religion, the Reformation and Social Change", in Religion, the Reformation and Social Change, London: Macmillan, I967.

6 VAN BERKEL (I999), pp. 83-84.

7 David LANDES, The Wealth and Poverty of Nations (London: Abacus, I999), pp. 444-5 (all data and some sentences in this paragraph are quoted from this book). The index is cited by Immanuel WALLERSTEIN, "Dutch Hegemony in the Seventeenth-Century World-Economy", in Maurice Aymard, ed., Dutch Capitalism and World Capitalism (Cambridge: Cambridge University Press), p. 98, but its precision must be taken with a grain of salt.

8 Cf. John MARKS, Science and the Making of the Modern World (Oxford: Heinemann, I983), pp. I42-3 and I45.

9 Quoted by LANDES, p. 447, from Peter W. KLEIN, Traditionele ondernemers en ecomomische groei in Nederland 1850-1914 (Haarlem, i966), p. 3.

Io The text on the aims of the Royal Society was written by Robert Hooke in I663 and is quoted by MARKS, (I983), p. 82. That the Dutch decline in the I8th century should be explained in part by a lack of interest in applied mechanics and experimental methods has been argued convincingly by Margaret C. JACOB, Scientific Culture and the Making of the Industrial West (Oxford: Oxford University Press, I997), pp. I4I-I54: "Science and the Decline of the Dutch Republic".

II Newton's simple-minded philosophy of science, according to which he inferred his laws of motion by induction from experience, describes not at all what he did (or should have done) as a natural scientist. Cf. Brian ELLIS, "The Origin and Nature of Newton's Laws of Motion", in R. G. COLODNY, ed., Beyond the Edge of Certainty. Englewood Cliffs: Prentice-Hall, I965, pp. 29-68.

I2 In order to get an impression of philosophical work on these latter two issues, one might read papers such as J. EARMAN and M. FRIEDMAN, "The Meaning and Status of Newton's Law of Inertia and the Nature of Gravitational Forces", Philosophy of Science (1973), pp. 329-358, and Steven F. SAVITT, "The Direction of Time", British Journal for the Philosophy of Science 47 (I996), pp. 347-370.

I3 McLean v. Arkansas Board of Education 529 F. Supp. I255 (E. D. Ark. I982).

I4 The definition is still defended by philosophers such as Edmund Husserl. Cf. his 
Logische Untersuchungen, Vol. I (Halle: Niemeyer, I900), II 63-64.

I5 This conclusion will be qualified somewhat if one takes other branches of mathematics into account. One major attempt to reconstruct mathematics in the form of a foundationalist axiomatic-deductive system was made by the logicist movement of Frege and Russell at the beginning of the twentieth century. The logicists hoped to reduce all concepts of mathematics to the clear terms of logic. If such a reduction of terms would have been successful, all truths of mathematics would have been deducible from the axioms of logic, which were thought to be obviously true. But unfortunately, mathematics turned out to be reducible only to set theory with a number of questionable assumptions, and not to logic proper. Since the axioms of set theory are less obvious and certain than most of the mathematical theorems which we derive from them, the foundationalist ideal was not realised by this reduction. Moreover, Gödel proved that no consistent axiom system can cover mathematics even when we renounce the self-evidence of the axioms. Nevertheless, the reduction brought to light many interesting relations between the different branches of mathematics.

I6 Cf. for a first introduction to Baysianism: David STIRZAKER, Probability and Random Variables. A Beginner's Guide. Cambridge: Cambridge University Press, I999; Cf. also Alexander BIRD, Philosophy of Science (London: UCL Press, I998), pp. 203-2I3.

I7 I am using the term "foundationalism" in a somewhat more restricted sense than is common in present-day analytical epistemology.

I8 See for this list of theoretical virtues: Ernan McMULLIN, "Values in Science", in E. D. KLEMKE et al., eds., Introductory Readings in the Philosophy of Science (Amherst: Prometheus Books, I998), pp. 526-530.

I9 In ordinary language, there is an internal relation between the notions of knowledge and truth. We cannot claim without inconsistency both that 'A knows that p' and that ' $\mathrm{p}$ is not true'. For this reason, the idea that truth is a necessary condition for knowledge has a great initial plausibility. But if we want to retain this condition at the level of theoretical knowledge, we will have to admit that, although we may in fact possess theoretical knowledge, we will never be able to show that we do.

20 Cf. Nicholas RESCHER, Priceless Knowledge? Natural Science in Economic Perspective (Lanham: Rowman \& Littlefield, I996), pp. 13-34.

$2 \mathrm{I}$ Cf. James McALLISTER, Beauty and Revolution in Science (Ithaca: Cornell 
University Press, I996), pp. I-2. My distinction between levels of generality is different, however.

22 Popper claimed that the methodological rules he proposed define the scientific enterprise. Cf. Karl POPPER, The Logic of Scientific Discovery (London: Hutchinson, I968), p. 54: "Just as chess might be defined by the rules proper to it, so empirical science may be defined by means of its methodological rules".

23 Cf. BIRD (I998), p. 238.

24 In his more nuanced moments, Popper admitted all these points, without admitting, however, that they seriously undermined his falsificationism. Popper's refusal to abandon falsificationism aptly illustrates the shortcomings of falsificationism: obviously, it is a matter of decision whether counterarguments falsify a theory!

25 BIRD (I998), p. 238. If I speak of "the scientific method" in what follows, I mean either the family resemblance of this spectrum, or a set of minimum rules that, individually, are necessary for science, even though, collectively, they are not sufficient.

26 A. D. DE GROOT, Academie en Forum. Over hoger onderwijs en wetenschap (Amsterdam: Boom Meppel, I982), chapter II.I, “Een minimale methodologie op sociaal-wetenschappelijke basis", pp. I34-I35.

27 DE GROOT (I982), pp. I43-I45.

28 DE GROOT (I982), p. I45.

29 Cf. DE GROOT (I982), p. I47: "Principieel gezien meen ik dat wij in de uitwerking van onze democratische procedures de prioriteiten verkeerd om hebben gesteld. Unanimiteit zou de regel moeten zijn; besluitvorming bij meerderheid de laatst toegestane, zorgvuldig geclausuleerde, uitzondering."

30 Derek J. DE SOLLA PRICE, Little Science, Big Science (New York: Columbia University Press, I963), Chapter I.

3I DE SOLLA PRICE (I963), p. 53.

32 Wetenschapsbudget 1997. Tweede Kamer der Staten-Generaal, vergaderjaar I997I997, 25008 , nr. 2, p. Io. Unfortunately, later documents, such as Voortgangsrapportage Wetenschapsbeleid (Ministerie van O, C \& W, October 2000) are less informative in this respect.

33 Cf. Document KT-CO-oo-org-NL-C of the European Union.

34 DE SOLLA PRICE (I963), p. 98.

35 RESCHER (I996). Rescher draws on many of his earlier publications here. 36 RESCHER (I996), p. 37. 
37 RESCHER (I996), p. IO4.

38 RESCHER (I996), p. 95.

39 Cf. Press Release: The 1993 Nobel Prize in Chemistry, at http://www.nobel.se/ chemistry/laureates/1993/press.html. I am grateful to Mahbod Elmi who drew my attention to this example.

40 According to the latest policy document of the Dutch Organisation for Scientific Research, NWO, the costs of adequate research equipment are rising steadily, whereas the write-off period becomes ever shorter. Such empirical observations confirm Rescher's argument. Cf. Thema's met Talent. Strategienota 2002-2005 (Den Haag: NWO, 200I), pp. 5-7, 20, and 29.

4I POPPER (I968), p. I5.

42 Paul FEYERABEND, "How to be a Good Empiricist: A Plea for Tolerance in Matters Epistemological”, reprinted in P. K. FEYERABEND, Knowledge, Science and Relativism. Philosophical Papers, Volume 3 (ed. by John Preston, Cambridge: Cambridge University Press, I999), pp. 78-103. Cf. also “Outline of a Pluralistic Theory of Knowledge and Action”, ibidem, pp. ı०4-III.

43 Thomas KUHN, The Structure of Scientific Revolutions (second edition, Chicago: The University of Chicago Press, I970), chapters VI-VIII.

44 Paul FEYERABEND, "Knowledge without Foundations", in his (I999), pp. 50-77. In other words, Feyerabend rejected falsifiability as a valid criterion of demarcation for science, but he still endorsed Popper's idea of the critical attitude as a distinctive feature of scientists.

45 FEYERABEND (I999), pp. I87 and I9०.

46 Cf. DE GROOT, "Forum-(dys-)functie in de psychologie" and "Strategieën voor forum-convergentie", in his (1982), pp. 152-203.

47 Felix KLEIN, Vorlesungen über die Entwicklung der Mathematik im 19. Jahrhundert (Berlin: Springer Verlag, I979), pp. 63-66.

48 DE GROOT (I982), P. I7I.

49 Prof. Dr. S. S. BLUME et al., Balans en Flexibiliteit. De functie van Onderzoeksscholen in het universitaire bestel: opleiding, onderzoek en organisatie. Beleidsgerichte studies Hoger onderwijs en Wetenschappelijk onderzoek 7I (Zoetermeer: Ministerie van Onderwijs, Cultuur en Wetenschappen, 2000) p. I3.

50 Karakteristieken Erkende Onderzoeksscholen per 1 januari 2001, Report of the "Erkenningscommissie Onderzoeksscholen" 200I, Amsterdam: Koninklijke Nederlandse Akademie van Wetenschappen, 200 I.

5I Cf. BLUME (2000), p. 58. Surprisingly, the dilemma is not even mentioned in a 
recent document on research schools published by the Koninklijke Nederlandse Akademie van Wetenschappen (Royal Netherlands Academy of Arts and Sciences), titled Rijzende sterren. Om de kwaliteit van de onderzoekersopleiding, Amsterdam, 2000.

52 For the "In-depth Strategy" see Top Research in the Netherlands. Zoetermeer: Ministerie van Onderwijs, Cultuur en Wetenschappen, I998.

53 J. A. BARTELSE et al., De onderzoeksschool. Een analyse van het functioneren van het beleidsinstrument onderzoeksschool, in Beleidsgerichte studies Hoger onderwijs en Wetenschappelijk onderzoek 7I (Zoetermeer, 2000), pp. 97-98.

54 See document NL I5 or Io ०8, Catalogue number KT-CO-০o-org-NL-C. Brussels, 2000.

55 John von NEUMANN and Oskar MORGENSTERN, Theory of Games and Economic Behaviour, second edition. Princeton: Princeton University Press, I947.

56 Cf. for an overview: Reid HASTIE and Robyn M. DAWES, Rational Choice in an Uncertain World. The Psychology of Judgment and Decision Making. Thousand Oaks, California: Sage Publicationss, 200I.

57 L. J. SAVAGE, The Foundations of Statistics. New York: John Wiley, I954.

58 Ben MARTIN, Ammon SALTER, et al., The Relationship Between Publicly Funded Basic Research and Economic Performance. A SPRU Review. Brighton: University of Sussex, I996.

59 Most of my examples are taken from HASTIE \& DAWES (200I).

60 Cf. HASTIE \& DAWES (200I), pp. 35-36.

6I This is the present-day Dutch case. In its report no oI2 of September 200I, called Mogelijkheden en beperkingen van overheidsinvesteringen: analyse ten behoeve van de Verkenning Economische Structuur (CENTRAAL PLANBUREAU, 200I), the Dutch Central Planning Agency observes that the present outstanding performance of Dutch scientific research is to a large extent the effect of high research quality in the past (p. Iо3: "Hierbij past de kanttekening dat de huidige onderzoeksprestaties voor een belangrijk deel het gevolg zijn van de kwaliteit van het wetenschappelijk onderzoek in het verleden").

62 Cf. on irrational decision-making by politicians John KINGDON's classic, Agendas, Alternatives, and Public Policies. Boston: Harper, Collins, I984.

63 Cf. document No or2 of the Dutch Central Planning Office (Centraal Planbureau) of September 200I on Mogelijkheden en beperkingen van overheidsinvesteringen: analyse ten behoeve van de Verkenning Economische Structuur, (CENTRAAL PLANBUREAU, 200I), p. 97: “Tegelijkertijd geldt dat creatie van 
doorbraaktechnologie voor kleinere landen zoals Nederland een beperkte rol speelt en dat kennisdiffusie aan belang wint. Wel blijft investeren in kennis van technologie en organisatie nodig om de doorbraaktechnologie toe te kunnen passen binnen de specifieke situatie op een bedrijf. Het belang van R\&D is dus zeker niet te veronachtzamen, maar per saldo verschuift de balans richting diffusie". It would be interesting to hear what research managers of Philips, Unilever, DSM, Shell, and the agricultural university at Wageningen think of this passage.

64 KT-CO-oo-oIg-NL-C, Luxemburg, 2000, p. 5. The other data mentioned in this paragraph are quoted from the same document.

65 Aristotle, Nicomachean Ethics, II76b.

66 Notwithstanding the great differences between the life of knowledge as Aristotle imagined it and the reality of modern research and scholarship.

67 Quoted by Karl POPPER, The Open Universe: An Argument for Indeterminism, Edited by W. W. Bartley, III. London: Hutchinson, I988, p. 62.

$68 \mathrm{Cf}$. for these arguments POPPER (I988), $\iint 2 \mathrm{I}-22$.

69 Quoted in RESCHER (1996), p. 7I.

70 It should be noted that in the early I930s, the theoretical basis of the atomic bomb did not yet exist. The scientific theory that made the bomb possible emerged only in 1938 and I939. In I939 the German physicist Otto Hahn (I879-I968) demonstrated that heavy elements such as uranium could fission or be split into more simple components, and in I939 Lise Meitner, an Austrian physicist who had emigrated to Sweden from Nazi Germany, proposed a theoretical explanation for fission and calculated the huge amounts of energy that in principle could be released from an explosive nuclear chain reaction.

7I RESCHER (I996), p. 72.

72 The first solid-state transistor was created in 1947 by scientists working at the Bell Laboratories, an achievement for which they won the Nobel Prize in physics in 1956. This solid-state device supplanted vacuum tubes and permitted the development of the first practical large computers in the I950s and I960s.

73 MARTIN \& SALTER et al. (1996), p. 57.

74 "Basic research" is usually defined as including both curiosity-driven research, that aims at acquiring new scientific or technical knowledge for its own sake, and strategic research, which is undertaken with some technical application in mind whereas the precise process is not yet known. But the concept is necessarily vague. 
75 MARTIN \& SALTER et al. (I996).

76 Cf. MARTIN \& SALTER et al. (I996), p. 25. This justification for public funding of basic research has been developed by Arrow and Nelson. It has been repeated by many authors since. Cf. K. ARROW, "Economic Welfare and the Allocation of Resources for Invention", in R. NELSON ed., The Rate and Direction of Inventive Activities. Princeton: Princeton University Press, I962, pp. 609-625.

77 Cf. MARTIN \& SALTER et al. (I996), pp. 25-32. The Dutch Central Planning Office admits that technological knowledge is indispensable for applying at home technology developed elsewhere. In their 200 report, they write: "Wel blijft investeren in kennis van technologie en organisatie nodig om de doorbraaktechnologie toe te kunnen passen binnen de specifieke situatie op een bedrijf” (CENTRAAL PLANBUREAU, 200I, p. 97). Yet this phrase sounds alarming and shows a total incomprehension of the real processes of knowledge diffusion in basic research. In order to absorb new knowledge, a "knowledge of technology" is not sufficient. One needs a substantial research capacity of one's own. The possibility for a small country such as The Netherlands of being a free rider in matters of scientific research was discussed by the leading Dutch physicist H.B.G. Casimir in I973 at the University of Leiden. In his essay "Wetenschapsbeleid, onmogelijk maar onmisbaar", he wrote: "Als voor Nederland het toepassen van elders verworven kennis zo belangrijk is, heeft wetenschapsbeoefening dan nog wel zin?... Kan een klein land als Nederland niet beter klaplopen? Ik ben ervan overtuigd dat men dat niet straffeloos zou kunnen doen en dat men niet van elders komende wetenschap kan absorberen zonder zelf wetenschap te beoefenen. En dan spreek ik nog niet eens over de algemene culturele afbrokkeling. Bewijzen kan ik mijn bewering niet, maar ik hoop dat Nederland niet op het onzalige denkbeeld zal komen te trachten haar op proefondervindelijke wijze te weerleggen". H. B. G. CASIMIR, Mens en Kosmos (Amsterdam: Meulenhoff, I993, p. 57). We are now able to substantiate Casimir's conviction.

78 MARTIN \& SALTER et al. (I996), p. 62.

79 The second "pillar" is to be found in MARTIN \& SALTER et al. (I996), p. 62.

80 MARTIN \& SALTER (I996), Chapter 5 .

8I MARTIN \& SALTER (I996), pp. I9-22. Cf. D. M. HICKS, P. A. ISARD, and B. R. MARTIN, “A Morphology of Japanese and European Corporate Research Networks", Research Policy, 25 (I996), pp. 359-387; and Francis NARIN and D. OLIVASTRO, “ Status Report: Linkage between Technology and Science”, 
Research Policy 2I (I994), pp. 237-250.

82 Cf. a recent OECD study of the long-term relationships between R\&D and productivity growth in I6 OECD countries over the years I980-I998 by Dominique GUELLEC and Bruno VAN POTTELSBERGHE DE LA POTTERIE (RQD and Productivity Growth: Panel Data Analysis of 16 OECD Countries, STI Working Papers 200I/3, OECD 200I, available at http://www.oecd.org/dsti/prod/ sti_wp.htm), p. 4:..."for a country to make the best of foreign technology (master and adapt it), it must have its own research capabilities".

83 OECD 2OOI, p. 5 .

84 OECD 200I, p. 4-5: "The effect of government and university performed research on productivity is positive and significant, and outweighs the cost of public research... The effect of public research is larger in countries where universities (as opposed to government laboratories) have a higher share in public research".

85 In the U.S., defence-related science expenditures continue to receive nearly half of all federal science spending, and applied science in defence-related spending approaches 100\% (96.5\% for FY I997).

86 Z. GRILICHES, "Productivity, R\&D, and Basic Research at the Firm Level in the I970s", American Economic Review, 76 (I986), pp. I4I-I54.

87 OECD 200I, pp. 3 and 4 .

88 MARTIN \& SALTER (I996), Chapter 4. Cf. E. MANSFIELD, “Academic Research and Industrial Innovation", Research Policy 20 (I99I), pp. I-I2.

89 One might argue, of course, that the difficulties of measurement are insurmountable in this domain. According to a report produced in I986 by the US Office of Technology Assessment, called Research Funding as an Investment: Can We Measure the Returns? (A technical Memorandum. Congress of the United States, I986), the various possible approaches are all too simplistic and potentially misleading.

90 Cf. OECD 200I, pp. 4-5.

9I Cf. Nota “De Kenniseconomie in zicht”, Tweede Kamer der Staten-Generaal, vergaderjaar 2000-200I, 27 407, nrs. I-2.

92 MARTIN \& SALTER (I996), p. 57.

93 Nota "De Kenniseconomie in zicht", Tweede Kamer der Staten-Generaal, vergaderjaar 2000-200I, 27 407, nrs. I-2, p. 3: "Nederland onderschrijft de doelstellingen van de strategie van 'Lissabon'. Het heeft de ambitie om tot de kopgroep van Europa te behoren".

94 Nota “De Kenniseconomie in zicht”, Tweede Kamer der Staten-Generaal, 
vergaderjaar 2000-200I, 27 407, nrs. I-2, p. 5: “een excellente

onderzoeksinfrastructuur", and p. I6: "Doelstelling zou moeten zijn om... op dit punt tot de wereldtop te gaan behoren".

95 For these intentions, see Nota "De Kenniseconomie in zicht", Tweede Kamer der Staten-Generaal 2000-200I, 27 406, nrs. I-2, pp. I6-I7. It is interesting to note, however, that according to the Dutch Central Planning Office, The Netherlands should not invest more in public research at all, because the level of public investment and research productivity are rather high. See CENTRAAL PLANBUREAU 200I, p. 97: "Nederland geeft relatief veel uit aan wetenschappelijk onderzoek bij universiteiten. Ook de Nederlandse onderzoeksprestaties zijn boven gemiddeld. Verhoging van uitgaven aan wetenschappelijk onderzoek ligt dan ook niet direct voor de hand". Another argument the Central Planning Office makes much of for not investing more in research is that given how few people opt for a career in research, investing more would result merely in higher salaries for researchers (ibidem, pp. 99-Io०: "In het extreme geval, bij volledige benutting van het beschikbare aanbod van hoogopgeleiden, leiden extra investeringen in kennis op korte termijn slechts tot hogere lonen voor kenniswerkers", etc.). This argument is extremely shortsighted. If The Netherlands really has the ambition to create an excellent infrastructure for research, and if there is a shortage of people choosing research as a career, it should raise salaries for researchers. Indeed, the low salaries are one of the main causes for the meagre supply of researchers. Reading the CPB document CENTRAAL PLANBUREAU 200I, one can only be irritated by the short-sightedness and the lack of strategic imagination of the economists who wrote it.

96 MARTIN \& SALTER (I996), p. 6I.

97 A Dutch version of this argument has been published under the title "Democratie is niet gebaat bij collectieve koppigheid", NRC-Handelsblad, II August 200I.

98 J. L. Heldring has argued (NRC-Handelsblad of 6 September 200I) that this quote from Matthew (in the newspaper version of this section) does not demonstrate Jesus' intolerance because in the relevant passages Christ was criticising the intolerance of the Pharisees and scribes. But the fact that Jesus criticised the intolerance of his opponents does not prove that he himself was not intolerant. The quote shows that he was, and Heldring's argument is a non sequitur. See for the quotation from the Koran, The Koran, translated with an introduction by Arthur J. Arberry. Oxford: Oxford University Press, I982, p. 532. 
99 I am grateful to Drs. E. A. A. M. Broesterhuizen of the Dutch Ministery of Education, who very generously provided me with documentation on Dutch research policies, and to Dr. J. W. McAllister and Dr. W. Houkes for their criticisms on an earlier version of this essay. 



\title{
Science and Democracy: a difficult relationship ${ }^{\mathrm{I}}$
}

'An enlightened and elitist essay on an unresolvable problem'

\author{
Paul Schnabel
}

I

The ability to provide such inescapable answers in such penetrating and clear English to questions which the author himself says can barely be comprehended is given to but a few. Herman Philipse is one such, and I read his essay with great admiration and generally agreed with it, but sometimes also with a feeling of unease and even irritation. He resolves the typical $18^{\text {th }}$ century contest question of the Hollandsche Maatschappij in a series of steps, ending in a notable Wahlverwandschaft of good politics, real democracy and modern science. That is almost too good to be true and leaves one feeling suspicious. The reality can only be less smooth than suggested here. Is what appears here as a perfect outcome of logical reasoning not in fact this infamous piece of soap that slips from one's grasp when one tries to get hold of it?

2

The opening starts as an elegant bow to the long history of the Maatschappij, turns soon into a harsh blow to the Dutch self-esteem. When the Hollandsche Maatschappij was set up as a learned society, the Republic of the Seven United Provinces was still wealthy but no longer powerful. The economy was in a drawn-out recession, and Philipse establishes a link here with the failure of the Republic in the field of science policy. In contrast to Britain and France, no investment was made in research and devel- 
opment. While that may be true, as an argument is it not an example of Whig history? In the Low Countries there was no question of a central government; science was the pastime of wealthy citizens, who in 1752 were not yet a leisure class in the traditional sense of the word. The first national institutions were established in French times by Louis Napoleon. Without him there would be no Rijksmuseum and no Royal Netherlands Academy of Arts and Sciences. What was missing in the 'Netherlands' was a powerful national government. I do not share Philipse's thesis that the Maatschappij was founded roo years too late. In my opinion, it was the national state and a central government that was long overdue. Just how important the will and money of the government are was shown at the end of the $19^{\text {th }}$ century when the Netherlands, thanks to the success of the HBs (former Dutch high school) system and the cautious modernisation of the universities, found its way back into the top ranks of the world academic community. The question of whether that step was also of major importance for the economy in a direct sense cannot be answered so readily. That strikes me as largely a $20^{\text {th }}$-century effect, especially in the form of technology and engineering. As far as I know, the link between the results of fundamental research and the development of a commercially successful technology remains to be properly established.

\section{3}

I always become a bit nervous when I read the question 'What is science?' I feel we can more profitably ask 'Why is it science? When is it science? Whence is it science and to whom is it science?' To overcome any tendency to overvalue our activities we may even ask the question 'Who cares what you would like to call it? For whom is this of any importance?' On the other hand, the absolute relativism of 'science is what scientists do' is the sort of truth that gets in the way of interesting questions. Philipse does not fall into the trap of 'foundationalism', as he calls it, but pilots the reader firmly but gently with cogent arguments in the direction of A.D. de Groot's theory of the scientific forum and the minimum methodology required for the forum to work. The forum is 'democratic' in a fundamental sense of the word: only arguments count, and the best arguments - or the best argu- 
mentation - win. Inevitably, this brings to mind the concept of the 'herrschaftsfreie Kommunikation' developed at the same time by Habermas, but the underlying line of reasoning is nevertheless very different. For Habermas the democratic consensus in ordinary life comes first - and he extends this practice normatively to scientific discourse. De Groot regards unanimity as the ideal of science - the best arguments should be recognised and acknowledged by all - and, if I understand that rightly, both he and Philipse are inclined to regard this unanimity rule as the political rule par excellence. Then I see Plato's republic of the wise rearing its head again, and that's something in which I have no confidence. I do, however, agree with Philipse's 'sceptical conclusion that there is not one simple answer to the question "what is science?"' by saying that, at the same time, it becomes impossible to formulate the 'universal characterisation of all branches of science and scholarship' for which the competition asks so hopefully.

'Maximising the growth of science' is the second subject of the essay. As nearly always happens, science is equated here with the natural sciences, and these in turn are taken as the model for all science. That takes place not just on paper; it is also the reality of scientific endeavour in the universities. In the same way that psychiatry around I900 had created a kind of hospital travesty with a great display of white coats, gleaming equipment, sharp knives and starched bed linen, the present turn of the century finds itself dominated by imitation of the rules, rites and rituals of the natural sciences. Although it repeatedly turns out that this is possible on only a very limited scale and has only limited meaning, it simply goes on. The arts and social sciences are consequently largely robbed of their individuality - and hence also of their essential meaning; that also applies to technology and the clinical disciplines. This also happens in Philipse's case, and with that the breadth that made the first part of his argument so attractive is lost. I always wonder why it is that natural scientists are so much more liberal in their attitude towards the best methodology for the sciences. Is it because they know from first hand how big the difference is with the prac- 
tical methodology of actual empirical work or can they afford to be liberal because no one will even challenge how they do their work? Is it insight or confidence?

\section{5}

At the academic and organisational level, the introduction of the system of the research school into the Dutch university system was the most important innovation in the final decade of the last century. Not everyone is enthusiastic about this, and Philipse also very clearly points out some of the anomalies that have been associated with the introduction of the research schools. I do not agree with him when he says 'it is debatable whether they have contributed positively to the quality and output of research'. Less than 20 years ago the number of PhDs awarded by Dutch universities was very low. This has now trebled to nearly 2500 a year. Not all of them are of course brilliant, but they are nevertheless of a good standard and methodologically certainly much more sophisticated than they used to be. In certain disciplines there was in fact no question whatsoever of serious independent scientific endeavour in the form of systematic research. The university was of course always the centre of study and learning, but it is only in recent times that scientific research has become the distinguishing feature of Dutch universities. In the social sciences, that did not take place until after the I970s and in the arts, even later. The number of PhDs awarded in the legal sciences as well as in the arts and in philosophy remains exceptionally small. Nevertheless, the dominant image of the university is now that of a centre of scientific research, even though the number of students is now so much higher than in the days the university was mainly an institute of learning and teaching.

\section{6}

I agree with Philipse: the universities must raise their standards and become more internationally competitive and also more exclusive from the Master's stage onwards. Privatisation is not the best or only path to that 
end, but can in certain circumstances be a good solution. The resistance in the Lower House of Parliament towards the introduction of a relatively expensive top-class Master's Degree determined in part by the students themselves is a rearguard action. Virtually all vocational training is now conducted outside the universities or at the postgraduate level and has long since ceased to be free of charge. That trend is continuing. This is not of major importance for scientific work, but it is for the future of universities. The same applies to the internationalisation of scientific activity. As a result of the introduction of the Bachelor's/Master's system throughout Europe, the already extensive international exchange of students will be strongly stepped up. The Dutch research assistant system is attracting increasing numbers of graduates from other countries, and not just because there are places to spare for want of Dutch interest. The international orientation has been programmed in and the comparatively good funding of $\mathrm{PhD}$. Projects through the AIO/oIO-system of research assistantships did the rest.

Yes, more money should be made available for fundamental scientific research. The Netherlands is seeking to be a knowledge economy and a knowledge country. That calls for good education as well as a good scientific infrastructure and thriving scientific activity. This is not solely a task for government; the problem is that all the major companies in the Netherlands have greatly reduced (or in some cases closed down) their scientific laboratories and made them more application-oriented. In part, this has involved the pooling of laboratories at the international level, while in part a gamble has been taken that interesting new research results will be procurable in the free market. That has, however, turned out to be disappointing, and noises can now be heard that would suggest a strengthening of independent scientific activity within the realms of industry. Since the Netherlands hardly has a pharmaceutical industry of its own and brings up the rear in the field of gene technology, it has become difficult to keep in touch with these two highly prominent areas of research-based economic activity. The smaller companies have never played a role of any significance in the scientific field in the Netherlands. 
The essay concludes with a notable attack on religion and politics. Above all - according to Philipse - these are areas in which the scientist encounters a great deal of stupidity and narrow-mindedness. However, scorn for science is not productive. It is mostly seen as a sign of extreme arrogance. Furthermore, it has been shown many times that science is not generally a good promoter of its own interests. The scientific community is also much too fragmented. A minister of science is not a solution for all ills, as this will always be a minister without portfolio, lacking authority in the Cabinet and having few possibilities for stimulating scientific research in practice. It must be an ominous sign for every scientist that the call for more resources for research and science is made so infrequently by others apart from scientists. One point of light as far as that is concerned is the joint call for a greater effort to be made in this field by employers and employees together with the universities, the Netherlands Organisation for Scientific Research (Nwo) and the Royal Netherlands Academy of Arts and Sciences (KNAW). It is now a matter of waiting for a new coalition agreement.

\section{Note}

I Comments on Science and Democracy, by Herman Philipse. 


\section{Epilogue}

When attempting to sum up the essays, the comments of the discussants and the exchanges in the Debate itself, two major themes would seem to dominate today's thinking and concerns:

- the blurring of disciplinary boundaries

- the need for social embedding of 'science'

They become manifest in different disguises, such as:

- the need to rethink the organization of our universities and other scientific research institutions;

- the evolution of and the increasing connection between the approaches to investigation in the sciences and humanities;

- the financial needs of science on the one hand, and the business opportunities created by science, on the other;

- the many areas and activities in our societies in which education and understanding of the sciences are crucial, including the limitations of their claims to socially useful and relevant knowledge.

If we should like to draw some conclusions at this stage, it may be done by fleshing out these last four points into broader statements:

- After two centuries of largely university-centred, monodisciplinary institutions, the future 'scientific enterprise' will comprise a fluid mix of scholars with varying backgrounds. Compared to the past it will be conducted much more outside, although often in close cooperation with, academic and the other traditional centres of education, research and development. Engineering and design activities may well constitute the primary tasks of new entities concerned with both physical production and non-physical services, but these will be intertwined inextricably with fundamental research.

- The area of information and cognition beautifully illustrates that to arrive at 'relevant' knowledge - not just aiming at short-term economic 
or political gains, but appropriate to this uniquely human endeavour one cannot stick to separate disciplinary approaches or narrow research traditions. This is not saying that anything goes, to paraphrase Paul Feyerabend, but just continuing our ways from the past and in isolation certainly will not do.

- Funding of 'scientific' activity will become ever more complex as innovation and knowledge become broader and more widespread phenomena. The traditional national GDP-related indicator for public and traditional enterprise financing of R\&D will come to hide a much more varied reality. There is the entrepreneurial nature of research in the context of innovative organizations that will generate its own remuneration. There is the increasing difficulty of defining and measuring innovative activities. The globalization of many new branches may entail tight as well as distant participation in international networks rather than hierarchies, making it more difficult and maybe less relevant to squeeze efforts into national straightjackets. However, it will remain important to base cooperative activity on units that maintain a primarily independent financial basis.

- The future arrangements will derive their legitimacy and impulses from tangible and intangible links between academia, industry and government. Most importantly, there is a need for more than a passive recognition of the importance of 'science' by the public at large, which requires new ways of involving the public in science. The appropriate metaphor is a quadruple helix with a variety of interactions, some strong, some weak, but nowhere nonexistent. It is incumbent on all parties to understand, to be informed, to participate and to support in direct and indirect ways. Civilization implies deeply rooted culture, in which wisdom can only be based on ever-growing knowledge. Thus, science must be considered one of the most essential elements of our cultural heritage.

That sums up the interactions reflected in the previous chapters and culminating in the lively "Sciences and Arts Debate" of the Holland Society. The Chairman of the Debate, Alexander Rinnooy Kan, in his closing remarks, pointed to one of the key elements society should be thinking of. These were his words. 
"Ladies and gentlemen,

Just a small final observation as we close this meeting, let me speak for myself and say that I believe that we have participated in a wonderful debate. It would be unforgivably arrogant even to try summarizing an afternoon that had so many high-level discussions and touched upon so many topics. We have heard many eloquent pleas to rethink the role - the organization, the structure - of the scientific enterprise, away from traditional boundaries. At the same time, many new classifications were proposed that clearly are also subject to criticism. It will be an inherently tough job to resolve all controversy.

I think we have had excellent papers in, by the way, excellent English, with excellent presentations and an excellent organization. Somebody once said that modern science is largely practised by people who lack a flair for conversation. That is manifestly unfair we have seen many counter-examples here today. We have been very well served by the laureates, by the reviewers and indeed by all of you who participated.

If there is one theme coming out of this meeting that links today's discussion to the history and the tradition of the Hollandsche Maatschappij and to the need for its continuing role, it is the notion of 'scientific literacy'. This is a very important ingredient for a balanced and sustainable economy, for a vibrant democracy and for the cultural whole that it needs to be part of. Implicitly or explicitly, all four prize-winning contributions touched upon that crucial point.

The idea that a scientific attitude, a scientific outlook, a scientific perspective on the major issues of our time is more than a luxury is a very important one to take along with us when we leave this meeting. It seems to me to be an essential condition for a civil society to be a truly civilized society.

There are many tools available to promote scientific literacy: newspapers, magazines, television, the Internet and so on. There are also many institutions for assisting in that role: the educational system at large, all the way up to and including the universities. I very much hope - and I am sure that I am speaking on behalf of all of you - that the Hollandsche Maatschappij will continue to appear on that list in a very prominent position, because it seems to offer a unique mixture of traders and teachers if you will, kooplieden en dominees" live up to its motto, its raison d'être, which is to build bridges between science and society.

Thank you very much."

We can say that, again. 


\section{Note}

I "Merchants and Ministers", a traditional characterization of the Dutch, recently referred to by the Mayor of Amsterdam when acting as magistrate for the marriage of Prince Willem Alexander of Orange and Máxima Zorregieta on 2 February 2002. 


\section{Appendix}

\section{A The Holland Society of Arts and Sciences}

The "Hollandsche Maatschappij der Wetenschappen" (Holland Society of Arts and Sciences) was established in 1752 by seven distinguished burghers of the city of Haarlem, in the then Republic of the United Provinces of the Netherlands, in order "to promote science". It is the oldest learned society in the country today and is constituted as a dual body comprising approximately 275 "science promoters" (known as "directors") and about 325 active scholars (known as "members"), drawn from the natural sciences, the humanities and the social sciences. It has always maintained relationships with scholars in other countries (the "foreign members", currently numbering about 25).

Thanks to its unusual structure, the Society can act as an effective meeting place for leading persons from within and outside academia. It is also in an unique position to provide independent judgement in many fields and does this by serving in the review process for a number of prestigious awards and fellowships.

Since I84I, the Holland Society has resided in a majestic town house, designed and built in 1794 by the municipal architect of Amsterdam, Abraham van der Hart (I747-I820), for the young and immensely rich Cornelia Catharina Hodshon (I768-I829), daughter of a linen merchant of English descent. Information about the Society is available by access to its website "www.hollmij.nl", including a virtual visit to the Hodshon House.

Apart from serving as a forum for the dissemination and discussion of scientific discoveries, the Society set out to promote the sciences and arts by prize competitions. In the spirit of the mid-I $8^{\text {th }}$ century, the themes often concerned application of (useful) knowledge rather than challenges to broaden theoretical insight. Over a period of I54 years, I206 competition questions were set, but only 169 responses were ever considered wor- 
thy of the gold medal of honour. In fact, after the rush of the early years, the interest in prize competitions waned. Other vehicles for promoting the arts and sciences presented themselves. First, the universities took over the role of the learned societies as centres of research and dissemination of knowledge. Next, specialized journals replaced the societies' transactions. Finally, research began being sponsored and supervised by national councils and publicly funded academies.

Competition $\mathrm{nr} \mathrm{I} 2 \mathrm{O} 2$ was entered by a single respondent, who only received his award after submitting an improved report. After four more failed attempts, the institution of the prize competition was abandoned. That was in I9I7. However, on the occasion of its $250^{\text {th }}$ anniversary, the Holland Society decided to revive its old tradition just once more. The subject was scholastic endeavour, itself.

Steering Committee Sciences Q Arts Prize Competition and Debate

Ir M.C. van Veen, President Holland Society (chair)

Dr R.J. van Duinen, Chairman Netherlands Organization for Scientific Research (NWO)

Prof. B.P.T. Veltman, Chairman Advisory Council for Science and Technology (AWT)

Dr P.A.J. Tindemans, Director Global Knowledge Strategies \& Partnerships

Dr R.P.W. Visser, Teyler Professor of History of the Sciences, Leiden University

Dr A.A. Verrijn-Stuart, Emeritus Professor of Computer Science, Leiden University and Secretary for the Sciences, Holland Society (secretary)

External member of the review committee

Prof. T.A.F. Kuipers, Professor of Theoretical Philosophy, Groningen University 


\section{B The Prize Competition (as posted on the website of the Holland Society, December i999)}

Prize Competition and Science Debate on the occasion of the 250th anniversary of the Holland Society of Arts and Sciences (est. 1752)

\section{Introduction:}

All over the world, scholarly endeavour in the arts and sciences appears to be evolving in two directions. On the one hand, specialisation ("depth") progresses steadily. On the other hand, there is a tendency towards "broadening" areas of interest, manifesting itself in multidisciplinary or otherwise cross-area approaches. Both are facilitated by the opportunities for varied and rapid exchanges with colleagues elsewhere, especially by Internet communication.

Those dedicated to specialisation often accuse the "broadeners" of fundamental shallowness. After all, branches of the sciences and humanities may only make progress in their chosen fields if this leads to greater depth of knowledge or insight. However, one should not forget that innovation often results from an unusual combination of views and techniques originating in disparate domains. In some instances - and in spite of resistance from traditional disciplines - totally new and independent areas came about. The primary gain in depth mostly consisted in the recognition and solution of ("deep") integration problems.

Undoubtedly, in the new century, both approaches will prove to be productive. However, and maybe even more strongly than in the past, "broadening" research may be hampered by "traditional" views and too rigid a set-up of research regimes. Among other things, one may rightly question the customary distinction: humanities, natural sciences, social sciences (sometimes referred to as alpha, beta and gamma disciplines). Such nomenclature will also lead to serious confusion in cases of more detailed cross-area research.

\section{Problem statement:}

For the above reasons, the Holland Society of Arts and Sciences ("Hollandsche Maatschappij der Wetenschappen”, which has always been dedicated to 
the promotion of the sciences and arts) intends to arrange a debate, to be triggered by four essays on the following problem statement ("to present ..."):

A universal characterisation of all branches of sciences and arts, such that a basis is established for positioning and evaluating current scholarly activity, and, additionally, an opportunity is provided to formulate new problem statements and approaches, including any that would not fit currently fashionable scientific or scholarly frameworks.

This characterisation - in essence a meta-description - shall not only contain a listing of science and arts elements, but also indicate which interest groups and professional categories would feel the closest affinity to any specific elements, so as to explain past accomplishments as well as anticipate opportunities for and obstacles to future developments. (*)

Paraphrasing, one may say that the required essays shall offer:

"insight into the nature of definitions of the sciences and arts, employing some metadescription", indicating "which elements might be helpful or, by contrast, obstructive in guiding scholarly endeavour in the 21st century", possibly including "a reasoned rejection of the classical distinction sciences/humanities and other restrictive classifications, replacing these by a more effective taxonomy"

The four authors will be selected through the following competition procedure:

Prize competition:

The Holland Society of Arts and Sciences calls on potential authors of essays as referred to above to submit I000-1500 word summaries, in which they indicate the approach they would intend taking. Submissions will be reviewed by a scholarly committee of members of the Society.

The four laureates will be commissioned to write a I0,000-I5,000 word essay, for which they will be rewarded by a medal of honour of the Holland Society and a prize amounting to EUR 5000.

Submissions should be addressed to the Honorary Secretary for the Sciences of the Holland Society, Prof. A.A. Verrijn-Stuart, P.O. Box 9698, NL-2003 LR Haarlem, The Netherlands, before ist October 2000. The se- 
lection procedure will be completed by the year's end. It is expected that the four laureates will complete their essays before ist October 200I so that they will be available in print well before the debate.

It is the intention of the Society to publish the proceedings of the debate, including the full texts of the essays. ${ }^{\mathrm{I}}$

(*) Re problem statement:

interest groups (government, business enterprises, academic institutions,

NGOs, professional organisations, etc.) are characterised by idiosyncratic terminology and an (often hidden) "agenda", which hamper mutual understanding and positive interaction;

professional categories - a similar conceptual misunderstanding is not only observed between various professional groups but even within organisations, in particular between different task groups (management, staff, advisors, specialists), each of which may be viewed as a local "professional category";

(opportunities for and obstacles to) future development - it is not intended that a normative "science-and-arts-agenda" for the 2Ist century be proposed - rather an objective path be shown for policy developers (especially in The Netherlands, but always in an international context).

\section{Note}

I This book is the realization of that expectation! 


\section{The Contributors}

Essayists:

J.F.A.K. (Johan) van Benthem (I949)

M.A. (Philosophy, I972 - Mathematics, I973) University of Amsterdam

Ph.D. (Mathematics) University of Amsterdam (I977)

Professor of logic and its applications, Institute for Logic, Language and Computation, University of Amsterdam (I986-)

Bonsall visiting chair of humanities, Stanford University (I994-)

Founding Director Institute for Logic, Language and Computation, University of Amsterdam (I986-I99I)

Member Academia Europaea (I99I)

Member Royal Netherlands Academy of Arts and Sciences (1992)

Recipient Spinoza Award NWO (I997)

Doctor honoris causa, Université de Liège (1998)

Membre Institut International de Philosophie (200I)

James W. McAllister (I962)

B.A. (Natural Sciences) University of Cambridge (I984); M.A. (I988)

M.A. (Philosophy) University of Toronto (I987)

Ph.D. (History and Philosophy of Science) University of Cambridge (I989)

University Lecturer, Faculty of Philosophy, University of Leiden (I990-)

Herman Philipse (195I)

M.A. (law) Leiden University (I973)

M.A. (philosophy) Leiden University (1974)

Ph.D. (thesis “Edmund Husserl's philosophy of logic”) Leiden University (I983)

Professor of Epistemology and Metaphysics, Faculty of Philosophy, University of Leiden (1985)

Member Hollandsche Maatschappij der Wetenschappen (200I)

Arie Rip (194I)

B.A. (philosophy) Leiden University (1965) 
M.A. (chemistry) Leiden University (1965)

Ph.D. (thesis "Social Responsibility of Chemists") Leiden University (I98I)

Professor of Science Dynamics, University of Amsterdam (I984-I987)

Professor of Philosophy of Science and Technology, University of Twente (1987-)

Discussants:

Keith J. Devlin (1947)

BSc (Mathematics) Kings College, London i968

PhD (Mathematics) University of Bristol I97I

Consulting professor of Mathematics, Stanford University (200I-)

Executive Director, Center for the Study of Language and Information, Stanford University (200I-)

Aant Elzinga (1937)

Born Bolsward (Friesland, Netherlands), emigrated Canada (I948), naturalized (I954)

B.A. honours (Theoretical Physics and Applied Mathematics) Univ. W. Ontario (1960)

Gold Medal Pure Mathematics

M.Sc. (History and Philosophy of Science) University College London (ig64)

Fil.Lic. (Theory of Science) Univ. Göteborg (1967)

Fil.Dr. (Theory of Science) Univ. Göteborg (I97I)

Associate Professor of Theory of Science and Research, Göteborg University (I972)

Science Adviser to the Canadian Government I983/84 (Science Council of Canada, Ottawa)

Professor of Theory of Science and Research, Göteborg University (ig86-)

Guest Professor Collegium Helveticum, ETH Zürich

D.J. (Diedel) Kornet (I950)

M.A. (Theoretical Biology) Leiden University (I984) 
M.A. (Philosophy of Science) University of Amsterdam (1987)

Ph.D. (Philosophy of Biology) Leiden University (I993)

Professor, Philosophy of the Life Sciences, Leiden University (1995-)

Coordinator curriculum development Philosophy and Natural Sciences

(Education stimulation fund, Leiden University, I998-)

Director of Education, Life Science \& Technology

(Leiden University \& Technical University Delft, 2000-200I)

Paul Schnabel (1948)

M.A. Degree (Sociology) Utrecht University (I973)

Ph.D. (thesis "Between stigma and charisma. New religious and mental health") Erasmus University Rotterdam (I982)

Professor of Social and Cultural Policy, Faculty of Social Sciences, Utrecht University (I987-)

General Director, Social and Cultural Planning Office of the Netherlands (I998-)

Member of the Hollandsche Maatschappij der Wetenschappen (I999)

Chairman Sciences and Arts Debate:

A.H.G. (Alexander) Rinnooy Kan (1949)

M.A. (Mathematics) Leiden University (I972)

Ph.D. (Mathematics) Amsterdam University (1976)

Professor of Operational Research, Erasmus University Rotterdam (1980-1996)

Rector Maginificus, Erasmus University Rotterdam (I986-I99I)

Doctor honoris causa, Free University of Brussels (I994)

President Federation of Netherlands Industry and Employers (VNO,

I991 | VNO-NCW, I995-1996)

Member Executive Board ING Group (I996-)

Member of the Hollandsche Maatschappij der Wetenschappen (I989)

Co-authors:

P.A.J. (Peter) Tindemans (I947)

M.Sc. (Theoretical Physics) Leiden University (I97I) 
Ph.D. (Theoretical Physics) Leiden University (I975)

Director Research and Science Policy, Ministry of Education, Culture and Science (I99I-I998)

Chairman OECD Megascience Forum (I99I-I999)

Director Global Knowledge Strategies \& Partnerships (2000-)

Director of the Hollandsche Maatschappij der Wetenschappen (2000)

A.A. (Alexander) Verrijn-Stuart (I923)

M.A. (Experimental Physics) University of Amsterdam (I950)

Ph.D. (Experimental Physics) University of Michigan (1952)

Royal/Dutch Shell Group, Research physicist (I952-I958), Computers/ Planning (1958-1970)

Professor of Computer Science, Department of Mathematics and

Computer Science, University of Leiden (I970-I99I)

Member of the Hollandsche Maatschappij der Wetenschappen (I975)

Secretary for the Sciences, Hollandsche Maatschappij der

Wetenschappen (1989-)

R.P.W. (Rob) Visser (1942)

M.A. (Biology and History of Science) Utrecht University (I967)

Ph.D. (thesis “The zoological work of Petrus Camper”) Utrecht University (I985)

Associate professor of the History of Biology, Utrecht University (I987)

Teyler Professor of History of the Natural Sciences, Leiden University (1996)

Member of the Hollandsche Maatschappij der Wetenschappen (I997) 
